\title{
Herstellung und Charakterisierung metallorganisch deponierter Pufferschichten für $\mathrm{YBa}_{2} \mathrm{Cu}_{3} \mathrm{O}_{7-\delta}$
}

\author{
Dissertation \\ zur Erlangung des Doktorgrades \\ der Mathematisch-Naturwissenschaftlichen Fakultäten \\ der Georg-August-Universität zu Göttingen
}

vorgelegt von

Harald Jarzina

aus

Kassel

Göttingen, 2003 
D 7

Referent: Prof. Dr. H. C. Freyhardt Korreferent: Prof. Dr. Winzer

Tag der mündlichen Prüfung: 18. Dezember 2003 


\section{Inhaltsverzeichnis}

\begin{tabular}{lll}
\hline & Einleitung & 1
\end{tabular}

2 Metallorganische Dekomposition (MOD)

2.1 Metallorganische Dekomposition (MOD) als Methode zur Schichtherstellung 5

2.1 .1 Der Zwei-Stufen-Prozeß $\ldots \ldots \ldots$. . . . . . . . . . . . 8

2.1 .2 Texturierte Schichten . . . . . . . . . . . . . . . . . . . . 9 9

2.2 Beschichtungsmaterialien . . . . . . . . . . . . . . . . . . . . 10

$2.2 .1 \quad \mathrm{CeO}_{2}, \mathrm{CeO}_{2}: \mathrm{Gd}_{2} \mathrm{O}_{3}(5 \mathrm{~mol} \%)(\mathrm{CGO}) \ldots \ldots \ldots$

2.2 .2 Yttrium-stabilisiertes-Zirkondioxid (YSZ) . . . . . . . . . . . . . 11

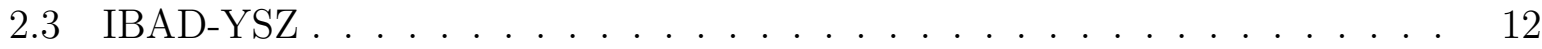

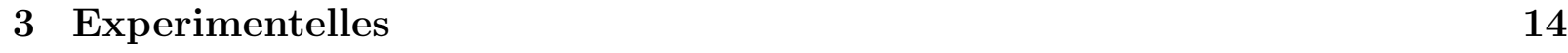

3.1 Schichtherstellung . . . . . . . . . . . . . . . . . . . 14

3.1 .1 Spincoating . . . . . . . . . . . . . . . . . . 15

3.2 Texturanalyse . . . . . . . . . . . . . . . . . . . . . . 16

3.3 Reflection High Energy Electron Diffraction (RHEED) . . . . . . . . . . . 18

3.4 Rasterelektronenmikroskopie und EDX . . . . . . . . . . . . . . . . . . . . 18

3.5 Transmissionselektronenmikroskopie . . . . . . . . . . . . . . . . . . . 19

3.6 Rasterkraftmikroskopie (AFM) . . . . . . . . . . . . . . . . . . . . . . . 19

3.7 Infrarotspektroskopie . . . . . . . . . . . . . . . . . . . . . . 19

3.8 Secondary-Ion-Mass-Spectroscopy (SIMS) . . . . . . . . . . . . . . . . . . 19

3.9 In-situ Synchrotronmessungen . . . . . . . . . . . . . . . . . . . . . 20

3.10 Magnetooptik . . . . . . . . . . . . . . . . . . . . . . 21

3.11 Gepulste Laserdeposition . . . . . . . . . . . . . . . . . . . . . . . . . . . . 21

3.12 Thermogravimetrie . . . . . . . . . . . . . . . . . 22 
3.13 Rutherford Rückstreuung . . . . . . . . . . . . . . . . . . . . 23

3.14 Einkristallröntgenstrukturanalyse . . . . . . . . . . . . . . . . 23

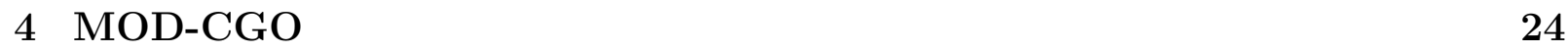

4.1 Die Precursorsysteme . . . . . . . . . . . . . . . . . . . . . 24

4.2 Dekompositionsverhalten der Precursoren . . . . . . . . . . . . . . . . . . . 25

4.2 .1 Acetylacetonate . . . . . . . . . . . . . . . . . . . 25

4.2 .2 Ethylhexanoate . . . . . . . . . . . . . . . . 27

4.3 Oberflächenmorphologie der Schichten . . . . . . . . . . . . . . . . . . . . 28

4.4 Wachstum auf YSZ-(001) Einkristallen . . . . . . . . . . . . . . . . . . . . 29

4.4 .1 Röntgenographische Analyse . . . . . . . . . . . . . . . . . . . 29

4.4 .2 RHEED Untersuchungen . . . . . . . . . . . . . . . . . . . . 32

4.4 .3 Vervollständigung des Schichtwachstums . . . . . . . . . . . . . . 33

4.4 .4 Einfluß der Atmosphäre . . . . . . . . . . . . . . . . . . . . . . 33

4.5 Schichtwachstum auf IBAD-YSZ Substraten . . . . . . . . . . . . . . . . 35

4.5.1 Einfluß der Rauhigkeit auf Kinetik und Auslagerungstemperatur . . 35

4.5 .2 Einfluß der Textur auf die Auslagerungstemperatur . . . . . . . . . 37

4.5 .3 Interdiffusion Schicht-Substrat . . . . . . . . . . . . . . . . . . 38

$4.5 .4 \quad$ In-situ Synchrotron Experimente zur Nukleation auf IBAD-YSZ-

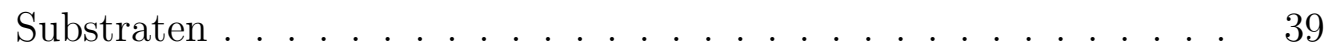

\begin{tabular}{lll}
5 & MOD-YSZ & 42 \\
\hline
\end{tabular}

5.1 Das Precursorsystem . . . . . . . . . . . . . . . . . . . 42

$5.2 \quad$ YSZ-Schichten auf YSZ-(001) Einkristallen . . . . . . . . . . . . . . . . . 45

5.3 YSZ-Schichten auf IBAD-YSZ Substraten . . . . . . . . . . . . . . . . 45

5.4 YSZ-Multischichtpakete . . . . . . . . . . . . . . . . . . . . 47

6 Einfluß von Oberflächenstörungen des MOD-Puffers auf die Stromtragfähig$\begin{array}{ll}\text { keit des Supraleiters } & 49\end{array}$

$6.1 \quad$ YBCO-Film auf MOD-YSZ/YSZ-(001)-Einkristall . . . . . . . . . . . . . . 49

$6.2 \quad$ YBCO-Film auf MOD-YSZ/IBAD-YSZ . . . . . . . . . . . . . . . 51

$6.3 \quad$ YBCO-Film auf MOD-CGO/YSZ-(001)-Einkristall . . . . . . . . . . . 53 


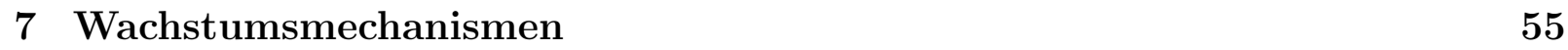

$7.1 \quad$ Frühstadien des Wachstums nach der Pyrolyse . . . . . . . . . . . . . . . . 56

7.2 Wachstum auf einkristallinen, glatten Substraten . . . . . . . . . . . . . 56

7.2 .1 Treibende Kräfte der Kristallisation . . . . . . . . . . . . . . . . . . 56

7.2 .2 Einfluß der Gitterfehlpassung . . . . . . . . . . . . . . . . 58

7.2 .3 Einfluß der Interdiffusion zwischen Substrat und Schicht . . . . . . 59

$7.3 \quad$ Wachstum auf rauhen und polykristallinen Substraten . . . . . . . . . . . . 60

$7.3 .1 \quad$ Einfluß von Substrattextur und Morphologie . . . . . . . . . . . . . 61

7.3 .2 Einfluß der Rauhigkeit . . . . . . . . . . . . . . . . . 62

7.4 Vergleich mit anderen Arbeiten . . . . . . . . . . . . . . . . . 66

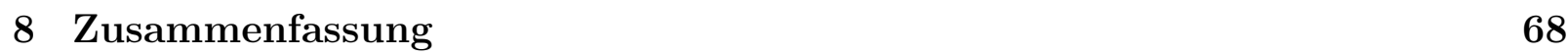

\begin{tabular}{ll}
\hline Literaturverzeichnis & 71
\end{tabular}

\begin{tabular}{lr}
\hline Danksagung & 86
\end{tabular}

\begin{tabular}{lr}
\hline Lebenslauf & 88
\end{tabular} 


\section{Kapitel 1}

\section{Einleitung}

Eine interessante Eigenschaft von Supraleitern ist es, daß ihr elektrischer Widerstand unterhalb einer kritischen Temperatur $\mathrm{T}_{c}$ verschwindet. Dadurch ergeben sich faszinierende Anwendungsmöglichkeiten in der Energie- und Meßtechnik. Schon heute werden in einigen Spezialanwendungen, die hohe Magnetfelder erfordern, wie Kernspintomographen und NMR, Supraleiter als Stromleiter zur Magnetfelderzeugung eingesetzt. Seit der Entdeckung im Jahr 1911 [1] ist Supraleitung daher Gegenstand intensiver Forschung. Allerdings war die technische Einsetzbarkeit aufgrund der niedrigen Sprungtemperaturen von $23.2 \mathrm{~K}$ in $\mathrm{Nb}_{3} \mathrm{Ge}$ sehr begrenzt. Mit der Entdeckung der Hochtemperatursupraleitung (HTSL) im System $\mathrm{La}_{1.85} \mathrm{Sr}_{0.15} \mathrm{CuO}_{4}[2]\left(\mathrm{T}_{c} \approx 35 \mathrm{~K}\right)$ im Jahr 1986 und der darauffolgenden Entdeckung von Supraleitung bei $92 \mathrm{~K}$ in $\mathrm{YBa}_{2} \mathrm{Cu}_{3} \mathrm{O}_{7}$ (YBCO) [3] ergaben sich durch die Kühlbarkeit mit flüssigem Stickstoff (Siedetemperatur $77 \mathrm{~K}$ ) kostengünstigere und energiesparende Kühlverfahren.

Eine Besonderheit der Kuprat-Hochtemperatursupraleiter ist die Anisotropie ihrer stromtragenden Eigenschaften: Der Stromtransport findet in zweidimensionalen $\mathrm{CuO}_{2}$-Ebenen statt, die für gute stromtragende Eigenschaften parallel zur Richtung des Stromes ausgerichtet sein müssen. Darüberhinaus unterdrücken Korngrenzen im Supraleiter aufgrund der kleinen Kohärenzlänge in den HTSL die Stromtragfähigkeit. Die beobachteten Stromdichten in einkristallinen YBCO-Filmen von $5 \cdot 10^{6} \mathrm{~A} / \mathrm{cm}^{2}(77 \mathrm{~K})$ werden für große Korngrenzwinkel um zwei bis drei Größenordnungen reduziert [4].

Gute supraleitende Eigenschaften lassen sich dadurch nur in einkristallinen oder nahezu einkristallinen Materialien erzielen. Bei den supraleitenden Bandleitern der zweiten Generation, den Coated Conductors, wird ein nahezu einkristalliner YBCO-Film durch epitaktisches Wachstum auf einem texturierten Substrat hergestellt. Die verwendeten YBCO-

Schichtdicken liegen im Bereich von 1500-3000 nm. Dabei kommen zwei verschiedene Substrattypen zum Einsatz:

- RABiTS [5]: hier werden durch Rekristallisation verformter Ni-Bänder biaxiale Texturen eingestellt. Nach Deposition epitaktischer Pufferschichten wie beispielsweise 
$\mathrm{CeO}_{2}$ oder Yttrium-stabilisiertem Zirkondioxid (YSZ) wird der YBCO-Film mit gepulster Laserdeposition, Koverdampfen, MOCVD, MOD oder dem TFA-Prozeß abgeschieden.

- IBAD: Mit ionenstrahlunterstützter Deposition (Ion-Beam-Assisted-Deposition (IBAD)) [6] können zwangstexturierte Funktionsschichten (z.B. IBAD-YSZ) mit einer biaxialen Textur auf polykristallinen, metallischen Substraten hergestellt werden, die sich dann als epitaktische Unterlage für die Abscheidung eines YBCO-Filmes eignen. Bei diesem Verfahren wird während der Deposition von YSZ durch Ionenstrahlsputtern mit einem zweiten Ionenstrahl unter schrägem Einfall die Schicht beschossen. Dadurch bildet sich eine biaxiale Textur, wobei der Grad der Texturierung mit wachsender Schichtdicke zunimmt [7].

Bestandteil der Pufferarchitektur (Abb. 1.1) sind bei beiden Konzepten keramische Schichten wie YSZ und $\mathrm{CeO}_{2}$. Diese dienen als Texturvermittler und als Diffusionsbarriere zwischen metallischem Substrat und Supraleiter.

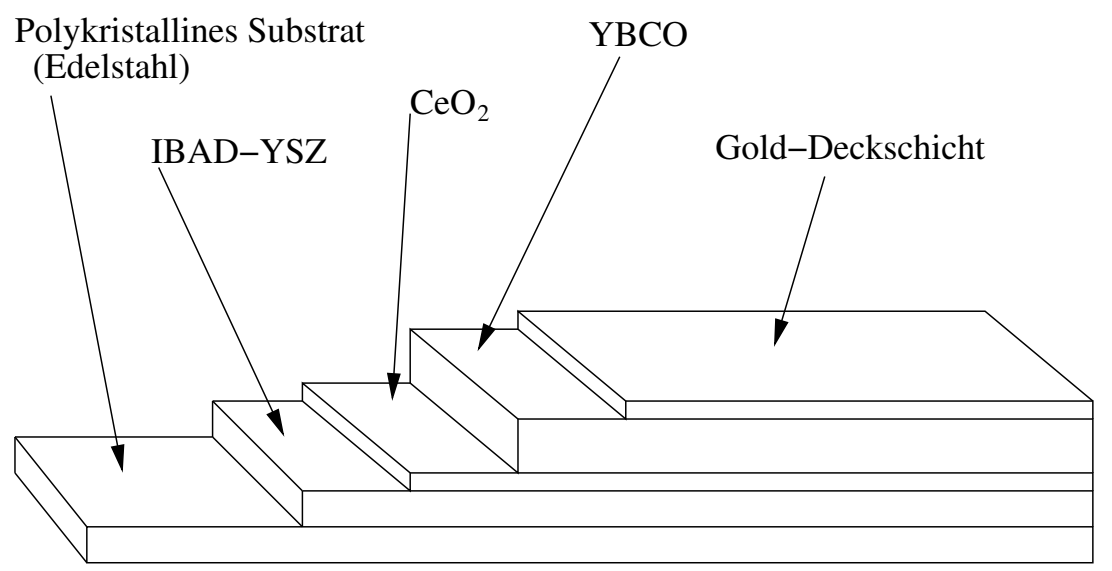

Abbildung 1.1: Schematischer Aufbau eines IBAD-Bandleiters.

Am zeit- und kostenintensivsten bei der Herstellung eines IBAD-Bandleiters ist dabei die Deposition der zwangstexturierten Schicht. Da für hohe Stromdichten eine gute Textur der Unterlage erreicht werden muß, müssen die IBAD-YSZ-Schichten 1-2 $\mu$ m dick werden um kritische Stromdichten der darauf deponierten YBCO-Schicht in der Größenordnung einiger $\mathrm{MA} / \mathrm{cm}^{2}$ bei $77 \mathrm{~K}$ zu ermöglichen. Es sind daher eine Reihe von Untersuchungen durchgeführt worden, deren Ziel die Herstellung sehr dünner (einige 10 Nanometer) biaxial texturierter Keimschichten war [8,9]. Durch epitaktisches Abscheiden ohne IBADUnterstützung wird dann für einige Materialien eine Verbesserung der Textur mit wachsender Schichtdicke beobachtet [10].

Das epitaktische Aufdicken einer Keimschicht und auch die Pufferabscheidung auf RABiTSBändern war zunächst mit Vakuumdepositionsmethoden erfolgreich, die es erlauben, qua- 
litativ hochwertige Filme zu deponieren. Um die Abscheidung hochstromtragfähiger Supraleiterschichten zu ermöglichen, müssen diese Puffer sehr glatt, homogen und trotz des spröden Charakters ohne Risse abgeschieden werden. Sie sollten quasi-einkristallin und epitaxiefähig sein. Vakuumabscheideverfahren erfordern allerdings einen relativ hohen technischen Aufwand, weshalb angestrebt wird, die Pufferabscheidung ganz oder teilweise durch alternative Verfahren zu ersetzten.

In diesem Zusammenhang sind chemische Nichtvakuumverfahren wie Metallorganische Deposition (MOD) oder Sol-Gel Prozesse interessant. Hier wird bei Normaldruck und - atmosphäre eine Lösung einer metallorganischen Verbindung (z.B. Ce-Acetylacetonat gelöst in Essigsäure zur Herstellung von $\mathrm{CeO}_{2}$-Schichten) auf das Substrat aufgebracht und durch eine geeignete Wärmebehandlung in das Oxid überführt. Durch Optimierung der Auslagerungsparameter läßt sich ein biaxiales Wachstum auf einer texturierten Unterlage erreichen. Im Vergleich zu den Vakuummethoden könnten diese Verfahren kostengünstiger werden und mit weniger technischem Aufwand verbunden sein. Allerdings finden sich in der Literatur nur wenige Darstellungen von der Herstellung epitaxiefähiger Templates für YBCO-Filme mittels MOD/Sol-Gel [11,12].

Das epitaktische Wachstum der MOD-Pufferschicht findet aus einer polykristallinen Matrix statt, die während der Zersetzung des Precursors entsteht. Im Idealfall kristallisiert der Film ausgehend von der Substratoberfläche, wodurch ein Epitaxieübertrag möglich wird. Die treibende Energie für das Wachstum ist die Korngrenzenenergie [13]. In Konkurrenz zum epitaktischen Schichtwachstum findet eine Kornvergrößerung im polykristallinen Gefüge statt, die die treibende Kraft verringert. Für Systeme mit einer hohen Gitterfehlpassung oder bei rauhen Substraten kommen weitere Energiebeiträge hinzu, die die Wachstumsbedingungen der Schicht beeinflussen [14]. Weitestgehend unverstanden ist der Einfluß eines rauhen, polykristallinen und texturierten Substrates auf die Wachstumsbedingungen.

Im Rahmen dieser Arbeit soll die Herstellung epitaxiefähiger Templates aus $\mathrm{CeO}_{2}$, Gddotiertem $\mathrm{CeO}_{2}$ (CGO) und YSZ auf YSZ-(001)-Einkristallen als Modellsystem für einzelne Körner in IBAD-YSZ-Schichten untersucht werden. Dabei kommt der Betrachtung des Einflusses der Auslagerungsbedingungen auf die einzelnen Phasen der Pufferbildung besondere Bedeutung zu. Darüber hinaus sollen in dieser Arbeit die Veränderungen der Wachstumsmechanismen von $\mathrm{CeO}_{2}$ bzw. Gd-dotierten $\mathrm{CeO}_{2}$ (CGO) beim Übergang von glatten einkristallinen Substraten auf die rauheren, polykristallinen und biaxial texturierten IBAD-YSZ-Substrate untersucht werden. Letztlich soll geprüft werden, ob homoepitaktisches Aufdicken einer IBAD-YSZ-Schicht mit MOD zu einer Verbesserung der Oberflächentextur des YSZ führt. Ziel dieser Untersuchungen ist es, ein Verständnis für die am Wachstum beteiligten Mechanismen zu entwickeln und daraus ein Modell für den Zusammenhang von Herstellungsparametern und den Eigenschaften der entstehenden Schicht abzuleiten. Unter Einsatz dieser Kenntnisse sollen dann epitaktische Puffer abgeschieden und ihre Eignung als Template für Supraleiter nachgewiesen werden.

Die vorliegende Arbeit gliedert sich wie folgt: In Kapitel 2 wird die MOD als Schicht- 
herstellungsverfahren vorgestellt. Ebenfalls in Kapitel 2 befindet sich eine Beschreibung der verwendeten Substrate und Beschichtungsmaterialien. Kapitel 3 fasst die experimentellen Methoden zusammen. In Kapitel 4 wird die Herstellung von epitaxiefähigen Templaten aus $\mathrm{CeO}_{2}$ und CGO auf YSZ-(001)-Einkristallen unter Verwendung von Ceund Gd-Acetylacetonaten bzw. Ce- und Gd-2-Ethylhexanoaten als Precursoren dargestellt. Ebenfalls in Kapitel 4 finden sich Untersuchungen der Wachstumsbedingungen von CGO auf aufgerauhten Einkristallen als Modellsystem für die ebenfalls dort untersuchten IBAD-YSZ-Substrate. Hier wird bei dem heteroepitaktischen Wachstum des CGO auf YSZ der Einfluß von Substratrauhigkeit und Textur betrachtet. In Kapitel 5 werden Untersuchungen zum homoepitaktischen Wachstum von YSZ auf YSZ-(001)-Einkristallen und IBAD-YSZ-Substraten gezeigt. Hier wird auch der Frage nachgegangen, ob bei dem Aufdicken einer IBAD-YSZ-Schicht mit MOD eine Texturverbesserung eintritt, also ob die Oberflächentextur oder der Texturgradient des Substrates von dem Wachstum des MOD-YSZ übernommen wird. Kapitel 6 beschäftigt sich mit den supraleitenden Eigenschaften von auf den Pufferschichten aus Kapitel $4 \& 5$ abgeschiedenen YBCO-Schichten. Dabei sind insbesondere Defektstrukturen interessant, die sich aus den Besonderheiten des MOD-Verfahrens ergeben. Die Modifikation der verschiedenen konkurrierenden Energiebeiträge zu den Wachstumsbedingungen auf YSZ-Einkristallen, aufgerauhten Einkristallen und IBAD-YSZ-Substraten wird in Kapitel 7 diskutiert. In Kapitel 8 werden die Ergebnisse dann noch einmal hinsichtlich des Verständnisses des Wachstums zusammenfassend dargestellt. 


\section{Kapitel 2}

\section{Metallorganische Dekomposition (MOD)}

Gegenstand dieses Kapitels ist die Metallorganische Dekomposition (MOD) als Methode zur Dünnschichtherstellung. In dieser Arbeit wird die Präparation epitaktischer Template für den Hochtemperatursupraleiter $\mathrm{YBa}_{2} \mathrm{Cu}_{3} \mathrm{O}_{7}$ (YBCO) betrachtet. Daher schließt sich nach einer Darstellung des allgemeinen MOD-Herstellungsprozesses eine Diskussion des epitaktischen Zwei-Stufen-Prozesses an. Anschließend werden die verwendeten Pufferschichten $\mathrm{CeO}_{2}$ und Yttrium Stabilisiertes Zirkondioxid (YSZ) vorgestellt. Den Abschluß dieses Kapitels bildet die Darstellung einiger wichtiger Eigenschaften von biaxial texturiertem IBAD-YSZ, das als Substrat für das epitaktische Wachstum der Pufferschichten verwendet wurde.

\subsection{Metallorganische Dekomposition (MOD) als Me- thode zur Schichtherstellung}

Die Metallorganische Deposition / Dekomposition (MOD) ist ein vielseitig einsetzbares Nichtvakuumverfahren zur Herstellung von verschiedenen Materialklassen. Neben metallischen Schichten der Edelmetalle und der Elemente $\mathrm{Rh}, \mathrm{Ru}, \mathrm{Pd}, \mathrm{Cu}, \mathrm{Bi}$ und $\mathrm{Pb}$ [15] findet dieses Verfahren bei den oxidischen Materialien breite Verwendung. Das Material, dessen Oxid hergestellt werden soll, wird als metallorganische Verbindung in einem Lösungsmittel gelöst und ergibt so den Precursor. Als metallorganische Verbindungen werden hauptsächlich Acetate, $\beta$-Diketonate und Alkoxide verwendet (Abb. 2.1) 16, 17, 18, 19]. Die Herstellung von Alkoxiden erfolgt über direkte Reaktion des Metalls mit einem Alkohol bzw. über die Reaktion von Metallhalogeniden oder Hydroxiden mit einem Alkohol. Durch Lösen dieses Alkoholates in einem $\beta$-Diketonat wie dem Acetylacetonat gelingt es bei einigen Elementen, den Alkohol aus der Koordinationsphäre des Metalls herauszudrängen und so das Acetylacetonat des Metalls zu bilden [20] ( $R, \mathrm{R}_{1}, \mathrm{R}_{2}$ : organische Reste): 


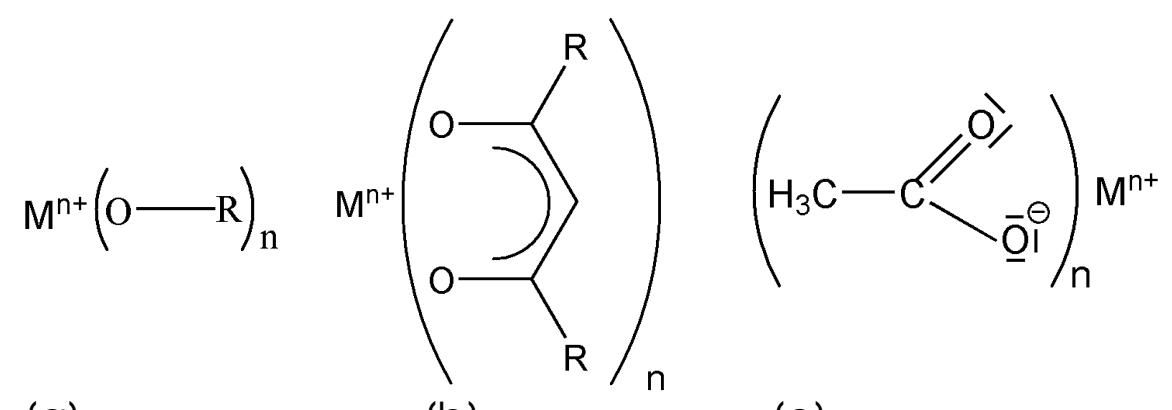

(a)

(b)

(c)

Abbildung 2.1: Alkoxide (a), $\beta$-Diketonate (b) und Acetate (c). $R$ bezeichnet einen organischen Rest, $M$ ein Metall.

$$
\mathrm{M}(\mathrm{OR})_{n}+\mathrm{x} \cdot \mathrm{R}_{1} \mathrm{COCH}_{2} \mathrm{COOR}_{2} \rightarrow \mathrm{M}(\mathrm{OR})_{n-x}\left(\mathrm{R}_{1} \mathrm{COCHCOOR}_{2}\right)_{x}+\mathrm{x} \cdot \mathrm{ROH}
$$

Grundsätzlich soll der Kohlenstoffanteil im Precursormolekül möglichst gering sein, da sonst eventuell Kohlenstoffreste in der ausgelagerten Schicht verbleiben. Kleinere Precursormoleküle sind aber aufgrund von stärkeren Polarisationseffekten reaktiver; übliche Precursormoleküle weisen 2-6 C-Atome pro Oxidationsstufe des Metalls auf. Bei der Wahl des Lösungsmittels ist zu beachten, daß Siedepunkt und Dampfdruck des Lösungsmittels die Oberflächenstruktur der fertigen Schicht maßgeblich bestimmen. Ein zu hoher Dampfdruck des Lösungsmittels führt zu einer rauhen oder sogar diskontinuierlichen Oberfläche, was für die Herstellung einer epitaktischen Pufferschicht für einen Supraleiter wie sie in dieser Arbeit betrachtet wird unerwünscht ist. Je nach metallorganischer Verbindung kommen Lösunsmittel wie Essigsäure, Alkohole, Wasser, Aceton etc. zum Einsatz. Die Deposition des Precursors auf ein Substrat erfolgt über Photoresistspinnen [21], Dip-coating [22, 21], Screenprinting, Spray-coating oder Elektro- bzw. Thermophorese [23]. Jede Beschichtungsart stellt neue Anforderungen an den Precursor. Für das Photoresistspinnen ist beispielsweise eine möglichst scherungsunabhängige Viskosität von $10 \mathrm{cP}$ erforderlich und der Precursor muß das Substrat benetzen können.

Während bei der MOD eine Reaktion der Precursormoleküle untereinander unerwünscht ist, wird eine solche bei dem Sol-Gel-Prozeß kontrolliert herbeigeführt [23]. Bei diesem Verfahren verbinden sich einzelne Precursoreinheiten zu gelösten Aggregaten im Nanometerbereich (Sol). Durch Veränderung beispielsweise des pH-Wertes kommt es dann zu Bindungen dieser Aggregate untereinander, bis ein Makromolekül der gewünschten Größe (Gel) entstanden ist [24]. Aufgrund der Molekülaggregate im Nanometerbereich kommt es bei mit Sol-Gel-Verfahren hergestellten Schichten aber zu einer im Vergleich zur MOD rauheren Oberflächenstruktur, was für die Pufferherstellung unerwünscht ist.

Nach der Deposition wird bei MOD/Sol-Gel-Verfahren durch eine geeignete Wärmebehandlung $\left(200-700^{\circ} \mathrm{C}\right)$ der Precursor in ein amorphes oder polykristallines Gefüge des herzustellenden Oxids überführt. Darüberhinaus kommen auch Ionenbestrahlung [25], 
Elektronenstrahlen [26] Laserbeschuß [27], Plasmabehandlung [28] und Bestrahlung mit Halogenlampen [29] als Dekompositionsverfahren zum Einsatz.

Die chemischen Nichtvakuumverfahren MOD und Sol-Gel finden wegen ihrer verschiedenen Vorteile:

- Geringer technischer Aufwand, z.B. werden keine Vakuumanlagen benötigt, die evtl. hohen Kosten für Targets entfallen ebenfalls.

- Durchmischung auf atomarer Skala und damit geringere Sintertemperaturen für polykristalline Gefüge

- Einfache Änderbarkeit der Stöchiometrie des herzustellenden Materials

- Staubfreies Arbeiten, wichtig bei Arbeiten mit giftigen oder radioaktiven Elementen 30 .

einen sehr breiten Anwendungsbereich. So werden schon schon seit Jahrzehnten verschiedene Industriegläser mit diesen Verfahren hergestellt [31, 32]. Die Eigenschaften dieser Gläser lassen sich dabei in weiten Grenzen durch die Verwendung eines geeigneten Precursorsystems und Auslagerungsprofils steuern. Chemische Nichtvakuumverfahren werden auch in der Beschichtungstechnik vielfach verwendet [33]. Das Spektrum der hergestellten Schichtsysteme ist aufgrund der technisch relativ wenig aufwendigen Verfahrensweise sehr breit. Nahezu alle als Puffermaterialien für YBCO in Frage kommenden Oxide wurden mit MOD bzw. Sol-Gel hergestellt 1 .

Die Forschungsaktivitäten im Bereich MOD/Sol-Gel teilen sich in (i) Untersuchungen der chemischen Vorgänge im Precursor und (ii) der Prozesse beim Übergang in das nanokristalline Gefüge auf. Eine gute Übersicht über beide Bereiche findet sich bei [23].

(i) Für die Schichtherstellung sind insbesondere Fragen nach dem Reaktionsverhalten und damit der Stabilität des Precursors z.B. gegen Luftfeuchtigkeit maßgebend. Bei vielen Alkoxiden $\mathrm{M}-(\mathrm{OR})_{n}$ ( $\mathrm{R}$ bezeichnet einen Alkylrest, $\mathrm{n}$ die Wertigkeit des Metallatoms) findet man in der Gegenwart von Wasser eine Veränderung des Ausgangsalkoxids durch die Bildung von Hydroxiden $\mathrm{M}-(\mathrm{OH})_{n}$ über den Teilschritt der partiellen Hydrolyse:

$$
\mathrm{M}(\mathrm{OR})_{n}+\mathrm{H}_{2} \mathrm{O} \rightarrow \mathrm{HO}-\mathrm{M}(\mathrm{OR})_{n-1}+\mathrm{ROH}
$$

Hydroxide neigen dazu, über weite pH-Bereiche Aggregate zu bilden, die den Precursor trüben und bei weiterem Fortschreiten der Hydrolyse zu einem weißlichen Bodensatz

${ }^{1} \mathrm{SrTiO}_{3} 34,35,36,37,38,39,40,41,42,43, \mathrm{BaTiO}_{3}$ 44, 45, 37, 46, 47, 40, 41, 42, $\mathrm{CeO}_{2}, 48,40,49$, 50, 51, 52, 53, 54, 55, YSZ [40, 56, 14, 13, 57, 58, 59, 54, 55, , $\mathrm{BaZrO}_{3}, 60,36,40, \mathrm{LaAlO}_{3}$ 11, 36, 61, 40, $\mathrm{Ba}_{x} \mathrm{Sr}_{1-x} \mathrm{TiO}_{3}\left[62 \mid 63\right.$, $\mathrm{NdAlO}_{3}$ 11], $\mathrm{GdAlO}_{3}$ [11], $\mathrm{YAlO}_{3}$ 11], $\mathrm{NdGaO}_{3}$ 11, 64, $\mathrm{La}_{0.7} \mathrm{Sr}_{0.3} \mathrm{MnO}_{3}$ 65 66, ITO 67,68, $\mathrm{Gd}_{2} \mathrm{O}_{3} 69,70,71,72,73,52, \mathrm{Eu}_{2} \mathrm{O}_{3}\left[69,74, \mathrm{La}_{2} \mathrm{O}_{3}\right.$ 70, $\mathrm{Pr}_{2} \mathrm{O}_{3}$ 70], $\mathrm{PrAlO}_{3}$ [75], $\mathrm{Sm}_{2} \mathrm{O}_{3}$ 70, $\mathrm{Tb}_{2} \mathrm{O}_{3}[70], \mathrm{Ho}_{2} \mathrm{O}_{3}$ 70, $\mathrm{Yb}_{2} \mathrm{O}_{3}\left[70, \mathrm{Lu}_{2} \mathrm{O}_{3}\right.$ 70], $\mathrm{Er}_{2} \mathrm{O}_{3}$ 77], $\mathrm{La}_{2} \mathrm{Zr}_{2} \mathrm{O}_{7}$ 71, 74, 76, 77], $\mathrm{LaNiO}_{3}$ [40, 78, ,

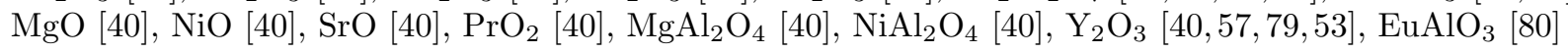


führen. Die Hydrolyse verbraucht pro Reaktionsschritt ein Wassermolekül, und sollte daher bei fast wasserfreier Handhabung des Precursors nach Verbrauch des Wassers zum Stillstand kommen. Allerdings können Reaktionen wie die Kondensation Wasser frei setzen:

$$
(\mathrm{OR})_{n-1}-\mathrm{M}-\mathrm{OH}+\mathrm{HO}-\mathrm{M}-(\mathrm{OR})_{n-1} \rightarrow(\mathrm{OR})_{n-1} \text {-M-O-M- }(\mathrm{OR})_{n-1}+\mathrm{H}_{2} \mathrm{O}
$$

Neben der Freisetzung von Wasser ist natürlich auch die eines Alkoholmoleküls ROH möglich. Der Verlauf solcher Reaktionen wurde mit Infrarotspektroskopie [81], RöntgenKleinwinkelstreuung [82], NMR [32, 83, 84] und Ramanstreuung [82 untersucht. Die Kinetik von Hydrolyse, Kondensation und Polymerisation lassen sich durch verschiedene Zusätze beeinflussen (beispielsweise unterdrückt Formamid die Hydrolyse von $\mathrm{Si}\left(\mathrm{OCH}_{3}\right)_{4}$ 82 ).

Andere Precursorsysteme (z.B. die der seltenen Erden) sind aber nicht zuletzt wegen experimenteller Schwierigkeiten (paramagnetische Kerne, stark IR-absorbierendes Lösungsmittel etc.) nur unvollständig untersucht. Dies gilt insbesondere für die Struktur von MODPrecursormolekülen, eventueller unerwünschter Reaktionen und der damit verbundenen Frage nach den bestimmenden Faktoren zur Stabilität und zur Verwenbarkeitsdauer des Precursors.

(ii) Beim Auslagern der deponierten Precursorschicht verdunsten mit wachsender Temperatur zuerst Reste des Lösungsmittels, bis dann bei Temperaturen von $200-700{ }^{\circ} \mathrm{C}$ ein stufenweiser Zerfall der Precursormoleküle einsetzt [85], der zu einem polykristallinen Gefüge mit Korngrößen von einigen Nanometern führt. Bei bestimmten Verbindungen, die über intermediäre Phasen entstehen verbleibt ein Teil des Kohlenstoffs aus dem Precursor im polykristallinen Gefüge (z.B. als Karbonat, das sich erst bei höheren Temperaturen zersetzt) $86,87,85,42$.

\subsubsection{Der Zwei-Stufen-Prozeß}

Der Zwei-Stufen-Prozeß ist mit einigen Ergänzungen der am verbreitetsten diskutierte Umwandlungsprozeß des polykristallinen Gefüges. Nach der Pyrolyse liegt hier ein nanokristallines Gefüge vor [13, 88, 37]. Erhöht man die Temperatur über die Pyrolysetemperatur hinaus, so bilden sich aus dem porösen Precursorgefüge Keime, die an dem Substrat epitaktisch anwachsen. Werden geeignete Auslagerungsparameter (Temperaturen, Rampen, Atmosphäre) gewählt, so wird das polykristalline Gefüge durch das Wachstum der epitaktischen Schicht aufgezehrt. Die Porosität wird dabei analog zu einer Zonenreinigung mit der Wachstumsfront zur Oberfläche durchgeschoben und wird bei hinreichend hohen Temperaturen durch Oberflächendiffusion ausgeheilt [13].

Verschiedene Energiebeiträge stehen beim Schichtwachstum in Konkurrenz zueinander:

- Die Korngrenzenenergie des polykristallinen Materials nach der Pyrolyse [13]. Diese stellt die treibende Kraft für die Neubildung des Gefüges dar. 
- Die Gitterfehlpassung zwischen Substrat und Schicht [39, 89, 14. Eine große Gitterfehlpassung führt zu stark verspannten Schichten. Dadurch kann die Energiedichte eines epitaktischen Keimes größer werden als die Korngrenzenergiedichte im Precursorgefüge. Die Keimbildung kann in einem solchen System behindert werden, was das epitaktische Wachstum der Schicht unterbindet.

- Die Beschaffenheit der Substratoberfläche: Oberflächenrauhigkeiten können als Keimbildungszentren das epitaktische Wachstum fördern oder zu einer wachstumshemmenden Nukleationsbarriere führen [88].

- Umwandlungen von Zwischenphasen [88,37]. Tritt eine intermediäre Phase wie ein Karbonat auf, so muß erst die Zersetzungstemperatur derselben erreicht werden, bevor ein epitaktisches Wachstum der gewünschten Phase eintreten kann.

- Spannungen durch Phasenumwandlungen können zusätzliche, das Wachstum der Schicht behindernde Defekte und Porosität in die Schicht einbringen.

- Die Zusammensetzung der Atmosphäre (z.B. Sauerstoffpartialdruck bei Oxiden) bewirkt eine Einstellung der Oxidationsstufe des Metallatoms und damit der Gitterstruktur 15].

\subsubsection{Texturierte Schichten}

Neben dem Gefüge und der chemischen Zusammensetzung ist für viele Anwendungen die Textur der sich bildenden Schicht von Bedeutung; neben dem epitaktischen Anwachsen der Schicht auf dem Substrat werden bei MOD/Sol-Gel-Verfahren aber auch weitere texturbildende Mechanismen beschrieben:

- Nichtepitaktische Texturbildung in $\mathrm{Bi}_{4} \mathrm{Ti}_{3} \mathrm{O}_{12}$ auf Silizium; die ausschließliche out-ofplane Textur kommt hier durch die Bildung von kettenförmigen Precursormolekülen zustande, die sich beim Spincoaten ausrichten [90].

- Einstellung einer out-of-plane Textur durch Minimierung der Oberflächenenergie zwischen Substrat und Schicht, z.B. im System $\mathrm{LaNiO}_{3}$ auf Glas [91].

- Texturbildung in $\mathrm{PbLaTiO}_{3}$ auf $\mathrm{MgO}$ durch Spannungen während der Pyrolyse.

- Epitaktisches Ankeimen aus einer flüssigen Phase bei der Herstellung von $\mathrm{YBa}_{2} \mathrm{Cu}_{3} \mathrm{O}_{7-\delta}$ mit Triflouracetaten als Precursoren 92 .

- Epitaktisches Ankeimen nach dem Zerfall einer Zwischenphase, z.B. $\mathrm{SrCO}_{3}$ bei der homoepitaktischen Abscheidung von $\mathrm{SrTiO}_{3}$ [88, 42.

- Rekristallisation des porösen und polykristallinen Gefüges, das sich nach der Pyrolyse gebildet hat (Zwei-Stufen Prozeß) in Konkurrenz mit Keimbildung und Wachstum im Volumen [88, 13] bzw. an der Oberfläche der Schicht [89]. 
Darüber wird von verschiedenen Autoren ein Einfluß des Precursors auf den Texturierungsgrad der Schicht berichtet $39,93,94,95,96$.

\subsection{Beschichtungsmaterialien}

Im Rahmen der hier vorgelegten Arbeit wurden insbesondere zwei Materialien untersucht: $\mathrm{CeO}_{2}$, auch mit Gd-Zusätzen, und Yttrium-Stabilisiertes Zirkondioxid (YSZ). Beide Materialien werden standardmäßig als Puffer bei der YBCO-Bandleiterherstellung eingesetzt. Sie dienen als Diffusionsbarriere zwischen metallischem Substrat und Supraleiter und als epitaxiefähige Unterlage. $\mathrm{CeO}_{2}$ stellt wegen seiner geringen Gitterfehlpassung zum YBCO die Übergangsschicht von der Pufferschichtarchitektur zum YBCO dar. Da in der entsprechenden Literatur nur sehr schlechte Supraleitung auf mit MOD hergestellten $\mathrm{CeO}_{2}$-Puffern beobachtet wurde, sollten die Ursachen dieses Verhaltens untersucht werden. YSZ ist unter Ionenbeschuß texturierbar [7]; die Textur verbessert sich dabei mit wachsender Schichtdicke. Beim YSZ soll deshalb der Frage nachgegangen werden, ob durch homoepitaktisches Aufdicken einer dünnen IBAD-YSZ-Keimschicht [8] durch MOD die Oberflächentextur der YSZ-Schicht verbessert werden kann. Generell soll dabei auch der Frage nachgegangen werden, was die Wachstumsbedingungen einer MOD-Schicht auf einem solchen IBADYSZ-Substrat bestimmt.

\subsection{1 $\mathrm{CeO}_{2}, \mathrm{CeO}_{2}: \mathrm{Gd}_{2} \mathrm{O}_{3}(5 \mathrm{~mol} \%)(\mathrm{CGO})$}

$\mathrm{CeO}_{2}$ kristallisiert in der $\mathrm{CaF}_{2}$-Struktur mit einer Gitterkonstante von 5,41 $\AA$. Dotierungen mit $\mathrm{Gd}_{2} \mathrm{O}_{3}$ ändern die Gitterkonstante auf 5,43 Åür die Zusammensetzung $\mathrm{CeGdO}_{3.5}$ [97]. $\mathrm{CeO}_{2}$ wird, mit verschiedenen Dotierungen, eingesetzt für Brennstoffzellen [98], UV-Schutzschichten [99], Antireflektionsschichten [100], Isolationsbeschichtungen, Katalysatoren [101], Pufferschichten für Supraleiter [48], Poliermittel in der optischen Industrie und wegen der strukturellen und thermodynamischen Ähnlichkeiten zum $\mathrm{PuO}_{2}$ als Modellsystem für dasselbige [102] $\mathrm{CeO}_{2}$ wird mit den bekannten Dünnschichtverfahren hergestellt, wie gepulste Laserdeposition [103, 104], Elektronenstrahlverdampfen [105], Ionenstrahlsputtern [106], MOCVD [107], MOD [40] oder direkte Abscheidung aus der Lösung [108]. Eine Zusammenstellung vieler Eigenschaften des $\mathrm{CeO}_{2}$ findet sich bei [109.

Es finden sich verschiedene Untersuchungen zum Wachstumsverhalten von metallorganisch deponiertem $\mathrm{CeO}_{2}$ : Als Precursoren kommen Ethylhexanoate [49], Acetate $\mathrm{Ce}\left(\mathrm{C}_{2} \mathrm{H}_{3} \mathrm{O}_{2}\right)_{3}$ $\cdot 1.5 \mathrm{H}_{2} \mathrm{O}$, Nitrate $\mathrm{Ce}(\mathrm{NO})_{3} \cdot \mathrm{H}_{2} \mathrm{O}$, Acetylacetonate $\mathrm{Ce}\left(\mathrm{C}_{5} \mathrm{H}_{7} \mathrm{O}_{2}\right)_{3} \cdot \mathrm{x} \mathrm{H}_{2} \mathrm{O}, \mathrm{Ce}^{4+}\left(\mathrm{NH}_{4}{ }^{+}\right)_{2}\left(\mathrm{NO}_{3}{ }^{-}\right)_{6}$ oder $\mathrm{Ce}\left(\mathrm{C}_{2} \mathrm{O}_{4}\right)_{3} \cdot 9 \mathrm{H}_{2} \mathrm{O}$ zum Einsatz [110]. Als Substrate finden Ni [110,48], polykristallines und einkristallines $\mathrm{Al}_{2} \mathrm{O}_{3}$ [54], YSZ-Einkristalle [49] oder $\mathrm{Y}_{2} \mathrm{O}_{3}$-beschichtete YSZEinkristalle 53 Verwendung. Die Stromtragfähigkeit von YBCO-Schichten auf epitaktischen $\mathrm{MOD}-\mathrm{CeO}_{2}$-Schichten ist im Vergleich $\mathrm{zu}$ mit Vakuumverfahren abgeschiedenen $\mathrm{CeO}_{2}$-Filmen verschwindend gering. 


\subsubsection{Yttrium-stabilisiertes-Zirkondioxid (YSZ)}

Bei Raumtemperatur liegt reines Zirkonoxid monoklin vor (siehe Phasendiagramm in Abb. 2.2. Durch Dotierung mit verschiedenen Materialien wie $\mathrm{Y}_{2} \mathrm{O}_{3}, \mathrm{MgO}$ [111], $\mathrm{CeO}_{2}, \mathrm{CaO}$ oder $\mathrm{La}_{2} \mathrm{O}_{3}$ läßt sich die kubische Phase stabilisieren, die für reines $\mathrm{ZrO}_{2}$ erst ab $2643 \mathrm{~K}$ stabil ist. Bei $\mathrm{Y}_{2} \mathrm{O}_{3}$ liegt die dazu nötige Dotierung je nach Autor zwischen 8-10 mol\% $\mathrm{Y}_{2} \mathrm{O}_{3}$. Das kubische YSZ hat eine $\mathrm{CaF}_{2}$-Struktur mit den Y- bzw. Zr-Atomen auf einem kubisch

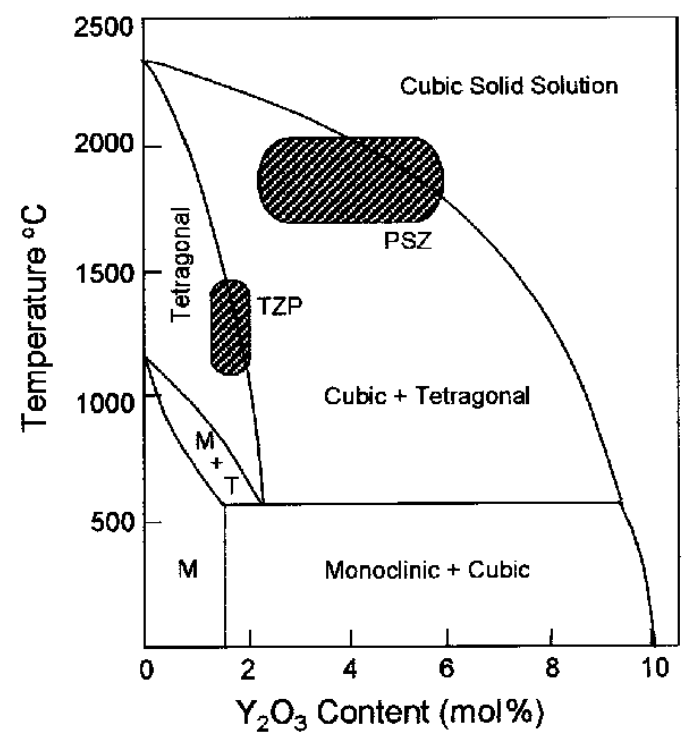

Abbildung 2.2: Phasendiagram $\mathrm{Y}_{2} \mathrm{O}_{3}-\mathrm{ZrO}_{2}$ [11].

flächenzentrierten Gitter (Gitterkonstante $5,13 \AA$ ). Die Gitterkonstante wächst mit steigendem $\mathrm{Y}_{2} \mathrm{O}_{3}$-Gehalt linear an [13]. Durch die Substitution von $\mathrm{Zr}^{4+}$ durch $\mathrm{Y}^{3+}$-Ionen werden strukturelle Sauerstoffleerstellen geschaffen, die YSZ zu einem guten Sauerstoffionenleiter machen, was zu einer breiten Verwendung des YSZ z.B. bei Brennstoffzellen führt [112]. YSZ findet auch Verwendung als Pufferschicht für YBCO, wobei insbesondere die Texturierbarkeit unter Ionenbeschuß [6] von technischem Interesse ist. Neben den Standardvakuummethoden wird YSZ auch mit MOD abgeschieden, z.B. auf YSZ-Einkristallen [13], $\mathrm{Ni}\left[113\right.$ oder ein- und polykristallinem $\mathrm{Al}_{2} \mathrm{O}_{3}$ [54]. Epitaktische Schichten wurden auf YSZ-Einkristallen [13] und $\mathrm{Al}_{2} \mathrm{O}_{3}$-Einkristallen [54] erzielt.

Eine Besonderheit im YSZ ist die Y-Segregation die beim Auslagern oberhalb von $1000{ }^{\circ} \mathrm{C}$ an den Korngrenzen und an der Oberfläche der Proben auftritt 114, 115, 116, 117]. Darüberhinaus werden auch andere Verunreinigungen beobachtet, die sich an Grenzflächen anreichern; z.B. Si, Na und Fe 114.

Von besonderem Interesse ist auch das Mischungsverhalten von $\mathrm{ZrO}_{2}$ und $\mathrm{CeO}_{2}$ 118, 119, 120, 98, 121, 122, 123], das Phasendiagramm [124, 125] weist im Temperaturbereich 
bis $1200^{\circ} \mathrm{C}$ eine Mischphase aus tetragonalem $\mathrm{ZrO}_{2}$ und kubischen $\mathrm{CeO}_{2}$ auf. Interdiffusion zwischen Substrat und Schicht, die bei Auslagerungstemperaturen zwischen 500 und $1100^{\circ} \mathrm{C}$ erwartet wird, führt abgesehen von einer Änderung der Gitterkonstanten also nicht zu einer Änderung der Kristallstruktur.

\section{$2.3 \quad$ IBAD-YSZ}

Direkt auf polykristallinen Substraten läßt sich die für die Abscheidung von YBCO-Filmen mit hoher Stromtragfähigkeit nötige biaxiale Textur nicht einstellen. Mit Ion-Beam-AssistedDeposition (IBAD) können biaxial texturierte YSZ-Schichten auf polykristallinen Substraten wie polierten Stahlbändern deponiert werden [6, 126, 127, 128], die dann als Substrat für eine darauf abgeschiedene epitaktische YBCO-Schicht dienen können. Die Textur der so hergestellten IBAD-YSZ Schichten verbessert sich mit zunehmender Schichtdicke (Abb.2.3(b)). In auf IBAD-YSZ Puffern mit gepulster Laserdeposition deponierten YBCOFilmen sind kritische Stromdichten von $2.2 \cdot 10^{6} \mathrm{~A} / \mathrm{m}^{2}(77 \mathrm{~K})$ in Bändern von bis zu $10 \mathrm{~m}$ Länge erreicht worden (die maximal erreichte Bandlänge (4 mm Breite) liegt derzeit bei $23 \mathrm{~m}$ ). Die Schichtdicken des IBAD-YSZ liegen dabei bei ca. $1.5 \mu \mathrm{m}$, die rms-Rauhigkeit ist von der Größenordnung 5-10 nm (Abb. 2.4). 22 Die Mikrostruktur der IBAD-YSZ-Schichten ist nach dem Anfangsstadium geprägt durch eine säulenartige Struktur und einen Gradienten in der in-plane-Textur, wie Abbildung 2.3 zeigt.

Die chemischen Nichtvakuumverfahren werden hier eingesetzt, um (i) die Pufferschichten nach Erreichen der notwendigen Textur als Diffusionsbarriere aufzudicken (besserer Schutz des YBCO vor Eindiffusion des Substrates) und (ii) weitere Schichten der Pufferarchitektur epitaktisch aufzubringen. Gelingt es darüberhinaus, eine Verbesserung der Textur mit wachsender Schichtdicke auch mit dem Nichtvakuumverfahren MOD zu erzielen, so würden dünne, schlecht texturierte IBAD-Keimschichten als Grundlage für ein mit MOD aufgedicktes Schichtpaket eine interessante Alternative zu den mit viel Aufwand im Vakuum hergestellten dicken IBAD-YSZ-Schichten darstellen.

\footnotetext{
${ }^{2}$ Für eine detailliertere Darstellung der Oberflächenmorphologie siehe 129.
} 

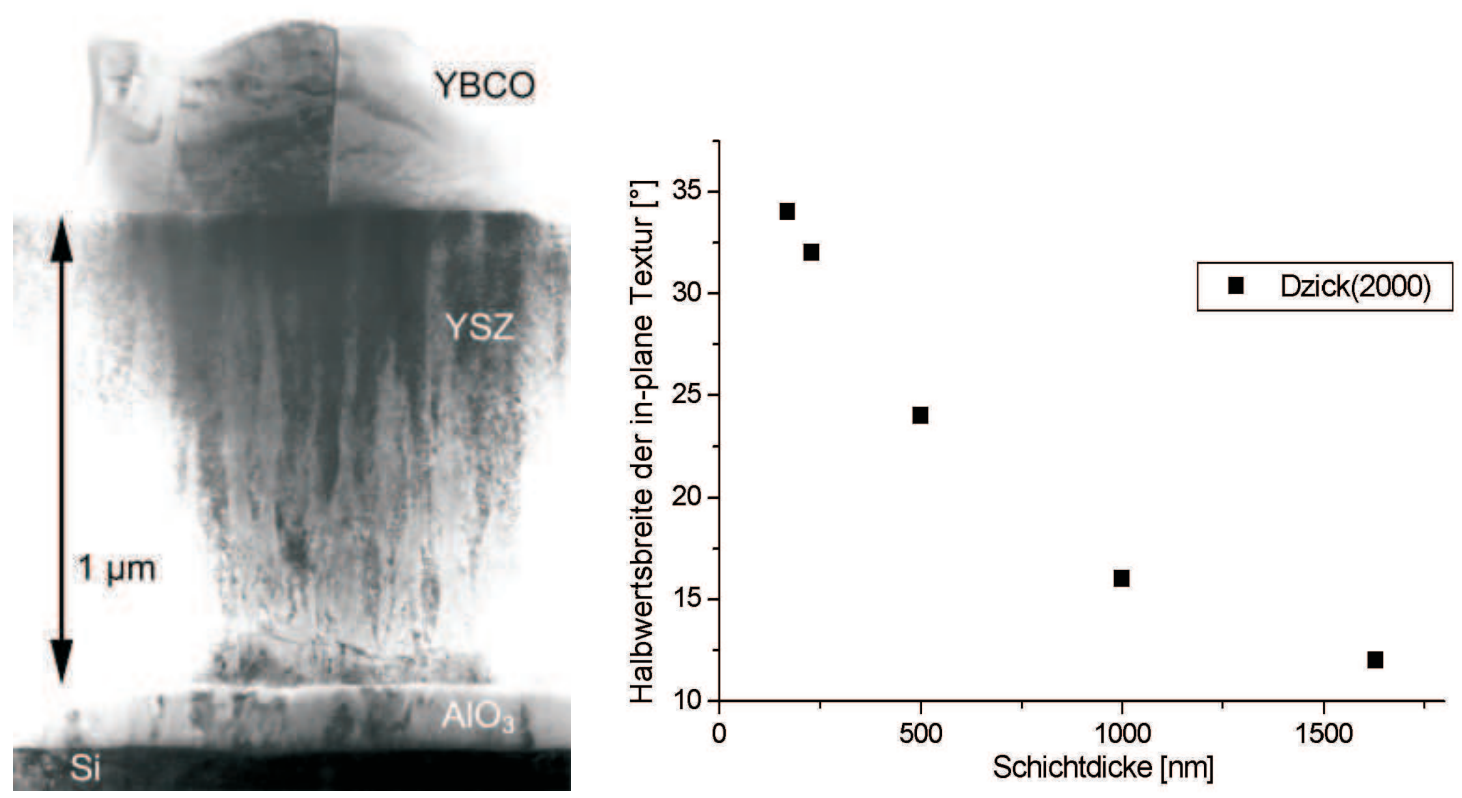

Abbildung 2.3: Transmissionelektronenmikroskopie an einem IBAD-YSZ-Film und Entwicklung der Textur mit zunehmender Schichtdicke (aus [7]).

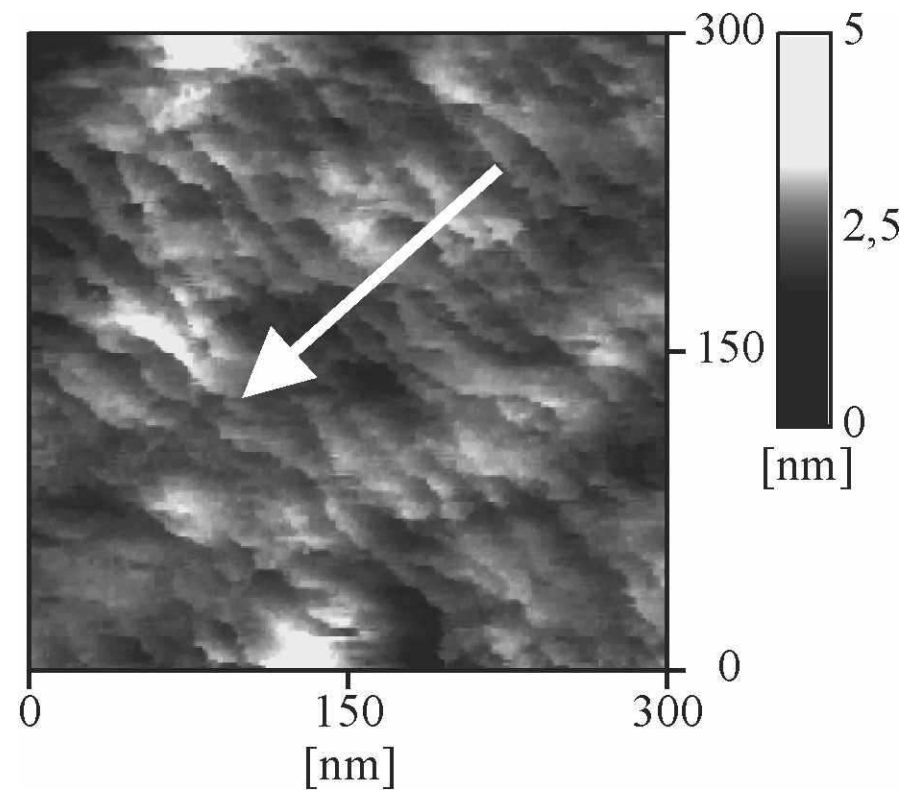

Abbildung 2.4: AFM Aufnahme einer IBAD-YSZ Schicht [7]. Der Pfeil kennzeichnet die Einfallsrichtung des IBAD-Strahls. 


\section{Kapitel 3}

\section{Experimentelles}

In diesem Kapitel werden kurz die für diese Arbeit verwendeten experimentellen Methoden vorgestellt. Neben der Schichtherstellung werden dabei besonders texturanalysierende Verfahren wie Röntgentexturanalyse und RHEED betrachtet.

\subsection{Schichtherstellung}

Als Substrate wurden YSZ-(001)-Einkristalle der Firma CrysTec und IBAD-YSZ-Schichten auf Stahl oder PSZ $\left(\mathrm{ZrO}_{2}\right.$ mit 2-6 mol\% $\left.\mathrm{Y}_{2} \mathrm{O}_{3}\right)$ verwendet. Diese wurden vor der Schichtherstellung in Aceton und Methanol in einem Ultraschallbad je 20 Minuten gereinigt und anschließend wurde der Flüssigkeitsfilm im Gasfluß so schnell entfernt, daß kein Lösungsmittel eintrocknen konnte. Für die Herstellung der Precursoren wurden stöchiometrische Mischungen von (i) Acetylacetonaten der Firma Strem in 0.25 M-Lösung in einem 70/30 Gemisch aus wasserfreier Essigsäure und iso-Propanol und (ii) 0.2 M-Lösungen von Ethylhexanoaten in Toluol der Firma Inorgtech (jetzt: Epichem) verwendet.

Die Schichtherstellung erfolgte dann in mehreren Schritten: Die gereinigten Substrate wurden in den Spincoater (siehe Abb. 3.3a) eingebaut und beschichtet. Die so erhaltene Schicht wurde nun verschiedenen Auslagerungsbehandlungen unterzogen, wie in Abb. 3.1 dargestellt. Im ersten Trocknungsschritt, der in einer $\mathrm{Ar} / \mathrm{H}_{2}(5 \%)$-Atmosphäre durchgeführt wird, verdunstet das restliche Lösungsmittel (Essigsäure bzw. Toluol); $\mathrm{T}_{T r}$ liegt bei $150^{\circ} \mathrm{C}$. Die Trockentemperatur wird durch lineares Erhöhen der Heiztemperatur eingestellt. Für diese Temperaturrampe $R_{T r}$ wird eine Anstiegsrate von $1 \mathrm{~K} / \mathrm{min}$ eingesetzt. Typische Haltezeiten $\mathrm{t}_{t r}$ sind 30 Minuten. Im darauf folgendem Heizschritt findet die Kristallisation statt; typische Heizraten liegen im Bereich von 1-10 K/min, die Haltezeiten 1-32 Stunden, die erreichte Endtemperatur zwischen $720^{\circ} \mathrm{C}$ und $1100^{\circ} \mathrm{C}$. Für einige Materialien ist dann noch ein dritter Auslagerungsschritt an Luft erforderlich bei Temperaturen bis zu $1300^{\circ} \mathrm{C}$ um das Wachstum der Schicht zu vervollständigen und den richtigen Sauerstoffgehalt einzustellen (siehe Abschnitt 4.4.3). 


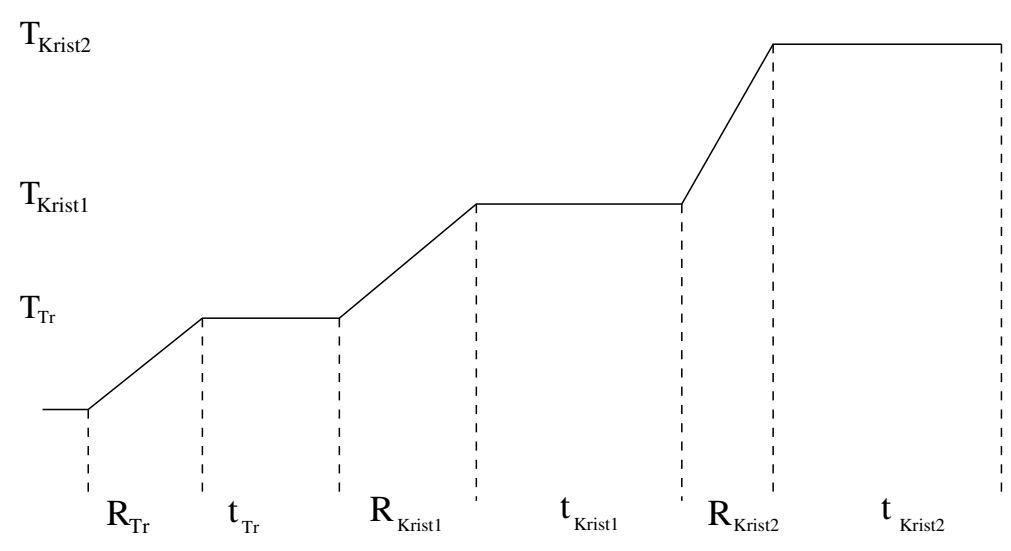

Abbildung 3.1: Heizprofil für die Schichtherstellung; die Auslagerung gliedert sich in einen Trocknungsschritt (bei der Temperatur $T_{T r}$, die mit einer Heizrate von $R_{T r}$ erreicht wird und für die Zeit $t_{T r}$ gehalten wird) und zwei Kristallisationsschritte (bei $t_{k r i s t 1}$ und $t_{k r i s t 2}$ ).

\subsubsection{Spincoating}

Das Photoresistspinnen oder Spincoating läßt sich in vier Stufen einteilen:

- Aufbringen des Precursors: Hier werden mit einer Pipette oder Kanüle ein bis zwei Tropfen des Precursors auf das Substrat aufgetropft. Dadurch bildet sich ein durch die Oberflächenspannung auf dem Substrat gehaltener Tropfen, der die ganze Substratoberfläche $(5 \times 5 \mathrm{~mm})$ bedeckt (Abb. $3.2 \mathrm{a}$.)

- Herunterschleudern des Flüssigkeitsüberschusses: Durch Einstellen einer Drehfrequenz von 5000 Umdrehungen pro Minute werden große Teile des aufgetropften Precursors vom Substrat geschleudert. Es verbleibt eine Schicht, die auf dem Substrat haften bleibt. Für kontinuierliche Schichten ist somit eine gute Benetzung des Substrates durch den Precursor nötig (Abb. 3.2b).

- Dünnen der haftenden Precursorschicht: Die nach dem Herunterschleudern des Flüssigkeitsüberschusses auf dem Substrat verbliebende Schicht wird in Konkurrenz zwischen Zentrifugalkraft und viskoser Reibung gedünnt. So entstehen sehr glatte Schichten und anfängliche Inhomogenitäten in der Schichtdicke können ausgeglichen werden (Abb. 3.2 c). Lediglich an den Rändern der Probe entsteht ein Schichtdickengradient (Abb. $3.3 \mathrm{~b}$ ), der sich aus der Benetzung des Substrates durch den Precursors erklärt.

- Trocknen: Die Drehung des Substrates erzwingt eine stationäre Konvektion über der Schicht, die ein homogenes Verdunsten des Lösungsmittel über den Schichtdurchmesser erlaubt. 
(a)

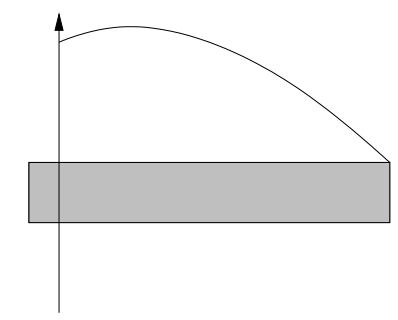

(b)

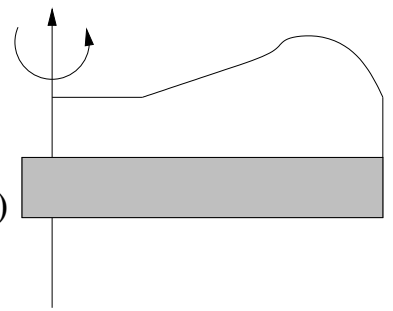

(c)

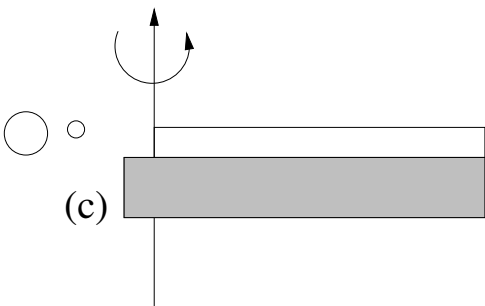

Abbildung 3.2: Spincoating: Nachdem ein Tropfen des Precursors auf das Substrat aufgebracht wurde (a), wird dieses in Rotation versetzt (5000 U/min). Dadurch wird das überschüssige Precursormaterial heruntergeschleudert (b), und es verbleibt nach dem Trocknen eine dünne Schicht aus dem Precursormaterial.
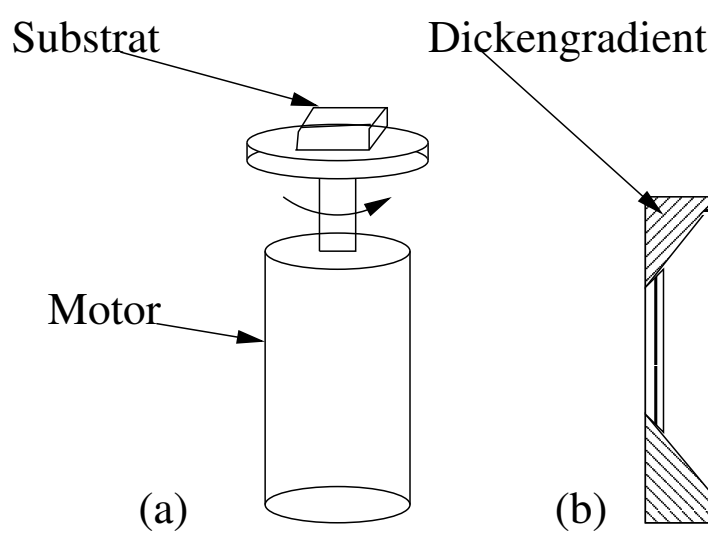

(b)

homogene Schichtdicke

Abbildung 3.3: (a) Spincoater, (b) Dickenverhältnisse auf dem Substrat nach der Beschichtung: die Schichtdicke an den Rändern ist ca. dreimal höher als im Zentralbereich der Probe.

\subsection{Texturanalyse}

Die Texturmessungen an den hergestellten MOD-Schichten lassen sich in zwei Klassen aufteilen. Die über die ganze Schichtdicke gemittelte integrale Textur einer Schicht wurde mit Röntgentexturanalytik bestimmt. Messungen in Bragg-Brentano-Geometrie erlauben die Bestimmung der out-of-plane Komponente der Textur. Von zentraler Bedeutung ist hier die Bragg-Beziehung $\mathrm{n} \cdot \lambda=2 \cdot \mathrm{d}_{h k l} \cdot \sin (\theta)$ mit $\mathrm{d}_{h k l}=\frac{a}{\sqrt{h^{2}+k^{2}+l^{2}}}$ (a: Gitterkonstante; $\lambda$ : Wellenlänge der Röntgenstrahlung; d: Netzebenenabstand; h,k,l: Miller'sche Indizes). Bei bekannter Wellenlänge $\lambda$ lassen sich so aus den Reflexpositionen Rückschlüsse auf Gitterkonstanten und Schichtorientierungen ziehen. Wird $\theta$ konstant gehalten, so lassen sich durch die Messung von Polfiguren Aussagen über die Textur der Probe erhalten. Da die Eindringtiefe der verwendeten $\mathrm{Co}_{-} \mathrm{K}_{\alpha}$-Strahlung $(\lambda=1,7903 \AA)$ mit ca. $7,4 \mu \mathrm{m}$ (YSZ) [127] größer als die Schichtdicke ist, stellen diese Messungen eine Mittelung über die gesamte Schichtdicke dar. Eventuelle Texturgradienten, die beispielsweise bei IBAD- 
Filmen aufgrund des Wachstumsmechanismus auftreten [7], werden somit nicht erfasst, was dazu führt, daß sich bei IBAD-YSZ-Proben die integrale Textur von der Oberflächentextur um ca. $5^{\circ}$ unterscheidet (gemessen anhand der Halbwertsbreite in $\Phi$-Scans).

Die zwei Texturkomponenten einer biaxial texturierten Probe können mit Rockingkurven und $\Phi$-Scans bestimmt werden. Bei Rockingkurven wird im Fall des YSZ und des $\mathrm{CeO}_{2}$ die Lage des (002)-Reflexes in einem $\theta / 2 \theta$-Diffraktogramm bestimmt, der $2 \theta$-Kreis fixiert und $\theta$ um das Maximum variert. Die Halbwertsbreite der so erhaltenen Rockingkurve stellt dann ein Maß für die Textur parallel zur Schichtnormalen, die out-of-plane Textur dar. Die Textur in der Schichtebene wird durch $\Phi$-Scans gemessen. Dazu wird die $\theta / 2 \theta$ Bedingung des (111)-Peaks fest eingestellt, der $\chi$-Kreis wird bei $\chi=54,7^{\circ}$ (für kubische Systeme) fixiert und dann ein $\phi$-Kreis gemessen. Für die in dieser Arbeit betrachteten Materialien ergibt sich eine Kurve mit vier Maxima, deren Halbwertsbreite ein Maß für die in-plane-Textur ist. Die Aufnahme vollständiger Polfiguren kam aufgrund der geringen Schichtdicken $(50 \mathrm{~nm})$ des $\mathrm{MOD}-\mathrm{CeO}_{2}$ und des geringen Unterschieds der Peaklagen von Substrat und Schicht aufgrund hypothetischer Meßzeiten von mehreren Wochen nicht in Frage. Die Röntgenmessungen wurden an einem 2-Kreis-Diffraktometer D500 (Fa. Siemens) und an einem 4-Kreis-Texturgoniometer D8 Advance (Fa. Bruker AXS) (Abb. 3.4) durchgeführt.
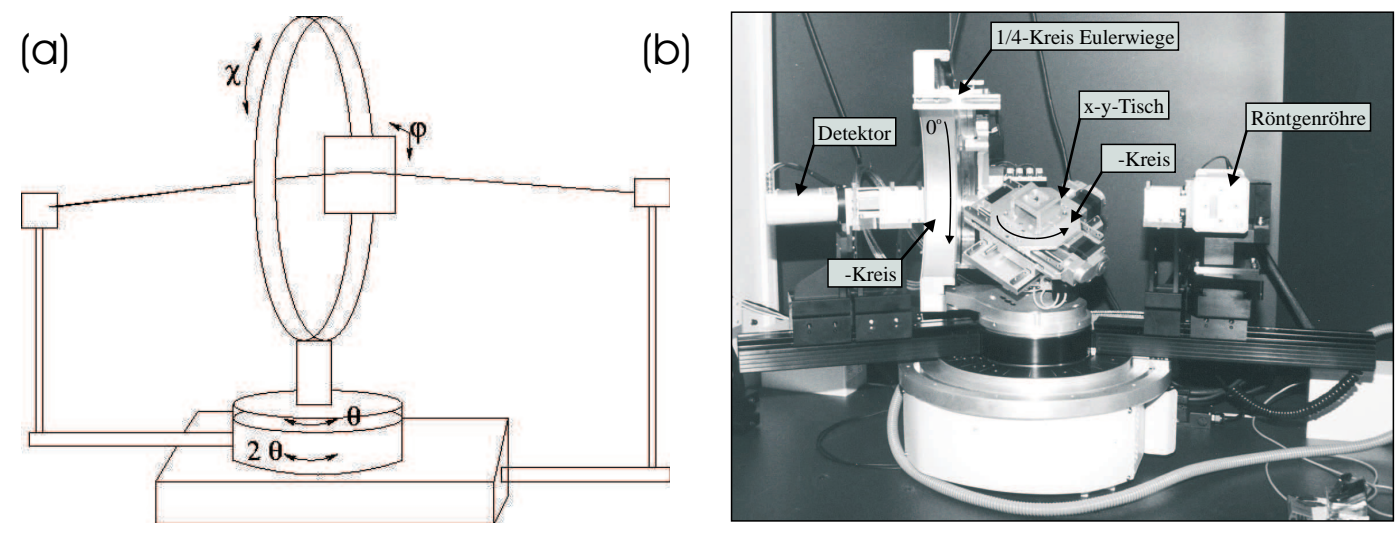

Abbildung 3.4: (a) Skizze eines 4-Kreis-Texturgoniometers (b)4-Kreis-Texturgoniometer D8 Advance (aus [7]).

Von besonderem Interesse für die Qualität der auf den Puffern aufzubringenden supraleitenden Schicht ist die Oberflächentextur. Qualitativ läßt sich diese mit RHEED bestimmen (Abschnitt 3.3), quantitative Aussagen sind mit auf die Pufferschichten aufgesputterten Deckschichten aus CGO möglich. Diese Deckschichten übernehmen die Textur der Oberfläche des Puffers, so daß die Halbwertsbreiten in $\Phi$-Scans der CGO-Deckschicht ein Maß für die Oberflächentextur des YSZ darstellen. Dieses Verfahren kommt insbesondere bei der Untersuchung des homoepitaktischen Wachstums des YSZ auf IBAD-YSZSubstraten zum Einsatz, da sich Substrat und YSZ-Schicht röntgenographisch mit den hier dargestellten Methoden nicht trennen lassen. 


\subsection{Reflection High Energy Electron Diffraction (RHEED)}

Um Zugang zur Textur der für das Wachstum der epitaktischen YBCO-Schicht entscheidenden Oberfläche der Pufferschichten zu erhalten, wurden RHEED-Messungen durchgeführt. Dabei fällt unter einem flachen Winkel (0.5-2 $)$ ein $35 \mathrm{keV-Elektronenstrahl} \mathrm{auf} \mathrm{die} \mathrm{Probe,}$ wird abhängig von der Oberflächenbeschaffenheit reflektiert und erzeugt ein charakteristisches Beugungsbild. Abbildung 3.5 zeigt RHEED-Messungen an YSZ-Einkristallen mit verschiedenen Rauhigkeiten. Der Elektronenstrahl fällt dabei parallel zu einer (001)-Richtung ein. An ideal glatten, zweidimensionalen Oberflächen wird der Elektronenstrahl praktisch
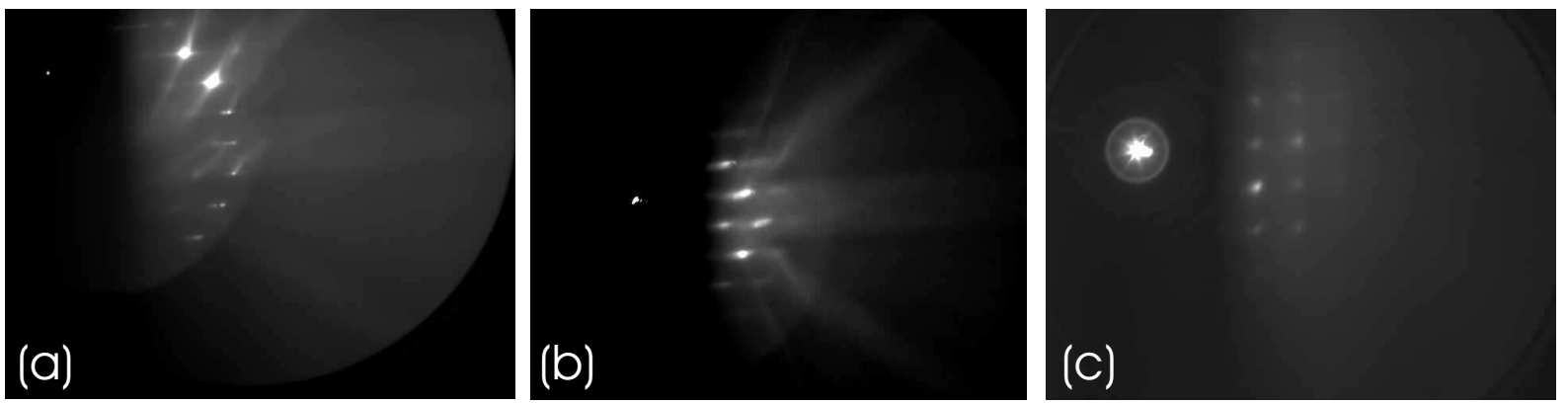

Abbildung 3.5: RHEED-Aufnahme an einem (a) glatten (b) rms=0,246 $\mathrm{nm}$ und (c) rms= 1,479 nm YSZ-(001)-Einkristall.

nur an der obersten Monolage gebeugt. Im reziproken Raum entspricht dies schmalen Säulen, deren Schnitt mit der Ewaldkugel einzelne Punkte sind (Abb. 3.5a). Für eine leicht rauhe Oberfläche (Abb. 3.5b) geht dieses Beugungsmuster dann in ein mehr streifenförmiges über, da der Schnitt der mit zunehmenden Rauhigkeit kugelförmig werdenden reziproken Gitterpunkte ebenfalls flächig wird. Für noch höhere Rauhigkeiten bestimmt dann die Topographie der Oberfläche den RHEED-Kontrast, wie in Abb. 3.5. an dem rechtwinkligen Reflexmuster zu sehen [130]. Die RHEED-Messungen wurden mit einem System kSA 400 der Firma k-Space Associates Inc. durchgeführt. Wegen der schlechten elektrischen Leitfähigkeit von $\mathrm{CeO}_{2}$ und YSZ wurden die Proben während der Messung auf $150-300^{\circ} \mathrm{C}$ aufgeheizt.

\subsection{Rasterelektronenmikroskopie und EDX}

Die rasterelektronischen Aufnahmen wurden an einem Stereoscan 360 Rasterelektronenmikroskop (REM) der Firma Cambridge Instruments durchgeführt. Da sich aufgrund der schlechten Leitfähigkeit der untersuchten Schichten eine Raumladung vor dem Substrat aufbaute, wurde eine Goldschicht (20-50 nm) aufgesputtert. Mit dem ins System integrierten EDX (Energy Dispersive X-ray Analysis) AN 10000 wurde die Zusammensetzung der Schichten untersucht. 


\subsection{Transmissionselektronenmikroskopie}

Transmissionselektronenmikroskopische Untersuchungen wurden von Frau Dr. C. Borchers an einem Phillips EM 420 ST bei einer Beschleunigungsspannung von 120 kV vorgenommen. Die Proben wurden für Querschnittsbetrachtungen präpariert.

\subsection{Rasterkraftmikroskopie (AFM)}

Die Untersuchungen der Oberflächenstruktur wurden von J. Garleff (IV. Physikalisches Institut der Universität Göttingen) an einem Rasterkraftmikroskop (Atomic Force Microscope, AFM) Nanoscope IIIA (Digital Instruments) durchgeführt. Bei diesem Meßverfahren wird über ein piezoelektronisches Positionierungssystem eine Meßspitze an die Filmoberfläche herangefahren bis eine definierte abstoßende Kraft erreicht ist. Unter Beibehaltung dieser Kraft wird jetzt die Probe abgerastert, und die Höhenänderungen der Spitze gemessen. Dadurch entsteht ein hochauflösendes Bild der Oberflächentopographie mit annähernd atomarer Auflösung. Ein Maß für die Rauhigkeit stellt die rms-Rauhigkeit $\mathrm{R}_{r m s}$ dar. Für eine Zeile aus N Datenpunkten der Höhe $\mathrm{z}_{n}$ ist diese definiert als:

$$
R_{r m s}=\sqrt{\frac{\sum_{n=1}^{N}\left(z_{n}-\bar{z}\right)^{2}}{N-1}}
$$

$\operatorname{mit} \bar{z}=\sum_{n=1}^{N} \mathrm{z}_{n} / \mathrm{N}$.

\subsection{Infrarotspektroskopie}

Die Infrarotspektroskopiemessungen wurden an einem FT-IR Spektrometer Bio-Rad FTS7 der Firma Bio-Rad vorgenommen. Die zu untersuchenden Materialien wurden auf infrarottransparente Substrate wie $\mathrm{NaCl}$ oder $\mathrm{KBr}$ aufgebracht und die IR-Absorption in Abhängigkeit von der Wellenzahl gemessen. Diese Messungen wurden von M. Hesse im Institut für Anorganische Chemie der Universität Göttingen durchgeführt.

\subsection{Secondary-Ion-Mass-Spectroscopy (SIMS)}

SIMS ist ein Verfahren zur qualitativen Bestimmung der elementaren Zusammensetzung einer Probe. Während ein $2 \mathrm{kV}-\mathrm{Ar}^{+}$-Ionenstrahl die Probe kontinuierlich abträgt, wird mit einem gepulsten Ga-Ionenstrahl mit einer Energie von $25 \mathrm{keV}$ auf die zu untersuchende Probe geschossen und die Flugzeit der abgesputterten Ionen gemessen. Aus der Flugzeit lassen sich dann die in der Probe enthaltenen Elemente bestimmen. Die Messungen für 
diese Arbeit wurden von Dr. P. Wilbrandt an einem TOF-SIMS IV der Firma ION-TOF vorgenommen.

\subsection{In-situ Synchrotronmessungen}

Aufgrund der geringen Röntgen-Intensität der zu messenden Schichten ist eine direkte zeitaufgelöste Beobachtung der Mikrostruktur- und Texturentwicklung während der Auslagerung mit Laborröntgengeräten nicht möglich. Eine sehr interessante Alternative bieten hier Synchrotrone, da aufgrund der hohen Strahlintensitäten eine viel bessere Zeitund Winkelauflösung möglich wird. Mit diesem Verfahren ist es möglich, die Wachstumsund Texturierungsprozesse in Echtzeit zu verfolgen. Die zu messende Probe wird dabei in Transmission gemessen und die entstehenden Beugungsringe vermessen. Abbildung 3.6 zeigt ein Beispiel einer mit diesem Verfahren gemessenen Aufnahme. Aus der zeitlichen

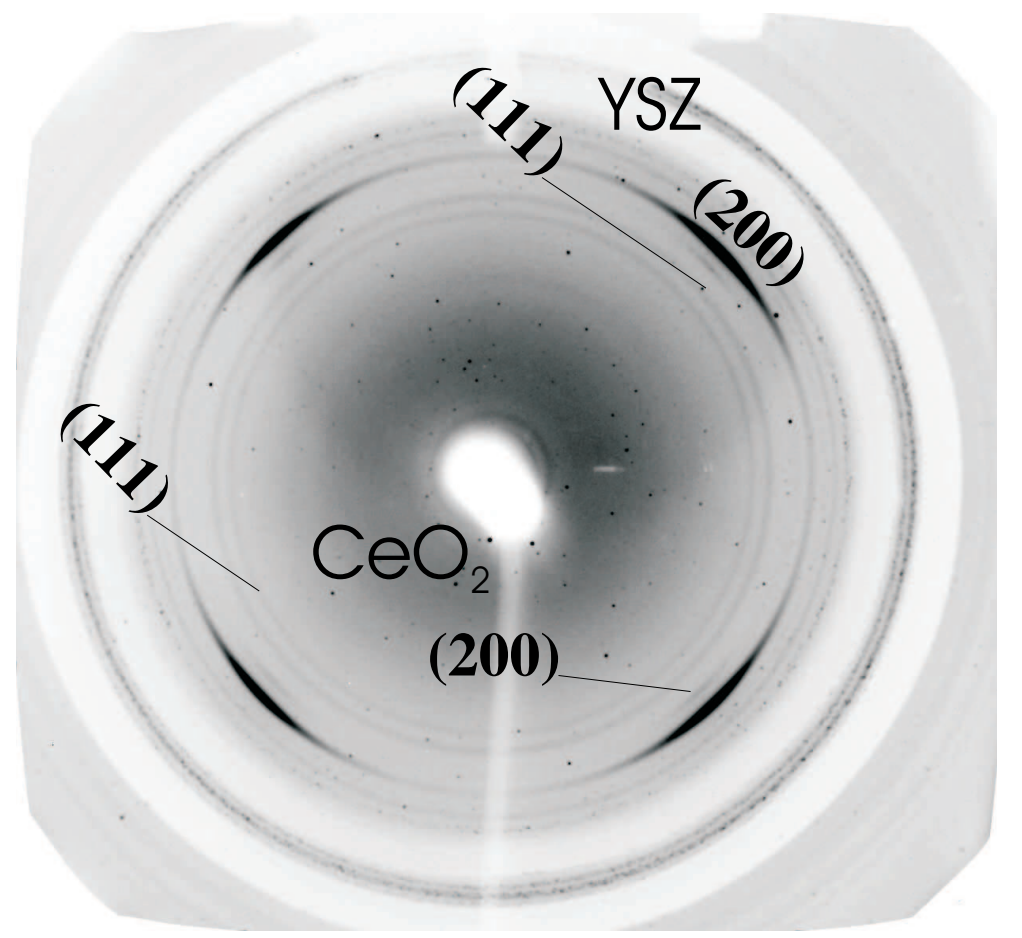

Abbildung 3.6: Detektorbild einer IBAD-YSZ-Probe mit $100 \mathrm{~nm} \mathrm{CeO} \mathrm{O}_{2}$. Im oberen Bildbereich sind die zum YSZ gehörigen Reflexe gekennzeichnet, im unteren die des $\mathrm{CeO}_{2}$.

Entwicklung der Beugungsringe können Informationen über die Texturentwicklung und die Korngrößenänderung gewonnen werden. Die Messungen wurden von Herrn Dr. F. Berberich an der Hochenergie-Beamline ESRF ID15 der European Synchrotron Research Facility (Grenoble) durchgeführt. 


\subsection{Magnetooptik}

Die magnetooptische Abbildung von Flußdichteverteilungen beruht auf dem magnetooptischen Faradayeffekt: die Polarisationsebene von linear polarisiertem Licht wird beim Durchgang durch eine magnetooptische Schicht gedreht, wenn diese von einem Magnetfeld parallel zur Ausbreitung des Lichtes durchsetzt wird. Liegt an einer Stelle der Probe eine Magnetfeldkomponente parallel zur Schichtnormalen vor, so wird die Polarisationsebene des linear polarisierten Lichtes gedreht, was zu einer ortsaufgelösten, in Graustufen codierten Information über die Magnetfeldverteilung über der Probe führt. Für die Messung

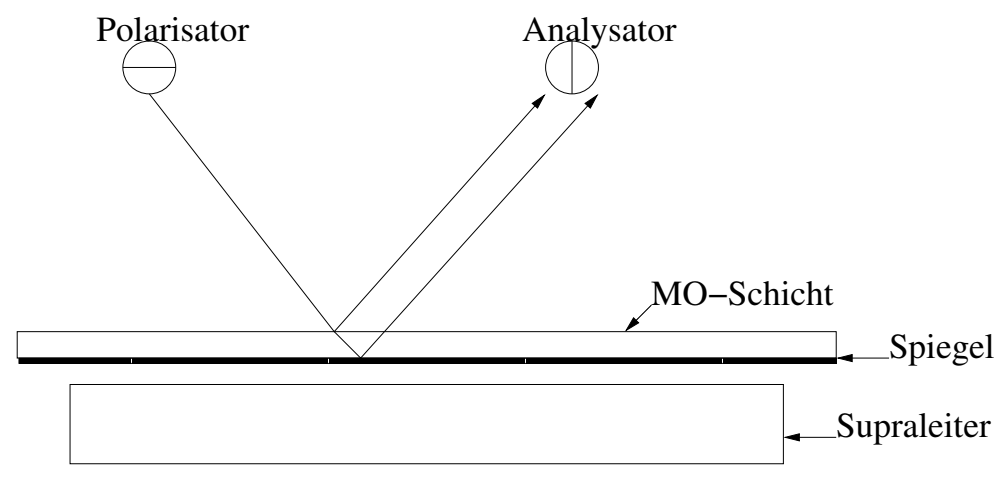

Abbildung 3.7: Darstellung des Meßprinzips zum magnetooptischen Faradayeffekt. Die Polarisationsebene des einfallenden polarisierten Lichtes wird abhängig von der lokalen magnetischen Flußdichte gedreht. Bei Beobachtung durch einen Analysator ergibt sich so ein ortsaufgelöstes Bild der Flußdichteverteilung über der Probe.

wird eine magnetooptische Schicht auf den Supraleiter aufgelegt, die an der Unterseite eine reflektierende Al-Schicht aufweist. Die gemessene Graustufenverteilung läßt sich in eine Flußdichteverteilung umrechnen. Die erreichbare Ortsauflösung beträgt je nach Meßparametern 1-5 $\mu \mathrm{m}$, die abbildbaren Flußdichten erreichen einige wenige $100 \mathrm{mT}$. Ein Beispiel zeigt Abb. 3.8: das magnetische Feld ist in weite Bereiche des Supraleiters eingedrungen, wie an dem Graustufengradienten und dem zugehörigen Flußdichteprofil erkennbar wird. in der Mitte verbleibt ein schwarzer Bereich ohne eingedrungenen magnetischen Fluß. Aus den Flußdichteverteilungen lassen sich mit einer Inversion des Gesetzes von Biot und Savart die Stromdichteverteilungen bestimmen [132].

\subsection{Gepulste Laserdeposition}

Die in dieser Arbeit besprochenen YBCO-Filme wurden mit gepulster Laserdeposition (PLD: Pulsed Laser Deposition) hergestellt. Dazu wurde ein KrF Excimerlaser Lambda LPX 110i mit einer Wellenlänge von $248 \mathrm{~nm}$ und Pulslängen von $30 \mathrm{~ns}$ verwendet. Bei diesem Verfahren trifft ein fokussierter Laserstrahl mit einer Energiedichte von ca. 1,8 J/m² 

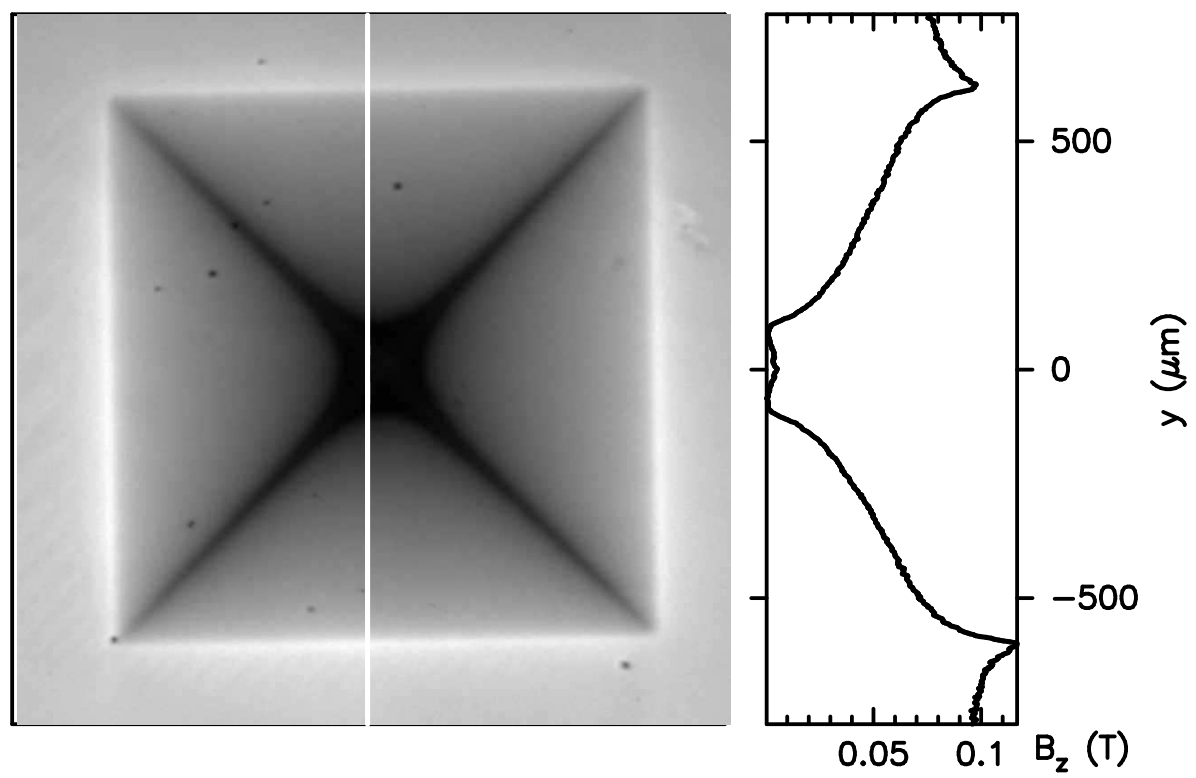

Abbildung 3.8: Magnetooptische Messung an einem 500 nm dicken PLD-YBCO-Film auf einem $\mathrm{SrTiO}_{3}$-Einkristall bei $8 \mathrm{~K}$ in einem äußeren Feld von $92 \mathrm{mT}[131]$. Die magnetische Flußdichte ist als Graustufenbild zu erkennen. Das Flußdichteprofil ist entlang der weißen Linie entnommen.

auf das YBCO-Target. Das ablatierte Material schlägt sich bei einem Sauerstoffpartialdruck von 0,6 mbar auf dem auf $760^{\circ} \mathrm{C}$ geheizten Substrat nieder. Zum Abschluß erfolgt eine Sauerstoffbeladung des Filmes bei $400^{\circ} \mathrm{C}$ und $500 \mathrm{mbar} \mathrm{O}_{2}$.

\subsection{Thermogravimetrie}

Bei der Thermogravimetrie (TGA) wird die Massenänderung einer Probe während eines definierten Heizprozesses gemessen. Aus diesen Messungen können Informationen über das Dekompositionsverhalten der Precursoren gewonnen werden. Die im Rahmen dieser Arbeit untersuchten Proben wurden mit Temperaturrampen von 3-5 K/min auf die Endtemperatur von $1200^{\circ} \mathrm{C}$ gebracht und die Entwicklung der Masse mit der Temperatur verfolgt. Die Messungen wurden im Analytischen Labor des Institutes für Anorganische Chemie der Universität Göttingen mit einem NETZSCH STA 409 PC durchgeführt. Die Messungen führten D. Kumpart, S. Petrich, A. Wraage und H. Rusev durch. 


\subsection{Rutherford Rückstreuung}

Die Rutherford Rückstreuungs Experimente (RBS) wurden von H. Kröger am IONAS [133 des II. Physikalischen Institutes der Universität Göttingen durchgeführt. Bei diesem Meßverfahren trifft ein $\mathrm{He}^{2+}$-Ion mit einer Energie von $900 \mathrm{keV}$ unter einem Streuwinkel von $165^{\circ}$ auf das Substrat. Die Energie des rückgestreuten Projektils ist dabei abhängig von der Masse des Targetatoms. Berücksichtigt man außerdem den Wirkungsquerschnitt und den Energieverlust in Materie, so können aus einer RBS-Messung mit dem Programm RUMP [134] Schichtdicke und Zusammensetzung berechnet werden.

\subsection{Einkristallröntgenstrukturanalyse}

Die Röntgenstrukturanalysen wurden auf einem Stoe AED 2 Vierkreisdiffraktometer, einem Stoe IPDS II und einem Stoe-Siemens-Huber-Vierkreisdiffraktometer mit monochromatischer Mo- $\mathrm{K}_{\alpha}-$ Strahlung durchgeführt. Die Strukturen wurden mit den Programmen SHELXS-97 und SHELXL-97 berechnet. Die Untersuchungen führten Dr. M. Noltemeyer und Herr H. G. Schmidt vom Institut für Anorganische Chemie der Universität Göttingen durch. 


\section{Kapitel 4}

\section{MOD-CGO}

Im Rahmen dieser Arbeit wurden vier Schichtsysteme untersucht: $\mathrm{CeO}_{2}$, auch mit $\mathrm{Gd}_{2} \mathrm{O}_{3}{ }^{-}$ Dotierungen, und YSZ jeweils auf YSZ-Einkristallen und IBAD-YSZ-Substraten. Beide Schichtmaterialien sind Bestandteile vieler Pufferarchitekturen für Coated Conductors. Gegenstand dieses Kapitels ist die Untersuchung des Wachstumsverhaltens von $\mathrm{CeO}_{2^{-}}$ Schichten auf verschiedenen YSZ-Substraten. Dazu wurden aufgrund der so erzielbaren glatten Oberflächenmorphologie und einfachen Handhabung Acetylacetonate in Essigsäure und 2-Ethylhexanoate in Toluol als Precursoren verwendet. In diesem Kapitel wird zunächst das Dekompositionsverhalten der Precursorsysteme beim Erhitzen untersucht. Darauf folgt eine Optimierung der Auslagerungsparameter und eine Untersuchung des Einflusses der Substratrauhigkeit und der Atmosphäre auf dieselbigen.

\subsection{Die Precursorsysteme}

Als Precursor wurden hauptsächlich Ce 17 und Gd ${ }^{2}$-Acetylacetonate gelöst in einer Mischung aus Essigsäure und iso-Propanol verwendet 3 . Exemplarisch für die Acetylacetonate findet sich die Strukturformel des Ce-Acetylacetonats in Abbildung 4.1(b). Das zentrale Ce-Atom wird von drei Acetylacetonatgruppen umschlossen, die bei Lösung in Essigsäure teilweise durch Acetatgruppen ersetzt werden. Die Essigsäure fungiert als Lösungsmittel; das iso-Propanol erhöht die Precursorstabilität (von einigen Minuten) bis zum Auftreten von Partikeln und der daraus resultierenden Trübung des Precursors auf einige Stunden. Dieses Verhalten läßt sich vermutlich mit der Hemmung der Ce-Acetatbildung und der damit verbundenen Minderung der Ausfällung in Essigsäure unlöslicher Hydroxide verstehen. Dadurch trägt eine Zugabe von iso-Propanol zu einer deutlich glatteren Oberflächenmorphologie bei, was Abbildung 4.2 belegt. Für eine eingehendere Diskussion der chemischen Vorgänge siehe [135]. Für die Schichtherstellung wurden 0,25 M Lösungen der Ace-

\footnotetext{
${ }^{1} \mathrm{Ce}(\mathrm{III})$-Acetylacetonat-Hydrat der Firma Strem Chemicals

${ }^{2}$ Gd-Acetylacetonat-Hydrat der Firma Strem Chemicals

${ }^{3} \mathrm{Zu}$ den Kriterien für die Precursorauswahl siehe Abschnitt 2.1
} 

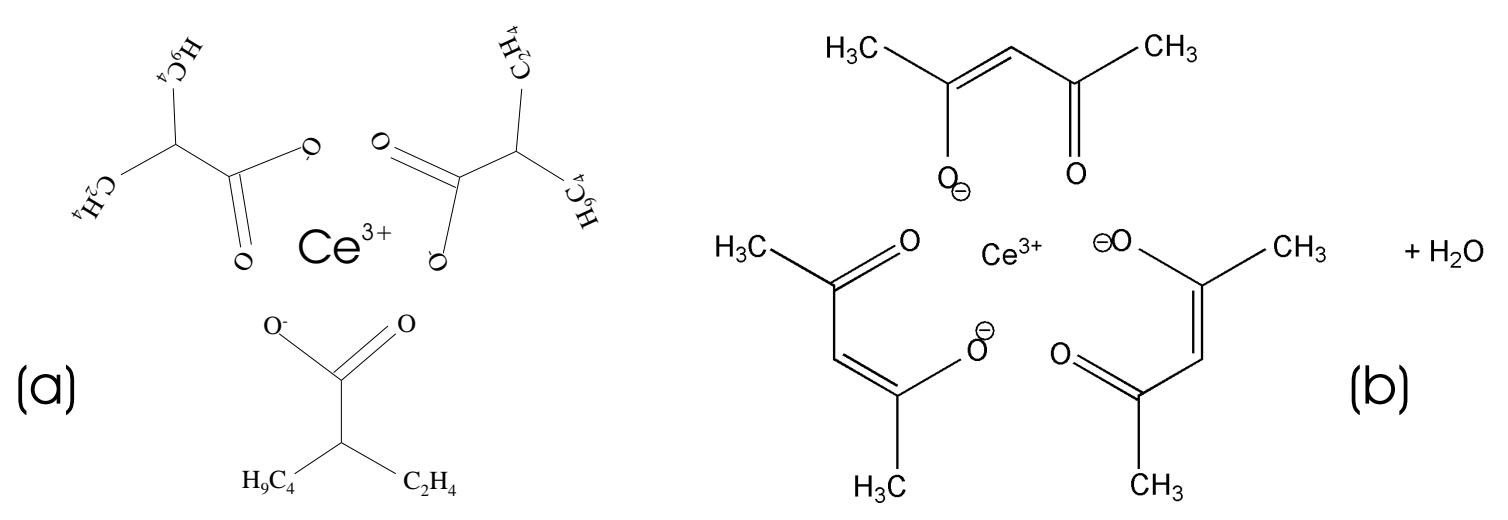

Abbildung 4.1: (a) Ce-2-Ethylhexanoat (b) Ce-Acetylacetonat.

tylacetonate in einer 70-30-Essigsäure/iso-Propanol-Mischung bei einer Temperatur von ca. $50{ }^{\circ} \mathrm{C}$ unter mäßigem Rühren präpariert.

Neben den Acetylacetonaten kamen auch Ethylhexanoate in Toluol (0.2 M) zum Einsatz (Abb. 4.1(a)). Die Ethylhexanoate sind für einige Wochen bis Monate stabil und ermöglichen so prinzipiell ein reproduzierbareres Arbeiten. Darüberhinaus greifen sie im Gegensatz zur Essigsäure metallische Substrate nicht an.

\subsection{Dekompositionsverhalten der Precursoren}

Das thermische Zersetzungsverhalten des Precursors ist wichtig für die Wahl des Auslagerungsprofils; so führt beispielsweise ein zu hoher Temperaturgradient zu Beginn der Wärmebehandlung durch zu schnelles Entweichen des Lösungsmittels u.U. zu einer mit Rissen belegten, unebenen Oberfläche. Aus diesen Gründen wurde mittels Thermogravimetrie und Infrarotspektroskopie das Zersetzungsverhalten der beiden Precusorsysteme untersucht.

\subsubsection{Acetylacetonate}

Zur Untersuchung des Dekompositionsverhaltens des Precursors wurde eine 0.2 M-Lösung des Ce-Acetylacetonates in Essigsäure bei Raumtemperatur an Luft getrocknet und das so entstehende Pulver für die TGA-Messung unter langsam strömenden $\mathrm{N}_{2}$ verwendet. Für die ex-situ IR-Untersuchungen wurde der flüssige Precursor auf NaCl-Trägerkristalle aufgetropft und bei den angegebenen Temperaturen für eine Stunde an Luft ausgelagert. Abbildung 4.3 zeigt die Gewichtsänderung des zuvor bei Raumtemperatur getrockneten Precursormaterials auf Acetylacetonatbasis und die Änderung des IR-Absorptionssprektrums, d.h. der chemischen Bindungsverhältnisse mit wachsender Auslagerungstemperatur. 

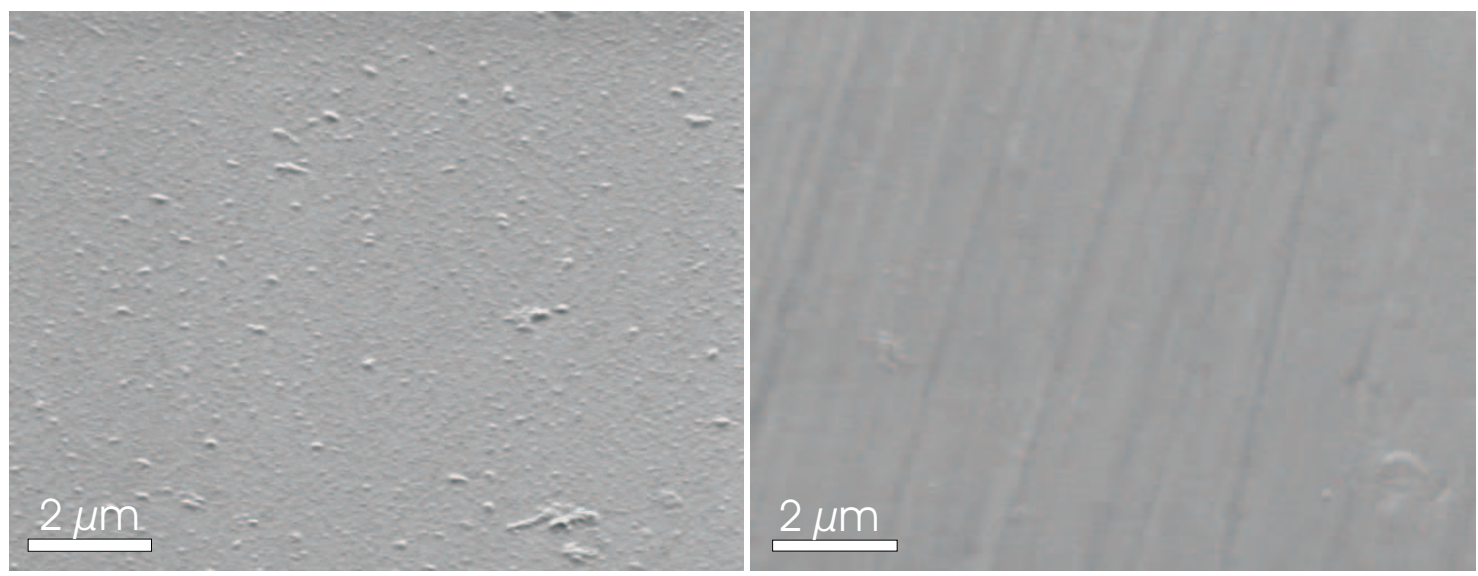

Abbildung 4.2: Veränderung der Oberflächenstruktur bei Zugabe von iso-Propanol im Falle des CGO (beide Aufnahmen entstanden nach einer Auslagerung bei 790-820 C in $\mathrm{Ar} / \mathrm{H}_{2}$ ); links (CGO auf YSZ-(001)-Einkristall) ohne, rechts (CGO auf IBAD-YSZ auf Stahl) mit iso-Propanol (Die schräg verlaufenden Riefen in (b) rühren vom Stahlband des Substrates her.).

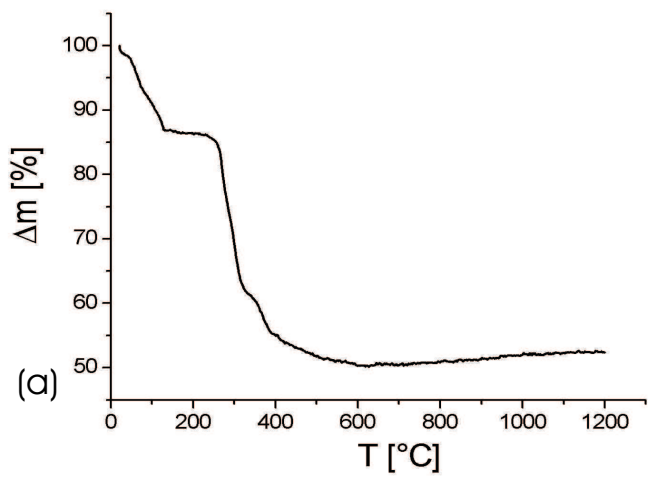

(b)

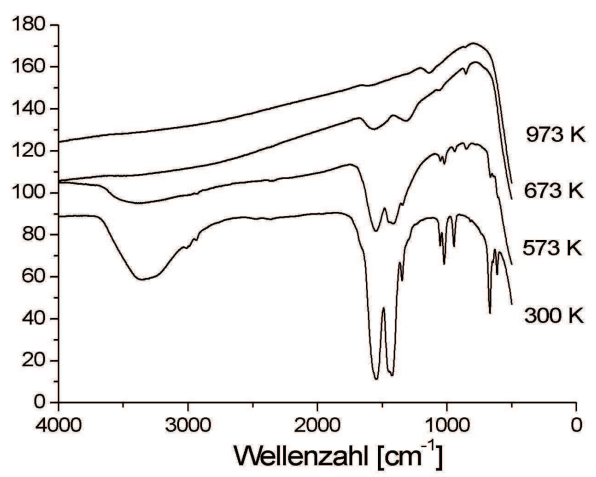

Abbildung 4.3: (a) Thermogravimetrie in $N_{2}$ und (b) Infrarotspektroskopie bei verschiedenen Temperaturen an Ce-Acetylacetonat in Essigsäure. 
Man beobachtet im Temperaturbereich von $20-120{ }^{\circ} \mathrm{C}$ eine Gewichtsabnahme um ca. $12 \%$, was dem Verdunsten der Essigsäure (Siedepunkt $118{ }^{\circ} \mathrm{C}$ ) in dem Precursor zugeordnet werden kann. Eine weitere Temperatureröhung führt dann, wie am Verschwinden der zugehörigen Absorptionsbanden zu erkennen, zur Zersetzung des Precursormoleküls, zuerst der Ce-Acetat-Bindungen (Wellenzahlbereich 1200-700 cm-1) später der Acetylacetonatbindungen bei ca. $1500 \mathrm{~cm}^{-1}$. Bei ca. $600^{\circ} \mathrm{C}$ ist der Zerfall dann weitestgehend abgeschlossen. Es verbleiben einzelne Absorptionsbanden $\left(850 \mathrm{~cm}^{-1}\right.$ und $\left.1130 \mathrm{~cm}^{-1}\right)$, die dem Ce-Karbonat zugeordnet werden können [136]. Die Ce-O-Schwingungen konnten aufgrund der Absorption des Trägerkristalls im Bereich kleiner Wellenzahlen nicht aufgelöst werden. Die Bildung von $\mathrm{CeO}_{2}$ konnte mittels Pulverdiffraktometrie nachgewiesen werden.

\subsubsection{Ethylhexanoate}

Nach der Verdunstung von Lösungsmittelresten bis ca. $130{ }^{\circ} \mathrm{C}$ findet sich thermogravimetrisch zwischen $200{ }^{\circ} \mathrm{C}$ und $400{ }^{\circ} \mathrm{C}$ ein Bereich ohne signifikante Massenabnahme (Abb. 4.4). Bei ansteigender Temperatur zerfällt im Temperaturbereich bis $500{ }^{\circ} \mathrm{C}$ dann der Precursor. In den IR-Spektroskopie-Messungen finden sich im Bereich 3050-2800 cm ${ }^{-1}$ die C-H-Schwingungen, die Carbonylgruppen zwischen 1500 und $1600 \mathrm{~cm}^{-1}$ gefolgt von

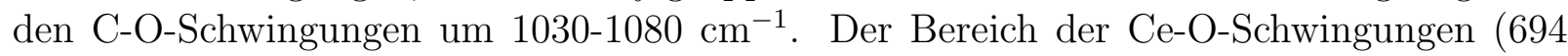
bzw. $464 \mathrm{~cm}^{-1}$ wird aufgrund der Absorption der Unterlage $(\mathrm{NaCl})$ nicht mehr aufgelöst. Wie im Fall der Acetylacetonate bleibt nach einer Auslagerung bei $900{ }^{\circ} \mathrm{C}$ auch hier eine Absorptionsbande bei $855 \mathrm{~cm}^{-1}$ bestehen, die dem $\mathrm{Ce}_{2}\left(\mathrm{CO}_{3}\right)_{3}$ zugeordnet werden kann, was auf den Verbleib von Resten von Kohlenstoff in der $\mathrm{CeO}_{2}$-Schicht hindeutet.
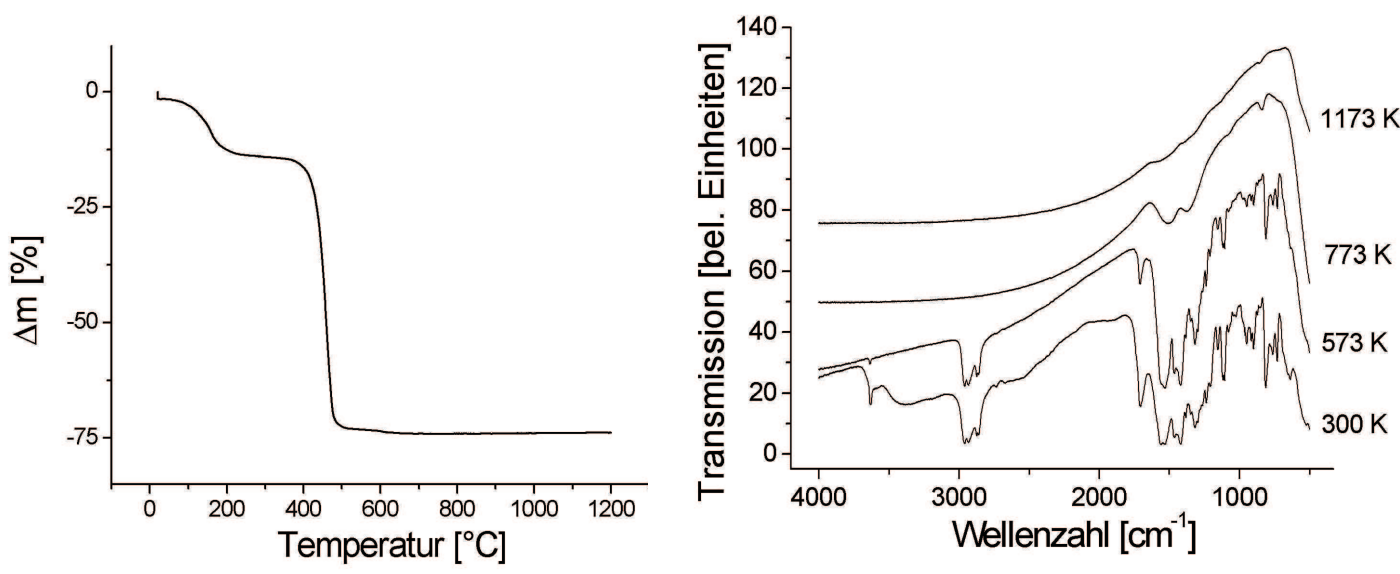

Abbildung 4.4: (a)Thermogravimetrie in $N_{2}$ und (b) Infrarotspektroskopie bei verschiedenen Temperaturen für die Ethylhexanoate. 


\subsection{Oberflächenmorphologie der Schichten}

Da bis zum Siedepunkt des Lösungsmittels ein Massenverlust von ca. $15 \%$ beobachtet wird, wird bei den im folgenden vorgestellten Schichten zunächst mit einer kleinen Heizrate von $1 \mathrm{~K} / \mathrm{min}$ bis auf $150{ }^{\circ} \mathrm{C}$ geheizt um Rissbildung durch heftiges Verdampfen der Lösungsmittelreste in der Schicht zu vermeiden. Diese Temperatur wird für 30 Minuten gehalten. Der mit Infrarotspektroskopie beobachtete Zerfall des Precursors ist bei $700-900{ }^{\circ} \mathrm{C}$ weitestgehend abgeschlossen. Um Inhomogenitäten in der Korngröße und Zusammensetzung der Schicht während der Zersetzung des Precursors vorzubeugen, wurde für die auf den Trocknungsschritt folgende Auslagerung eine höhere Heizrate von 3-5 K/min eingestellt.

Die in diesem Abschnitt betrachteten $\mathrm{CeO}_{2}$ und mit $5 \% \mathrm{Gd}_{2} \mathrm{O}_{3}$ dotierten $\mathrm{CeO}_{2}$ Schichten wurden mit einem einfachen Spincoater bei $5000 \mathrm{U} / \mathrm{min}$ auf die jeweiligen Substrate deponiert (Abschnitt 3.1.1). Abbildung 4.5 (a) zeigt eine Ce-Acetylacetonatschicht vor der Auslagerung. Die Oberfläche der Schicht ist kontinuierlich und abgesehen von einigen Prezipitaten aus Precursorreaktionen mit einer Ausdehnung von ca. 100-200 nm glatt. Nach einer Auslagerung unter einem $\mathrm{Ar} / \mathrm{H}_{2}$-Gasfluß bei Temperaturen $\mathrm{T}_{\text {Krist } 1}$ zwischen
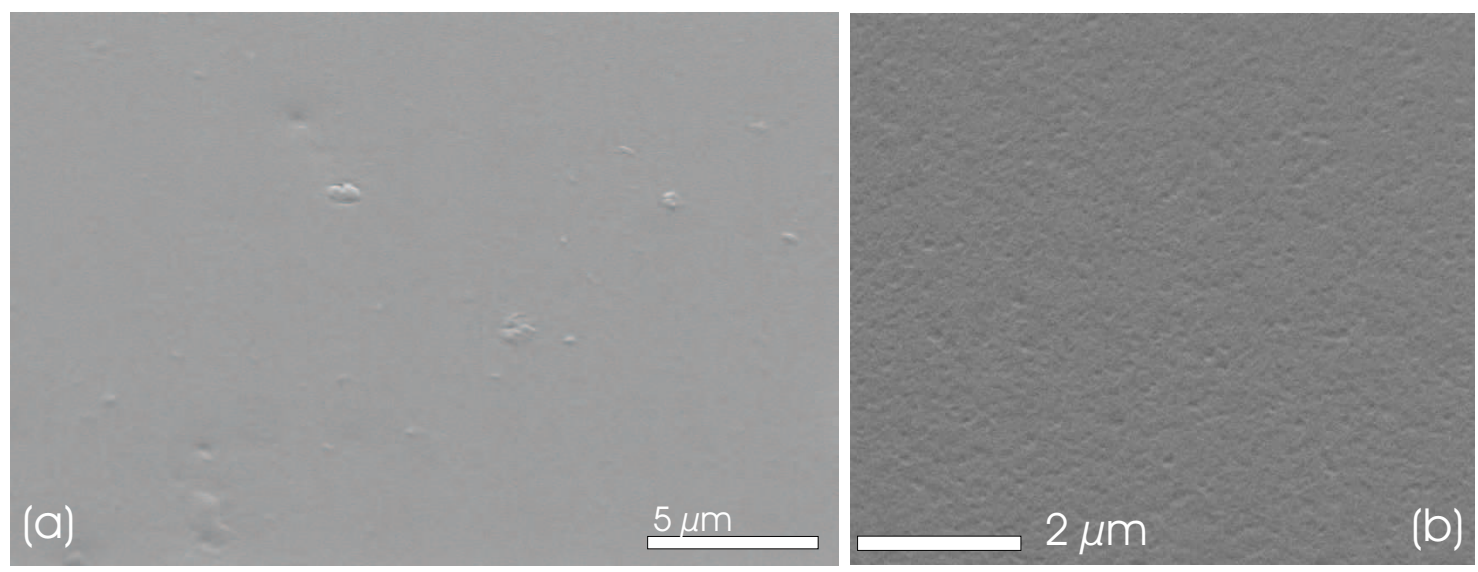

Abbildung 4.5: (a) Rasterelektronische Aufnahme einer deponierten CeAcetylacetonatschicht vor der Pyrolyse; (b) Typische Oberflächenstruktur bei Verwendung von Ce-2-Ethylhexanoat in Toluol als Precursor.

$755^{\circ} \mathrm{C}$ und $820^{\circ} \mathrm{C}$ zeigten sich Oberflächen mit einer um einen Faktor drei verringerten Größe der ehemaligen Prezipitate. Rasterelektronenmikroskopische Untersuchungen weisen darüberhinaus auf eine Abnahme der Schichtdicke um einen ähnlichen Faktor hin. Die organische Schicht schrumpft also bei der Auslagerung auf ca. 1/3 ihrer ursprünglichen Dicke auf 50-55 nm zusammen. Das mit EDX bestimmte Ce/Gd-Verhältnis liegt mit 88:12 (Einwaage 90:10) im Bereich der Meßgenauigkeit. Die so hergestellten Schichten sind sehr glatt, die mit dem Rasterkraftmikroskop gemessene rms-Rauhigkeit liegt bei $1.6 \mathrm{~nm}$. Die Schichtdicke wurde mit einem Profilometer und mit RBS (siehe Abb. 4.6) zu 50-55 nm be- 
stimmt. Die mit den Ethylhexanoaten hergestellten Schichten sind glatt und kontinuierlich (Abb.4.5b), die Einzelschichtdicke liegt hier bei $50 \mathrm{~nm}$.

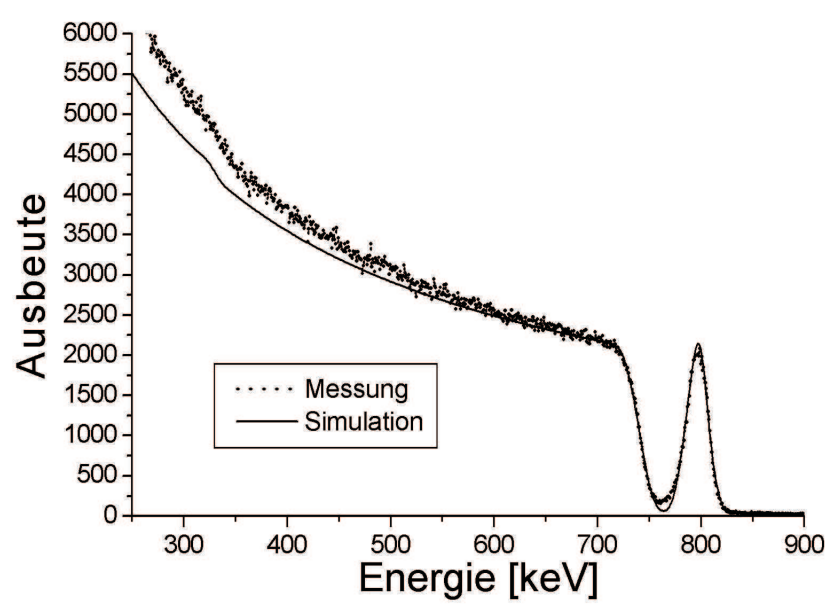

Abbildung 4.6: Rutherford-Backscattering an einer bei $820^{\circ} \mathrm{C}$ ausgelagerten $C G O$-Schicht auf einem YSZ-(001)-Einkristall. Für die Simulation wurde ein mit zunehmender Schichtdicke linear abnehmender $Y$ bzw. Zr-Konzentrationsgradient in der CGO-Schicht verwendet.

\subsection{Wachstum auf YSZ-(001) Einkristallen}

Zur Charakterisierung des Schichtwachstums wurden zunächst YSZ-Einkristalle als Substrat eingesetzt. Einkristalle weisen epitaxietaugliche, ungestörte Oberflächen auf. Ziel war es, zunächst das Pufferwachstum auf einer defektfreien Oberfläche zu untersuchen, um das intrinsische Wachstum zu verstehen. YSZ-Einkristalle können als Modellsystem für einzelne Körner von polykristallinen Schichten verstanden werden. Im zweiten Teil der Untersuchungen wird dann zusätzlich der Einfluss der Korngrenzen, der Texturverteilung und der Rauhigkeit der Substratoberfläche untersucht, indem definiert präparierte IBAD-YSZ-Schichten und aufgerauhte YSZ-Einkristalle als Unterlage eingesetzt werden.

\subsubsection{Röntgenographische Analyse}

Unter Verwendung des in Abb. 3.1 dargestellten Heizprofils ließen sich die für die Texturausbildung optimalen Auslagerungsparameter mittels Röntgenmessungen in Theta/2 ThetaGeometrie bestimmen. Die Endtemperatur wird dabei so lange variiert, bis der (111)Reflex vollständig unterdrückt ist und nur noch der das gewünschte (100)-Wachstum an- 
zeigende (200)-Reflex auftritt (Abb. 4.7 (a), hier ist der Anteil des (200)-Reflexes an der Summe aus (200) und (111)-Reflex aufgetragen, optimal gewachsene Schichten liegen in dieser Auftragung bei bei einem Wert von 1). Dies ist im Fall des $\mathrm{CeO}_{2}$ bei $775{ }^{\circ} \mathrm{C}$ erreicht. Wählt man zu niedrige Temperaturen, so tritt vorwiegend ein (111)-Wachstum auf. Wird die optimale Temperatur überschritten, so wird wiederum ein kleiner (111)-Anteil gemessen. Die bei optimalen Parametern hergestellten Schichten sind in- und out-of-plane texturiert mit Halbwertsbreiten in $\Phi$-Scans von $0.8^{\circ}$ bzw. $0.4^{\circ}$ in Rockingkurven. Die Entwicklung des Anteils des (200)-Reflexes ist in Abb.4.7(b) für $\mathrm{CeO}_{2}$ und $\mathrm{CGO}$ aufgetragen: unterhalb von $750^{\circ} \mathrm{C}$ wird fast nur ein (111)-Anteil gemessen. Mit Erhöhung der Auslagerungstemperatur steigt dann der (200)-Anteil an. Nach Überschreiten der optimalen Auslagerungstemperatur tritt dann wieder ein kleiner (111)-Anteil auf.
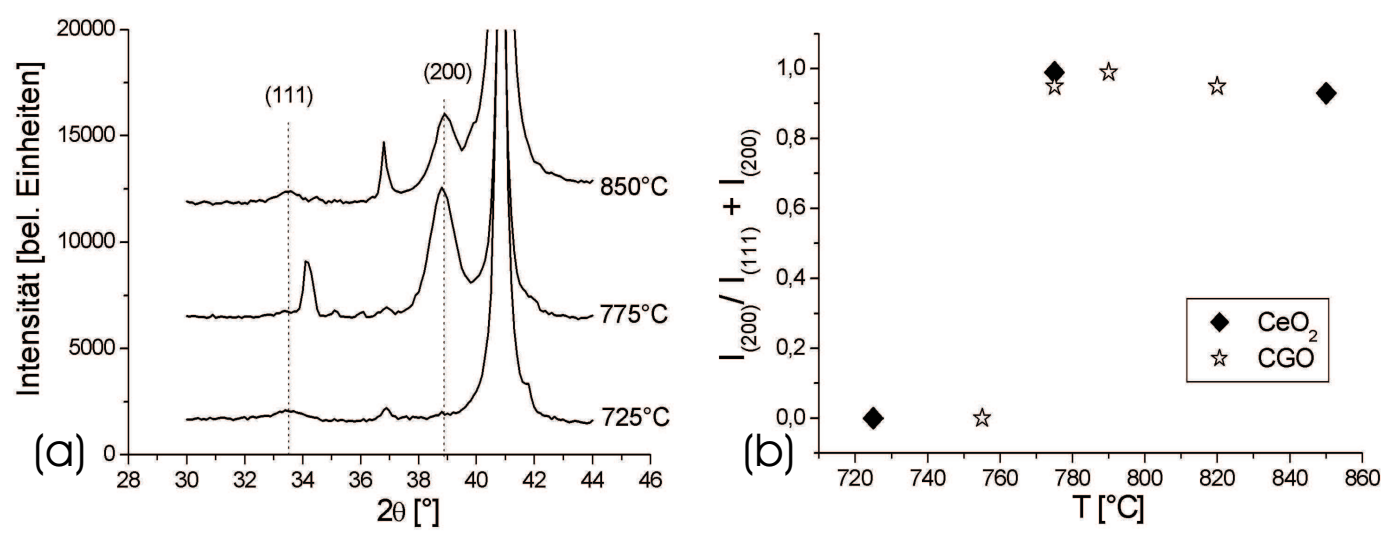

Abbildung 4.7: (a) Röntgenmessungen in Theta/2 Theta Geometrie von $\mathrm{CeO}_{2}$-Schichten auf YSZ-(001)-Einkristallen nach Auslagerungen bei verschiedenen Temperaturen; nicht explizit indizierte Reflexe sind dem Substrat zugehörig. (b) Entwicklung des Verhältnisses $I_{200} /\left(I_{200}+I_{111}\right)$ mit $T_{\text {Krist } 1}$ für CGO und $\mathrm{CeO}_{2}$-Schichten.

Den Einfluß der Heizrate auf die Texturausbildung zeigt Abb. 4.8 (b): zu schnelles Aufheizen führt zu einer unvollständigen (100)-Textur. Für Heizraten kleiner oder gleich $3 \mathrm{~K} / \mathrm{min}$ tritt fast nur noch der CGO-(200) Reflex auf.

Die Röntgenmessungen zeigen, daß im Schichtvolumen eine sehr gut texturierte Schicht vorhanden ist. Ein mittels gepulster Laserdeposition auf einer solchen Schicht abgeschiedener YBCO-Film platzte jedoch teilweise ab und zeigte keinerlei Textur. Offensichtlich sind die wie oben hergestellten Schichten noch keine Texturvermittler für den darauf zu wachsenden Supraleiter. Dieser Befund wird durch Transmissionselektronenmikroskopische Untersuchungen bestätigt: Abbildung 4.9 zeigt auf dem Substrat eine polykristalline, bei $790^{\circ} \mathrm{C}$ ausgelagerte MOD-CGO-Schicht, auf der das YBCO amorph mit polykristallinen Anteilen aufwächst. Die Korngröße in der polykristallinen CGO-Schicht liegt bei ca. $15 \mathrm{~nm}$. 

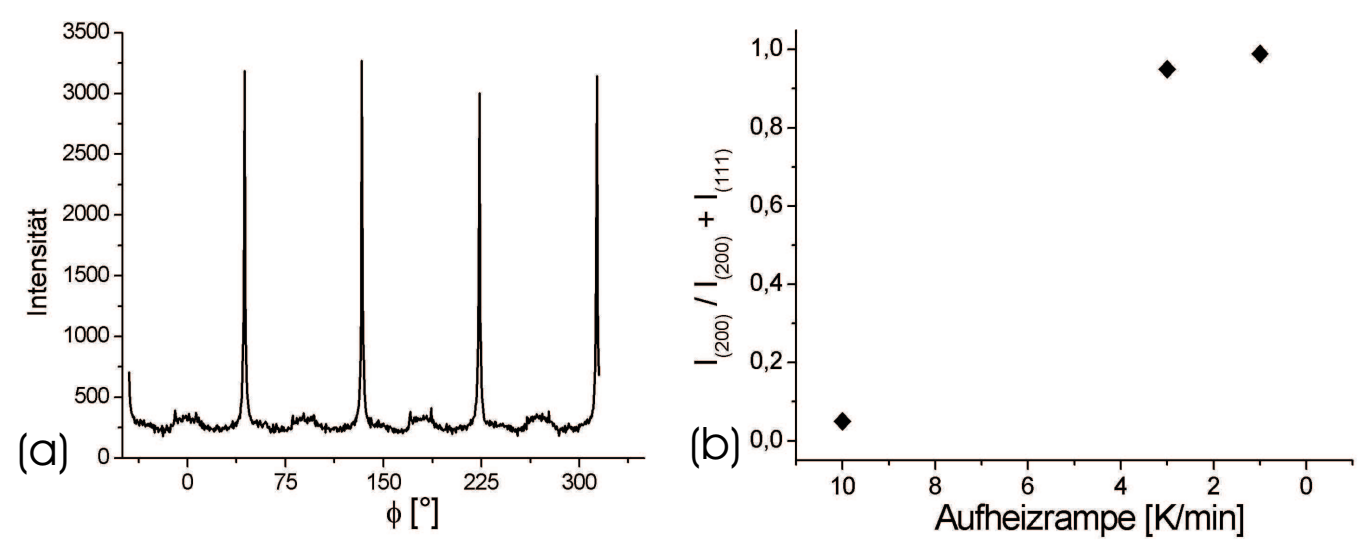

Abbildung 4.8: (a) $\Phi$-Scan auf dem CGO(111)-Reflex an einer bei $790^{\circ} \mathrm{C}$ ausgelagerten CGO-Schicht auf einem YSZ-(001)-Einkristall; (b) Optimierung der Heizrate bei einer Endtemperatur von $790^{\circ} \mathrm{C}$ anhand des Peakverhältnisses $I_{200} /\left(I_{200}+I_{111}\right)$ in Theta/2 ThetaMessungen.

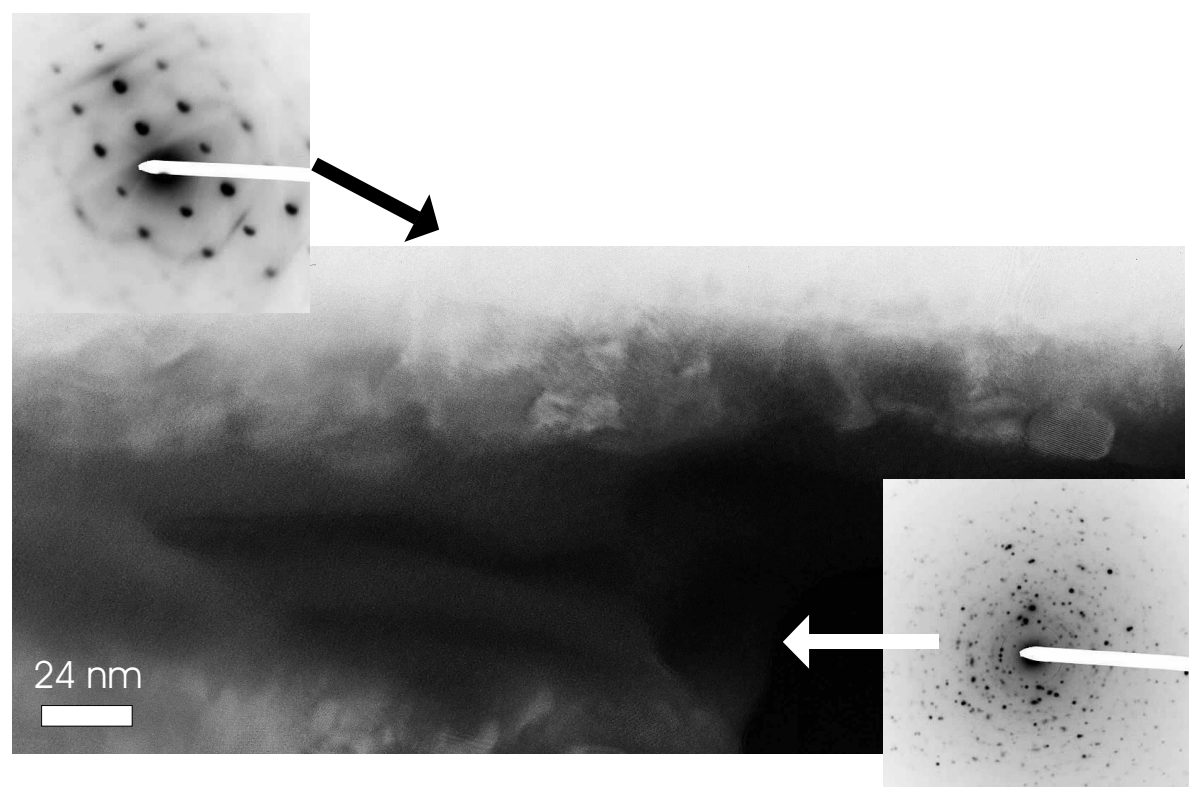

Abbildung 4.9: Transmissionselektronenmikroskopische Aufnahme einer bei $790^{\circ} \mathrm{C}$ ausgelagerten MOD-CGO-Schicht. Das einkristalline YSZ-(001)-Substrat ist im oberen Bildbereich zu finden; nach der epitaktischen MOD-CGO-Schicht (nicht vom Substrat zu trennen) folgt eine polykristalline CGO-Deckschicht auf der das YBCO amorph mit polykristallinen Anteilen aufwächst. 
Dieses Ergebniss deckt sich mit den Befunden aller dem Autor bekannten Veröffentlichungen zu diesem Schichtsystem. Offenbar ist die Texturausbildung der Oberfläche gestört. Deshalb wurden RHEED-Messungen durchgeführt, um die Schichtoberfläche zu charakterisieren.

\subsubsection{RHEED Untersuchungen}

Eine RHEED-Messung an einer unter optimalen Bedingungen hergestellten CGO Probe zeigt Abb. 4.10(a). Die Ringe im rechten Bildteil treten auch auf, wenn die Probe nicht von dem Elektronenstrahl des RHEED getroffen wird. Ansonsten wird keine Änderung des RHEED-Musters festgestellt, wenn der Elektronenstrahl von der Probe herunterbewegt und anschließend wieder zurückbewegt wird. Durch den Vergleich mit einer gesputterten CGO-Schicht, die für einkristalline Oberflächen typische Reflexe ${ }^{4}$ zeigt, läßt sich also schließen, daß die Oberfläche der MOD-CGO-Schicht nicht einkristallin ist. Entfernt man nun sukzessive durch Ionenstrahlsputtern Material von der Oberfläche der Probe, so werden nach ca. 10-15 nm (Abb. 4.10(b)) erste, der Schicht zuzuschreibende Reflexe sichtbar, die in einem rechteckigen Gitter angeordnet sind. Dieses Reflexmuster ist typisch für eine rauhe, einkristalline Oberfläche [130]. Auf einer so präparierten Oberfläche konnte
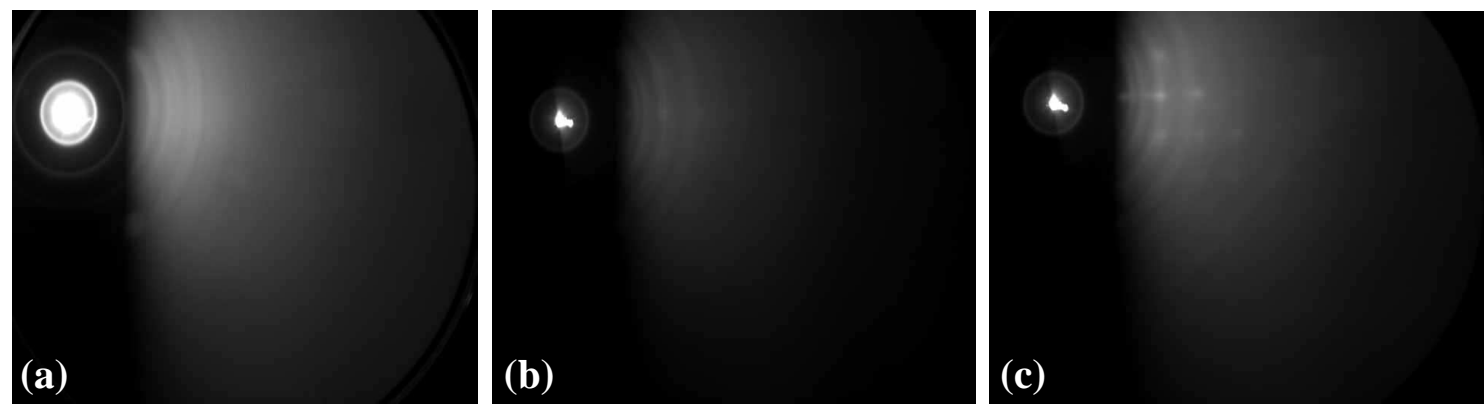

Abbildung 4.10: RHEED-Aufnahmen der Oberfläche einer röntgen-texturierten Schicht $\left(\mathrm{CeO}_{2}\right.$ auf einem YSZ-(001)-Einkristall, Auslagerung bei $\left.790^{\circ} \mathrm{C}\right)$ nach verschiedenen Bestrahlungszeiten mit $300 \mathrm{eV}$-Ar-Ionen: (a) Ausgangszustand, (b) nach 4:25 min, (c) 5:40 min (entspricht ca. $15 \mathrm{~nm}$ ).

mittels gepulster Laserdeposition ein biaxial texturierter YBCO-Film deponiert werden. Das epitaktische Wachstum der wie hergestellten CGO-Schichten erreicht also bei diesen Auslagerungsbedingungen nicht die Oberfläche der Probe. Dadurch verbleibt auf der Schichtoberfläche ein untexturierter Bereich, der als epitaxiefähiges Unterlage ungeeignet ist.

\footnotetext{
${ }^{4}$ Siehe Abschn. 3.3 für den Fall des ähnlichen YSZ.
} 


\subsubsection{Vervollständigung des Schichtwachstums}

Da sich die Ausbildung der texturierten Schicht bei den oben gewählten Auslagerungsbedingungen nicht bis an die Oberfläche fortsetzt, wurde untersucht, ob man durch einen zusätzlichen Auslagerungsschritt die Texturbildung vervollständigen kann. Die Proben wurden dazu an Luft $t^{5}$ mit einer Rampe von $5 \mathrm{~K} / \mathrm{min}$ auf die Endtemperatur erhitzt und für zwei Stunden gehalten. Abb. 4.11 zeigt RHEED-Aufnahmen für bei verschiedenen Temperaturen ausgelagerte Schichten. Bei $1090^{\circ} \mathrm{C}$ sind schwache in einem Gitter angeordnete Reflexe zu erkennen, die auf das Auftreten einer Vorzugsorientierung der Körner an der Oberfläche hindeuten. Bei $1200^{\circ} \mathrm{C}$ sind neben einem auf ein teilweise polykristallines Gefüge hindeutenden Reflexring auch erste streifenförmige Anzeichen einer einkristallinen Schicht zu sehen. Die Bildung dieser Streaks ist bei $1300^{\circ} \mathrm{C}$ abgeschlossen und ein polykristalliner Anteil ist im Rahmen der Meßgenauigkeit nicht zu beobachten. Damit einher geht eine Zunahme der Röntgenintensität des CGO-(200)-Reflexes relativ zum Substrat um eine Größenordnung. Die Qualität der Schichtoberfläche wurde wiederum durch die
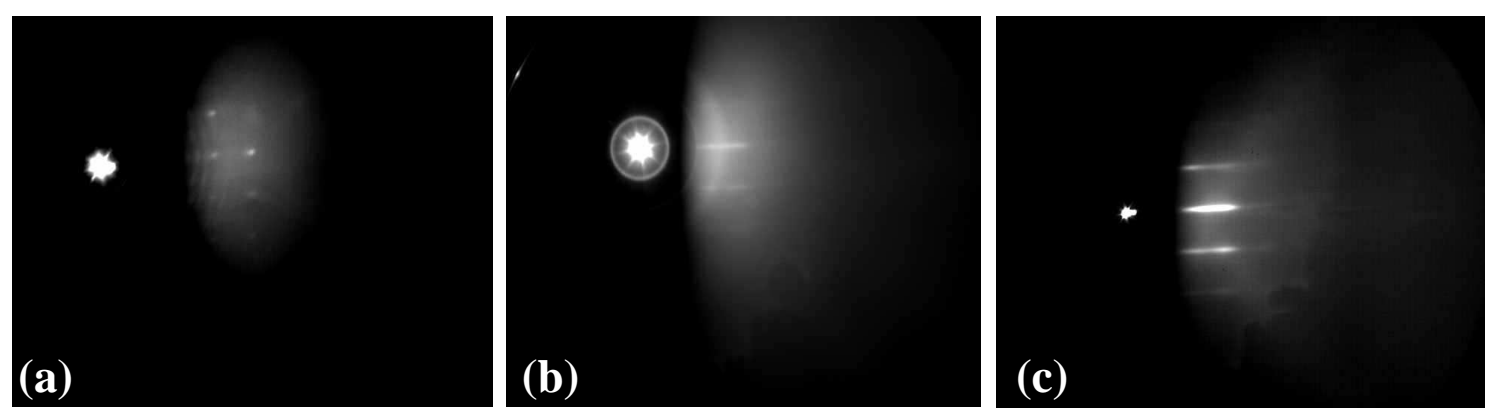

Abbildung 4.11: Ex-situ RHEED-Aufnahmen einer CGO-Schicht auf einem YSZ-(001)Einkristall nach einer Auslagerung mit Herstellungstemperaturen $T_{K r i s t 2}$ von (a) $1090^{\circ} \mathrm{C}$, (b) $1200^{\circ} \mathrm{C}$, (c) $1300^{\circ} \mathrm{C}$.

epitaktische Abscheidung einer Schicht des Hochtemperatursupraleiters YBCO geprüft. Eine magnetooptische Abbildung eines $400 \mathrm{~nm}$ dicken YBCO-Films auf der Probe aus Abb. 4.11 zeigt Abb. 6.5 in Abschnitt 6.3. Es werden Stromdichten von $1.1 \cdot 10^{11} \mathrm{~A} / \mathrm{m}^{2}$ bei $8 \mathrm{~K}$ erreicht, was vergleichbar mit kritischen Stromdichten von PLD-YBCO-Filmen auf physikalisch hergestellten CGO-Pufferschichten ist. Dies belegt die hohe Qualität der so gewonnenen Oberfläche bezüglich Kristallinität und Rauhigkeit.

\subsubsection{Einfluß der Atmosphäre}

In Abb. 4.12 sind Texturierungsgrade über der Auslagerungstemperatur für verschiedene Atmosphären aufgetragen. Enthält die Atmosphäre eine oxidierende oder eine reduzie-

\footnotetext{
${ }^{5}$ Die Auslagerung an Luft ist notwendig, da sich im Falle des Auslagerns in $\mathrm{Ar} / \mathrm{H}_{2} \mathrm{Ce}_{2} \mathrm{O}_{3}$ bildet 137 , 138, das in einer hexagonalen Struktur kristallisiert und somit nicht als Pufferschicht in Frage kommt.
} 
rende Komponente, so werden $(200) /(200)+(111)$-Verhältnisse größer 0,95 erreicht, wohingegen bei einer reinen Ar-Atmosphäre der erreichte Texturierungsgrad bei 0,83 liegt. Zur Erklärung dieser Beobachtung werden zwei Ansätze in Betracht gezogen:

- In den infrarotspektroskopischen Messungen sowohl an dem Ce-Ethylhexanoat als auch an dem Ce-Acetylacetonatsystem ließen sich Spuren von $\mathrm{Ce}_{2}\left(\mathrm{CO}_{3}\right)_{3}$ nachweisen. Enthält die Atmosphäre oxidierende oder reduzierende Gase, so können diese das Zersetzungsverhalten des Cerkarbonats beeinflussen. Darum erreichen die Texturierungsgrade der an Luft, in $\mathrm{H}_{2}$ und der in $\mathrm{Ar} / \mathrm{H}_{2}$ ausgelagerten Proben bei ähnlichen Temperaturen ihr Maximum im Bereich von 95\%. Die Zersetzung der organischen Reste in Ar erfolgt im Vergleich zu den anderen Atmosphären vermutlich bei höheren Temperaturen, so daß das Temperaturfenster für das epitaktische Wachstum des CGO zu höheren Temperaturen verschoben ist.

- Gasadsorption an Korngrenzen kann die Wachstumskinetik beeinflussen. So wird ein anormales Kornwachstum in nanokristallinem Palladium beobachtet [139], das auf eine Belegung der Korngrenzflächen mit Stickstoff zurückgeführt wird. Ein solcher Mechanismus kann ebenfalls die Abhängigkeit des Texturierungsgrades (d.h. das Verhältnis aus epitaktischem und polykristallinem Kornwachstum) erklären.

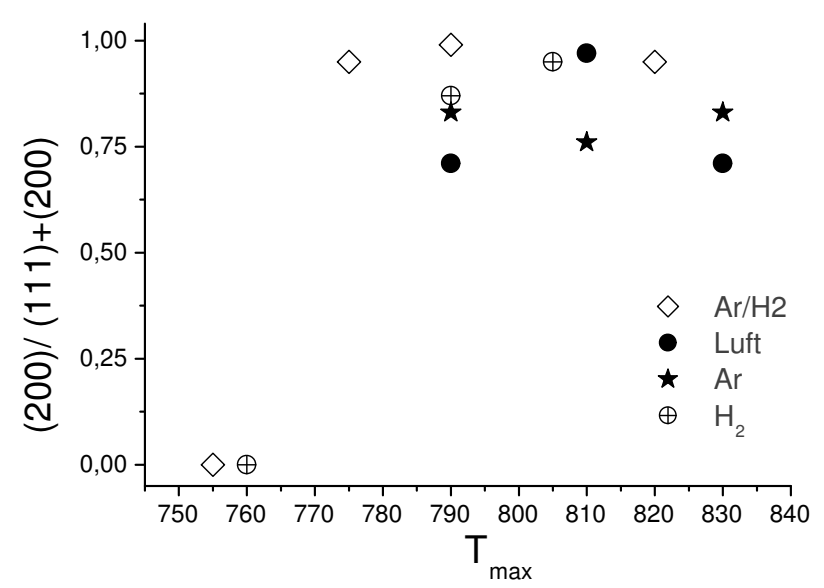

Abbildung 4.12: Abhängigkeit des Intensitätsverhältnisses $I_{200} /\left(I_{200}+I_{111}\right)$ von der Atmosphäre im Falle von CGO-Schichten auf YSZ-(001)-Einkristallen.

Da bei RHEED-Untersuchungen der Oberflächen keine polykristallinen Reflexe der CGOSchicht gefunden wurden und kein polykristallines Wachstum von YBCO auf diesen Proben beobachtet wurde, läßt sich vermuten, daß das mit IR-Spektroskopie nachgewiesene Cerkarbonat in einer Oberflächenschicht vorhanden ist, die sich erst bei höheren Temperaturen zu $\mathrm{CeO}_{2}$ zersetzt. 


\subsection{Schichtwachstum auf IBAD-YSZ Substraten}

Technische Substrate wie IBAD-YSZ weisen, anders als Einkristalle, eine Reihe von Oberflächenimperfektionen auf. Durch die Ionenstrahlunterstützung haben die Schichten eine charakteristische Morphologie mit rms-Rauhigkeiten von ca. $10 \mathrm{~nm}$ (Abschn. 2.3). Es treten einzelne Körner mit Korngrößen von ca. 100 nm auf, die durch Korngrenzen voneinander getrennt sind und deren Orientierung eine Vorzugsrichtung aufweist. Der Einfluß dieser Oberflächendefekte sowie der Substrattextur auf die Wachstumsbedingungen der MOD-CGO-Schicht wird in diesem Abschnitt untersucht. Der hauptsächlich betrachtete Parameter ist dabei die Änderung der optimalen, durch Röntgenmessungen bestimmten Auslagerungstemperatur und deren Änderung auf Substraten verschiedener Rauhigkeit und Textur.

\subsubsection{Einfluß der Rauhigkeit auf Kinetik und Auslagerungstem- peratur}

Zunächst wurde angestrebt, den Beitrag der Rauhigkeit unabhängig von der Textur des Substrates zu untersuchen. Als Modellsystem wurden mittels Ionenbeschuss künstlich aufgerauhte YSZ-(001)-Einkristalle ${ }^{6}$ mit MOD-CGO beschichtet und die Entwicklung des Verhältnisses $(200) /(111)+(200)$ mit variierender Auslagerungstemperatur verfolgt.

Untersucht wurden Schichten auf Substraten mit drei unterschiedlichen Rauhigkeiten:

- Wie vom Hersteller erhaltene YSZ-Einkristalle mit RMS-Rauhigkeiten von $0.09 \mathrm{~nm}$ (Herstellerangabe).

- Durch Beschuss mit 300 eV-Ar ${ }^{+}$-Ionen (25 mA, 45 min) aufgerauhte YSZ-Einkristalle mit einer rms-Rauhigkeit von $0.246 \mathrm{~nm}$ (Abb. 4.14(a)).

- Durch Beschuss mit $25 \mathrm{keV} \mathrm{Ar}{ }^{+}$-Ionen $(20 \mathrm{~mA}, 1.5 \mathrm{~h})$ hergestellte YSZ-Einkristalle mit einer rms-Rauhigkeit von $1.479 \mathrm{~nm}$ (Abb. 4.14(b)).

Eine anschließende Optimierung der Auslagerungsparameter auf den Substraten mit verschiedener Rauhigkeit hinsichtlich eines maximalen (200)-Anteils zeigte das in Abb. 4.15 dargestellte Verhalten: Mit zunehmender Rauhigkeit verschiebt sich die optimale Herstellungstemperatur im Vergleich zum atomar glatten Einkristall zu höheren Temperaturen. Erreicht die Rauhigkeit nach der Bestrahlung einen Wert von $1.5 \mathrm{~nm}$, so liegt die benötigte Auslagerungstemperatur im Bereich $870^{\circ} \mathrm{C}$. Die Rauhigkeit des Substrates hat also einen

\footnotetext{
${ }^{6}$ Dazu wurden atomar glatte YSZ-(001)-Einkristalle mit Ar ${ }^{+}$-Ionen mit Energien von 300 eV bzw.

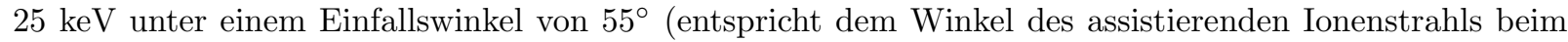
IBAD-YSZ) bestrahlt. Die Bestrahlung bei 300 eV erfolgte mit einer Sputterquelle, die bei $25 \mathrm{keV}\left(\mathrm{Ar}^{+}\right.$Strahlstromstärke $15 \mu \mathrm{A}$, Strahldurchmesser $15 \mathrm{~mm}$, Bestrahlungszeit 90 Minuten) am ADONIS (Anlage zur Deposition niederenergetischer Ionen auf Substrate) des II. Physikalischen Institutes der Universität Göttingen. Dabei entstehen Oberflächen mit rms-Rauhigkeiten von 0.25-2 nm (Abb. 4.13). Eine durch den Ionenstrahl induzierte Vorzugsrichtung ist nicht zu beobachten.
} 


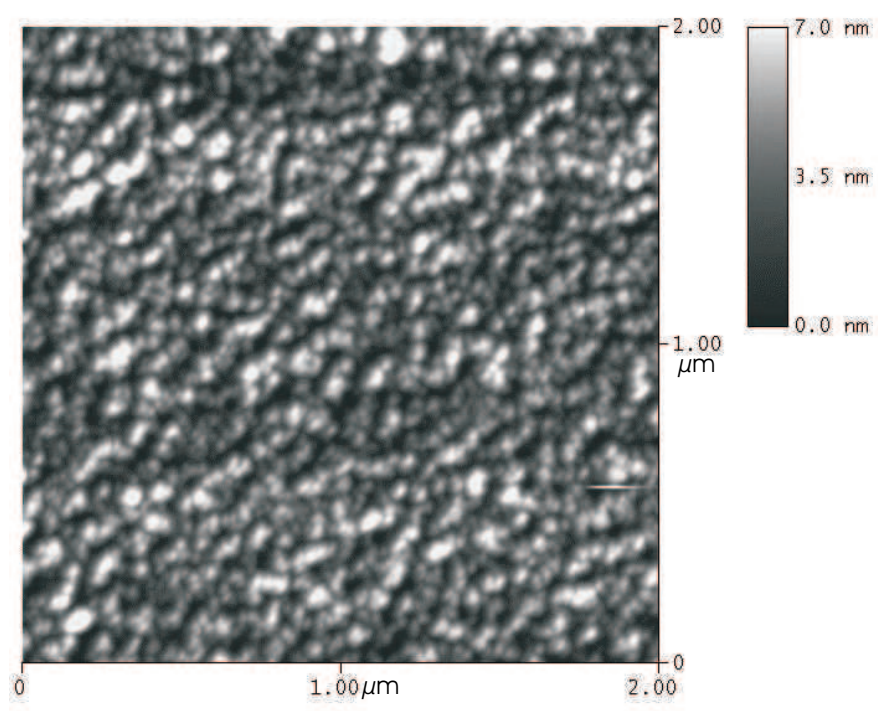

Abbildung 4.13: AFM-Aufnahme von einem künstlich aufgerauhten YSZ-(001)-Einkristall

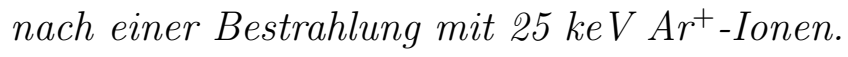

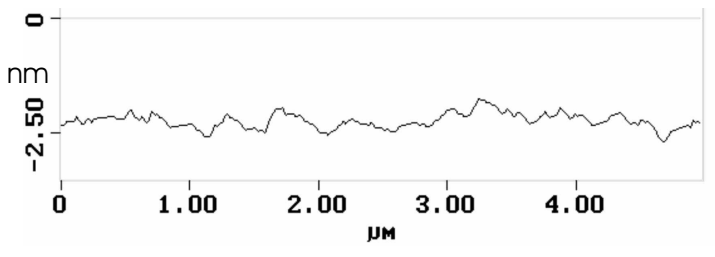

(a)

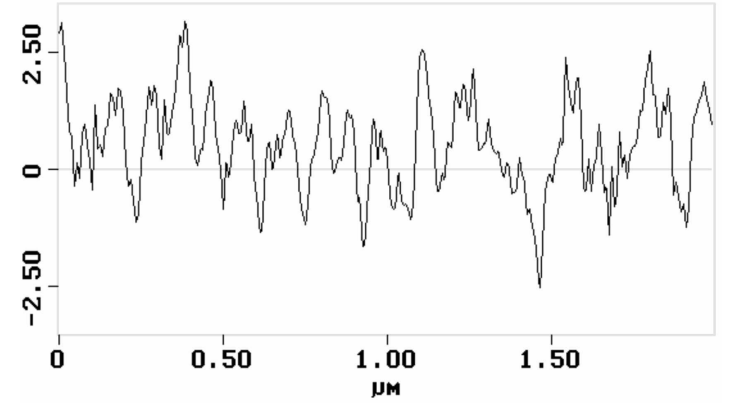

Abbildung 4.14: Höhenprofile der aufgerauhten YSZ-(001)-Einkristalle: (a) $300 \mathrm{eV}$, (b) $25 \mathrm{keV}$. Der y-Achsen-Maßstab ist in beiden Bildern gleich. Eine AFM-Oberflächenabbildung zu (b) findet sich in Abb. 4.13 . 


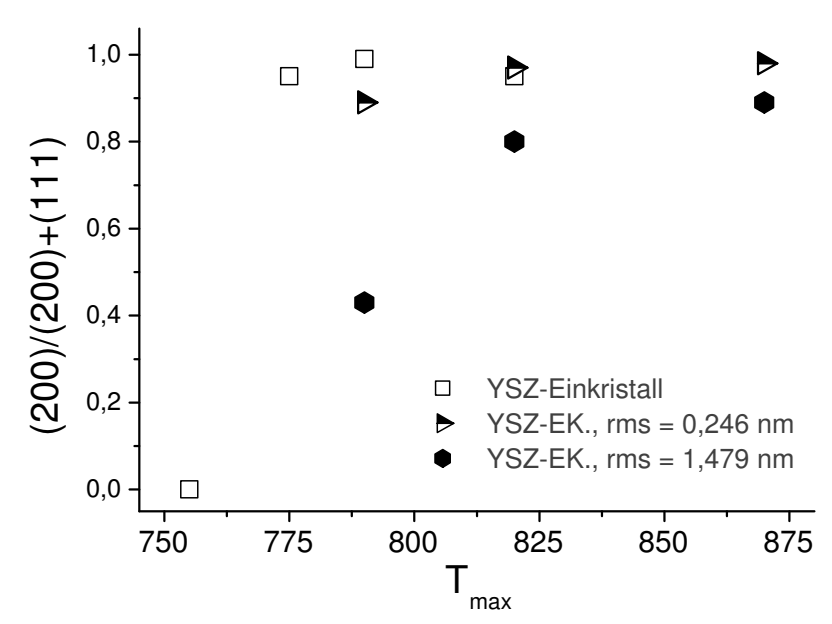

Abbildung 4.15: Temperaturabhängigkeit des Intensitätsverhältnisses $I_{200} /\left(I_{200}+I_{111}\right)$ von CGO-Schichten für verschiedene Rauhigkeiten des YSZ-(001)-Substrates.

maßgeblichen Einfluß auf die Auslagerungstemperatur und erhöht die benötigten Temperaturen gegenüber dem glatten YSZ-Einkristall um ca. $100^{\circ} \mathrm{C}$.

\subsubsection{Einfluß der Textur auf die Auslagerungstemperatur}

Zur Untersuchung des Einflusses der Textur des IBAD-YSZ auf die Wachstumsbedingungen des MOD-CGO wurden IBAD-YSZ-Substrate mit Qualitäten zwischen $9.8^{\circ}$ und $30^{\circ}$ inplane Halbwertsbreite untersucht. Die typische rms-Rauhigkeit dieser Substrate liegt bei ca. $10 \mathrm{~nm}$, die Korngröße um die $100 \mathrm{~nm}$.

Das Ergebnis dieser Optimierungen zeigt Abb. 4.16. Die optimalen Wachstumsbedingungen sind für alle drei Substratserien um ca. $100^{\circ} \mathrm{C}$ zu höheren Temperaturen verschoben 7 was nach den Ergebnissen des vorherigen Abschnittes durch die erhöhte Rauhigkeit erklärt wird. Die Textur ist somit bei den hier verwendeten IBAD-YSZ-Proben und den gewählten Auslagerungsparametern nicht der vorrangig wachstumsbestimmende Faktor. Dies kann ein Effekt des Korngrößenverhältnisses der YSZ-Körner und der CGO-Keime sein. Erreichen beide die gleiche Größenordnung, können zusätzliche Einflüsse das Wachstum bestimmen (siehe Kapitel 7).

\footnotetext{
${ }^{7} \mathrm{Im}$ Falle der $9.8^{\circ}$ und der $30^{\circ}$-Substrate ermöglichten Substratreflexe im Bereich der Schichtreflexe nur relative Angaben des Intensitätsverhältnisses.
} 


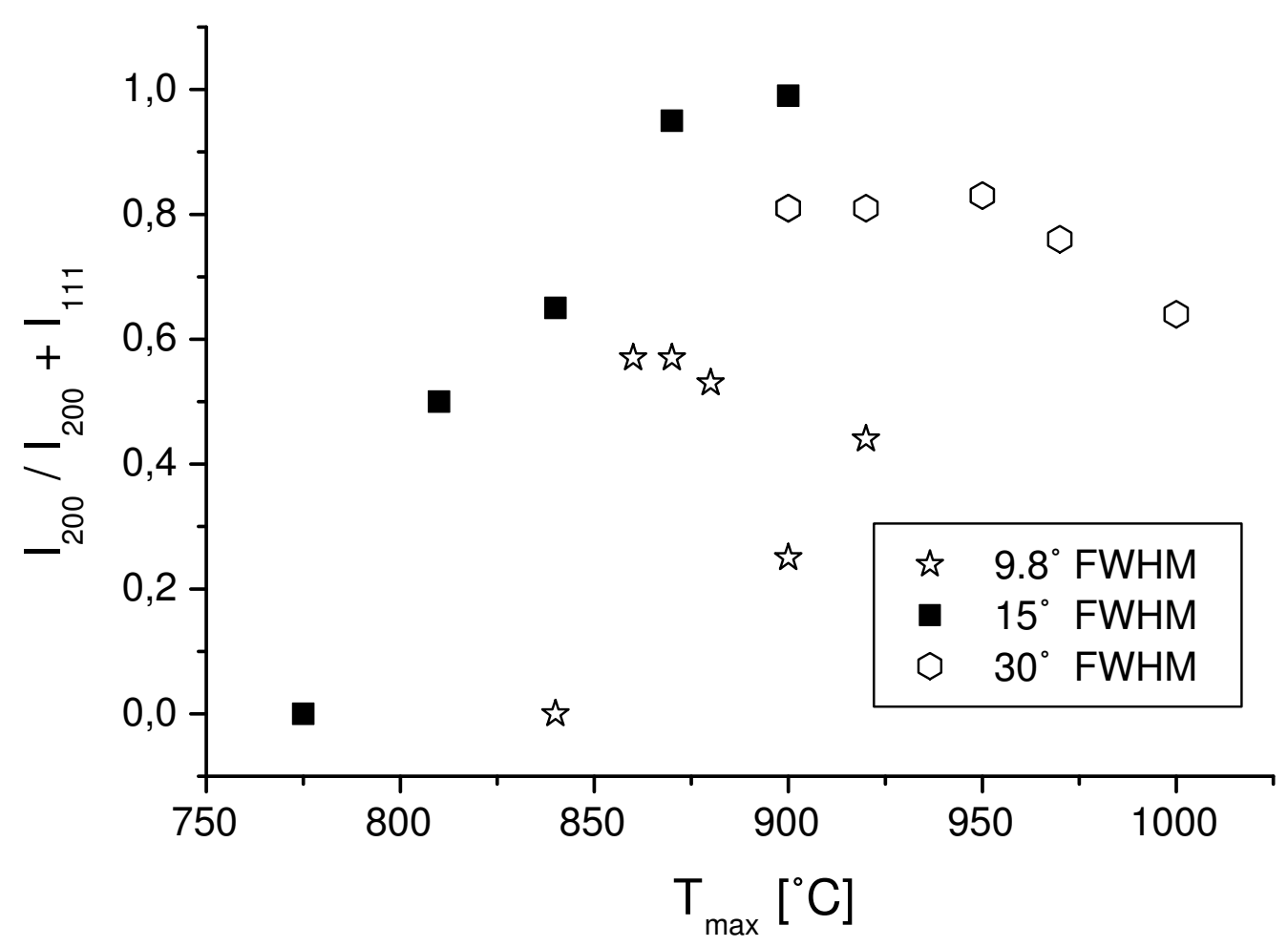

Abbildung 4.16: Textur einer CGO-Schicht in Abhängigkeit von der in-plane Halbwertsbreite des IBAD-YSZ Substrates; die optimalen Auslagerungstemperaturen liegen im Bereich $870-900^{\circ} \mathrm{C}$.

\subsubsection{Interdiffusion Schicht-Substrat}

Bei den hohen Auslagerungstemperaturen wird auch auf IBAD-YSZ-Substraten eine Interdiffusion von Substrat und Schicht beobachtet. Eine SIMS-Messung an einer bei $870^{\circ} \mathrm{C}$ ausgelagerten MOD-CGO-Schicht auf IBAD-YSZ auf Stahl zeigt Abbildung 4.17. Hier wird eine Interdiffusionszone von der Breite der halben $\mathrm{CeO}_{2}$-Schicht beobachtet. Gleichzeitig werden Spuren von Yb, La und Hf in der Schicht detektiert, die auf Verunreinigungen im Precursor zurückzuführen sind. Metallatome aus dem Substrat konnten in der Schicht nicht nachgewiesen werden. 


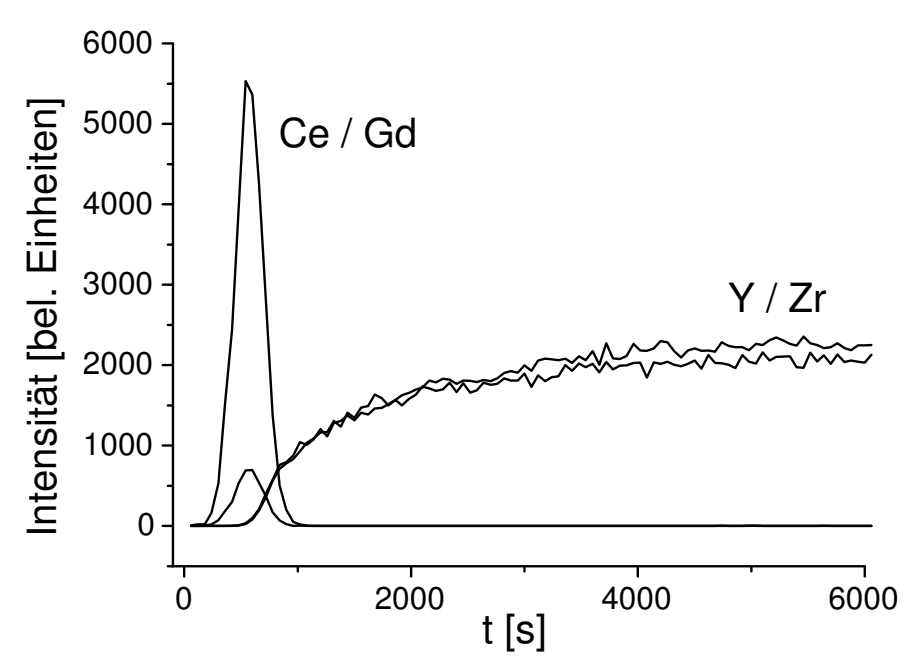

Abbildung 4.17: SIMS an einer CGO-Schicht auf einem IBAD-YSZ Substrat. Deutlich sichtbar ist der Bereich der Interdiffusion an der Grenzflüche zwischen Schicht und Substrat.

\subsubsection{In-situ Synchrotron Experimente zur Nukleation auf IBAD- YSZ-Substraten}

Zur Untersuchung des Anfangsstadiums und des zeitlichen Verlaufs der Texturbildung sind röntgenographische Standardverfahren nicht geeignet, da kleine kristalline Volumenanteile nicht nachgewiesen werden können. Deshalb wurden auch in-situ Synchrotronmessungen durchgeführt (Abschnitt 3.9). Dieses Verfahren ermöglicht die zeit- und temperaturaufgelöste Beobachtung der Bildung von Pufferschichttexturen.

Auf ein IBAD-YSZ Substrat (15 YSZ-FWHM) wurde unter Verwendung der 2-Ethylhexanoate in Toluol eine Precursorschicht deponiert, die einer $\mathrm{CeO}_{2}$-Schichtdicke von ca. $80 \mathrm{~nm}$ nach der Auslagerung entspricht. Abbildung 4.18 zeigt die Entwicklung des Volumenanteils der (200)- und (111)-Körner während eines Auslagerungsprofils. Die $\mathrm{CeO}_{2}$-Reflexe treten ab einer Temperatur von ca. $500^{\circ} \mathrm{C}$ auf, was der mit Thermogravimetrie bestimmten Zersetzungstemperatur des Precursors entspricht (Abb. 4.3(b)). Bis zum Ende der Haltestufe mit der Maximaltemperatur steigt der Anteil der (200)-Körner leicht an und stagniert dann bei ca. 80\%. Beim Abkühlen tritt dann verstärktes Wachstum des (111)-Anteils auf. Bei den Synchrotronmessungen war es auch möglich, die Textur des $\mathrm{CeO}_{2}$ eindeutig vom Substrat getrennt zu messen, was sich in Abbildung 4.19 ablesen läßt. Die Textur des IBAD-YSZ wird hier zu $13^{\circ}$ bestimmt, die des $\mathrm{CeO}_{2}$ zu $14^{\circ}$ FWHM. \&

\footnotetext{
${ }^{8}$ Die Abweichung der Halbwertsbreite des $\mathrm{CeO}_{2}$-Reflexes von dem nach Abschn. 3.2 erwarteten Wert ist in der Meßungenauigkeit der schwachen $\mathrm{CeO}_{2}$-Reflexe zu suchen.
} 


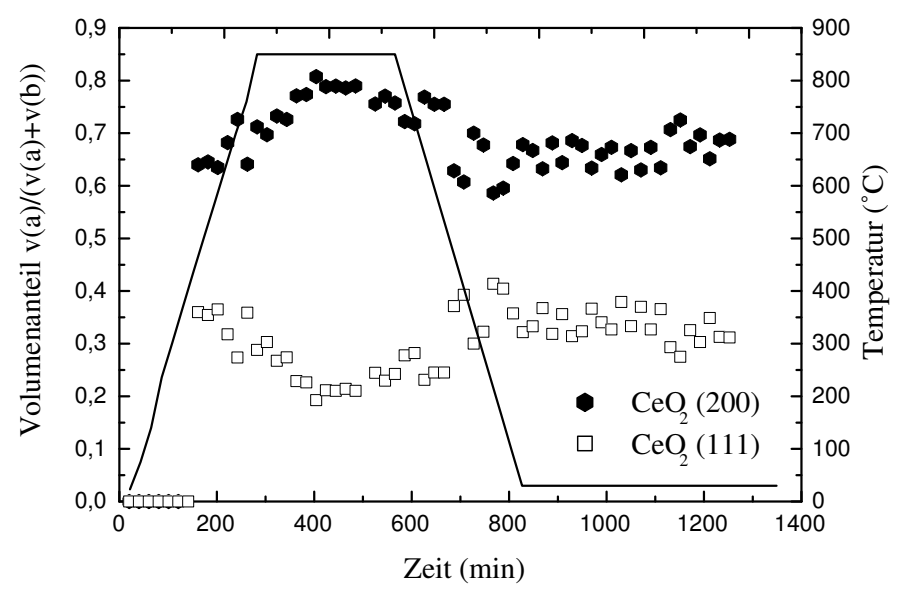

Abbildung 4.18: Entwicklung des Volumenanteils der (111) und der (200) Körner einer $\mathrm{CeO}_{2}$-Schicht auf IBAD-YSZ mit der Temperatur.

Auf Substraten aus IBAD-YSZ ließen sich aufgrund der benötigten hohen Auslagerungstemperaturen für ein epitaktisches Schichtwachstum bis zur Probenoberfläche $\left(1200^{\circ} \mathrm{C}\right.$ $1300^{\circ} \mathrm{C}$ ) Ablösungserscheinungen der IBAD-YSZ Schicht vom Substrat beobachten. Auf metallischen Substraten bewirkt die Oxidation des Metalls in der erforderlichen sauerstoffhaltigen Atmosphäre eine starke Deformation des Substrates. Ein Wachstum einer MODCGO-Schicht auf IBAD-YSZ wie oben für den Fall des Einkristalls beschrieben konnte daher nicht erreicht werden. 


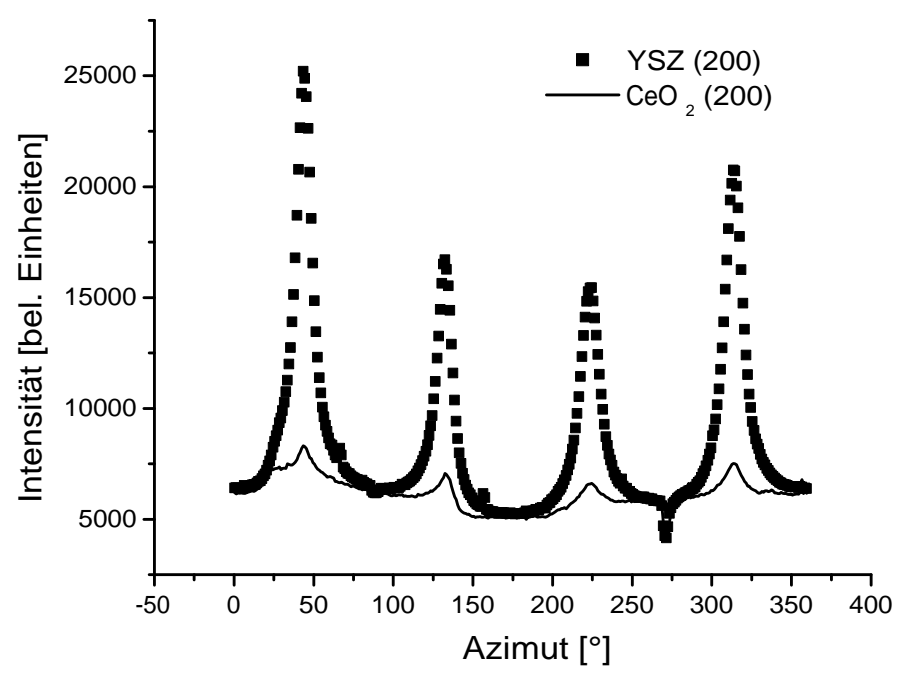

Abbildung 4.19: In-plane-Textur für $\mathrm{CeO}_{2}$ (200) und YSZ (200). Die Profile sind entlang des zu dem jeweiligen Reflex gehörigen konzentrischen Kreises in Abb. 3.6 entnommen. Das Auftreten der vier Maxima für das $\mathrm{CeO}_{2}$ (200) belegt das epitaktische Anwachsen der Schicht am Substrat. 


\section{Kapitel 5}

\section{MOD-YSZ}

Das zweite im Rahmen dieser Arbeit untersuchte MOD-Puffersystem ist das YttriumStabilisierte Zirkonoxid (YSZ). Die Schichten wurden auch hier auf YSZ-(001)-Einkristallen und IBAD-YSZ-Schichten abgeschieden. In diesem Kapitel geht es hauptsächlich um das Wachstumsverhalten von YSZ-Multischichten auf einem IBAD-YSZ-Substrat und die Texturentwicklung mit wachsender MOD-YSZ-Schichtdicke. Als Vorstufe dazu wurde die Schichtherstellung auf YSZ-(001)-Einkristallen untersucht.

\subsection{Das Precursorsystem}

Zur Herstellung der Schichten aus YSZ(10 mol\% $\left.\mathrm{Y}_{2} \mathrm{O}_{3}\right)$ kamen Yttrium (Abb. 5.1) und Zirkoniumacetylacetonate gelöst in einer 2:1-Mischung aus wasserfreier Essigsäure und isoPropanol (0.25 M) zum Einsatz.

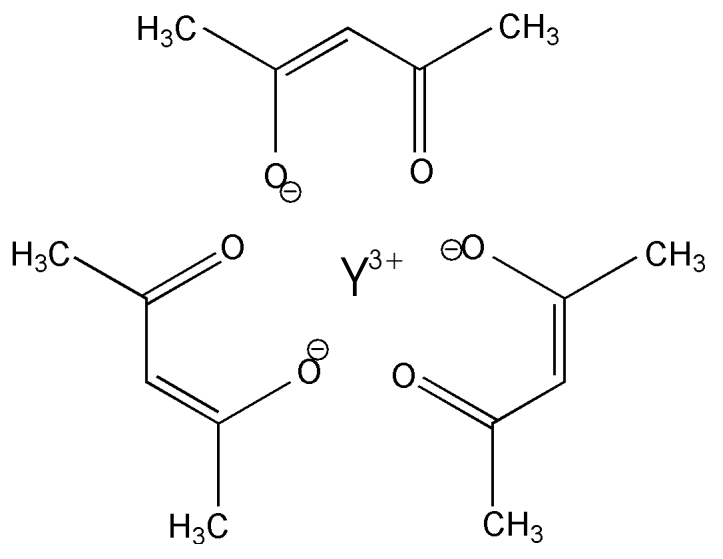

Abbildung 5.1: Y-Acetylacetonat 
Zur Untersuchung des Lösungsverhaltens und der damit verbundenen Frage nach der Verwendbarkeitsdauer des Precursors bis zum Auftreten von Prezipitaten wurde eine einmolare Lösung des Y-Acetylacetonates in Essigsäure hergestellt. Nach ca. 15 Minuten wurde mit NMR eine 3-4 Stunden andauernde Reaktion beobachtet, deren Endprodukt nach mehreren Wochen 1-2 mm große durchsichtige Kristalle bildete. Diese Kristalle wurden mittels Einkristallröntgenstrukturanalyse untersucht. Das Ergebnis findet sich in Abb. 5.2, Das

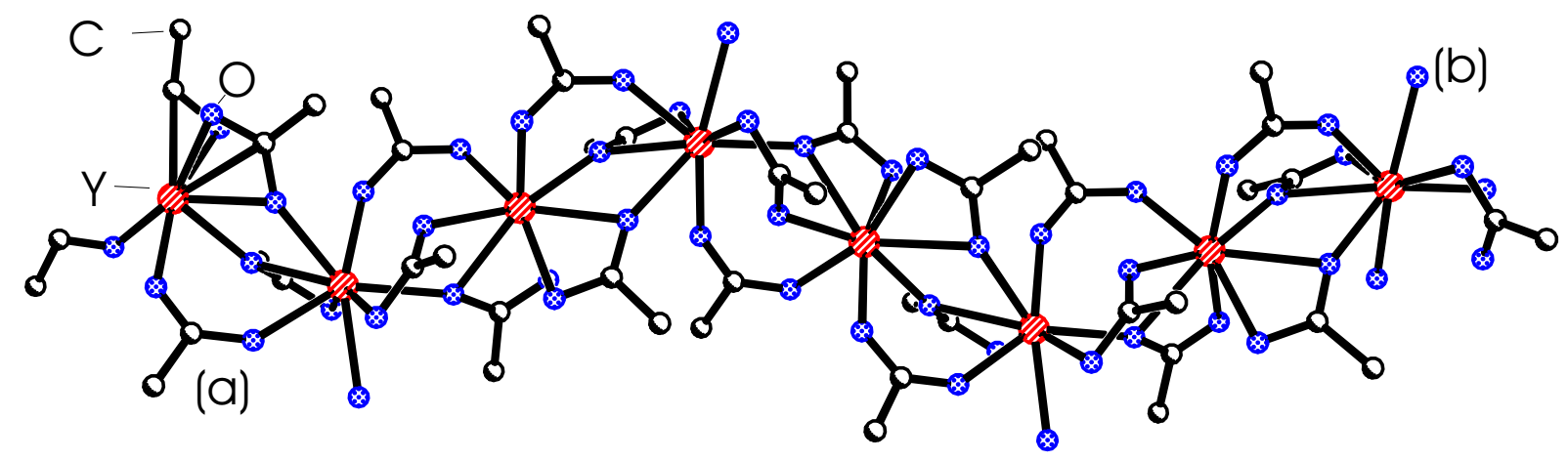

Abbildung 5.2: Kristallstruktur des Produktes des Lösungsvorganges von Y-Acetylacetonat (Y-acac) in Essigsäure; Yttrium: gestrichelt; Sauerstoff gepunktet; Kohlenstoff: offene Kreise; Wasserstoffatome sind nicht dargestellt.

Acetylacetonat wurde durch das Acetatanion der Essigsäure und durch in der Lösung enthaltende Wasser aus der Koordinationssphäre des Yttriums herausgedrängt. So entsteht eine Struktur, bei der die Yttriumionen durch Acetatbrücken miteinander verbunden sind ((a) in Abb. 5.2). Darüberhinaus sind auch freistehende O-H-Gruppen ((b) in Abb. 5.2) direkt an das Yttrium gebunden, die Bindungen zu weiteren Struktureinheiten eingehen können. Dies zeigt, daß das oben verwendete Precursorsystem metastabil ist. Im Gegensatz zu dem CGO-Acetylacetonatsystem sind die Umwandlungszeiten mit Tagen bis Wochen hier aber deutlich länger, was das Arbeiten mit diesem System vereinfacht.

Das thermische Zersetzungsverhalten wurde mittels Thermogravimetrie untersucht (Abb. 5.3). Dazu wurden Lösungen von Y/Zr-acac in Essigsäure bei $120^{\circ} \mathrm{C}$ vorgetrocknet und das entstehende gelartige Pulver für die Versuche verwendet. Bei dem YSZ-acac System sieht man im Temperaturbereich bis ca. $300^{\circ} \mathrm{C}$ eine rasche Gewichtsabnahme, die anfänglich auf die Verdunstung der im Pulver verbliebenen Essigsäure (bis ca. $118^{\circ} \mathrm{C}$ ) zurückzuführen ist bis dann die Zersetzung des Precursormoleküls erfolgt, die bei ca. $400^{\circ} \mathrm{C}$ abgeschlossen ist.

Die Precursor-YSZ-Schichten wurden mit einem Spincoater (5000 U/min für 2 min) auf die Substrate (YSZ-Einkristalle, verschiedene IBAD-YSZ-Substrate) aufgebracht. Die deponierten Schichten wurden anschließend in einer Argon/Wasserstoff(5\%)-Atmosphäre ausgelagert. Dazu wurde mit einer Rampe von $5 \mathrm{~K} / \mathrm{min}$ auf die Endtemperatur $\mathrm{T}_{\text {max }}$ geheizt und diese Temperatur für 1-4 Stunden gehalten; das Herunterkühlen fand bei ausgeschaltetem Ofen statt. Die so hergestellten Schichten sind ca. $50 \mathrm{~nm}$ dick, glatt und kontinuierlich, wie Abb. 5.4 zeigt. 


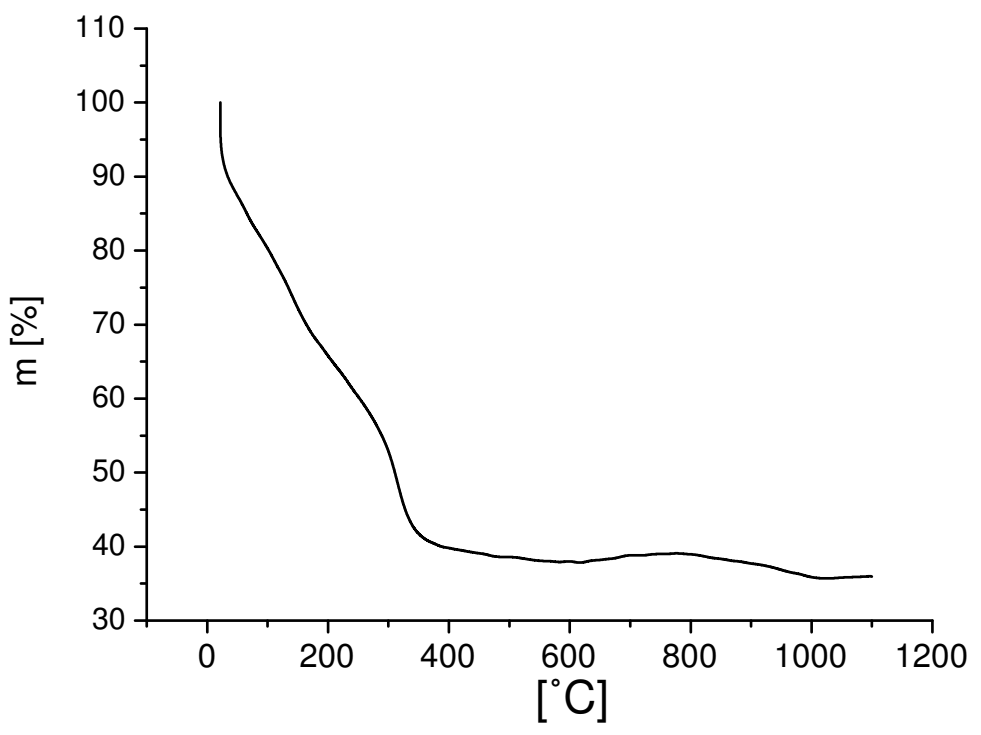

Abbildung 5.3: Gewichtsänderung bei steigender Temperatur für das YSZ-AcetylacetonatSystem, gemessen an bei $120^{\circ} \mathrm{C}$ vorgetrocknetem Precursormaterial.
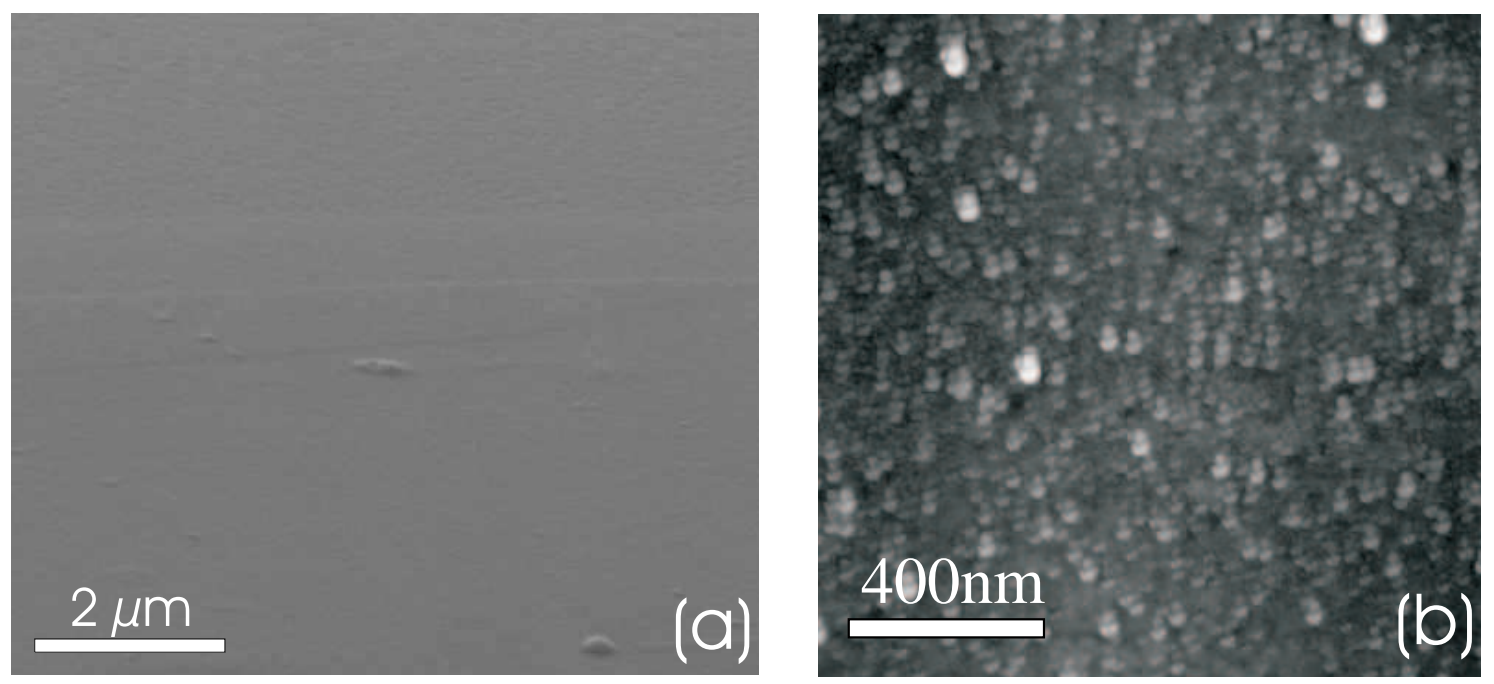

Abbildung 5.4: Rasterelektronenmikroskopische (a) und Rasterkraftmikroskopische (b) Aufnahme einer bei $1100^{\circ} \mathrm{C}$ ausgelagerten YSZ-Schicht auf einem YSZ-(001)-Einkristall; die rms-Rauhigkeit liegt unter $2.4 \mathrm{~nm}$. In (b) bewirkt die Spitzengeometrie das Auftreten von Doppelpeakstrukturen und damit eine Überschätzung der Rauhigkeit. 


\subsection{YSZ-Schichten auf YSZ-(001) Einkristallen}

Zur Bestimmung der optimalen Auslagerungsparameter wurden YSZ-Schichten auf YSZEinkristallen deponiert und diese mit einer Heizrate von $5 \mathrm{~K} / \mathrm{min}$ auf verschiedene Temperaturen $\mathrm{T}_{\max }$ im Bereich von $730-1100^{\circ} \mathrm{C}$ aufgeheizt und zwei Stunden ausgelagert. Die Schichten wurden anschließend ex-situ mittels RHEED untersucht (Abb. 5.5). Die bei $730^{\circ} \mathrm{C}$ wärmebehandelte Probe zeigt einen halbringförmigen Reflex (Abb. 5.5a), der auf eine polykristalline Oberfläche schließen läßt. Erhöht man $\mathrm{T}_{\max }$ auf $950^{\circ} \mathrm{C}$ (Abb. 5.5b), so tauchen streifenartige Strukturen auf, die auf eine einkristalline mit einzelnen Defekten belegte Oberfläche hindeuten und die sich bei Rotation des Substrates analog zum Einkristall ändern. Bei $\mathrm{T}_{\max }=1100^{\circ} \mathrm{C}$ (Abb. 5.5 $)$ werden dann auch Kikuchilinien sichtbar, die für eine sehr glatte, einkristalline Oberfläche sprechen.
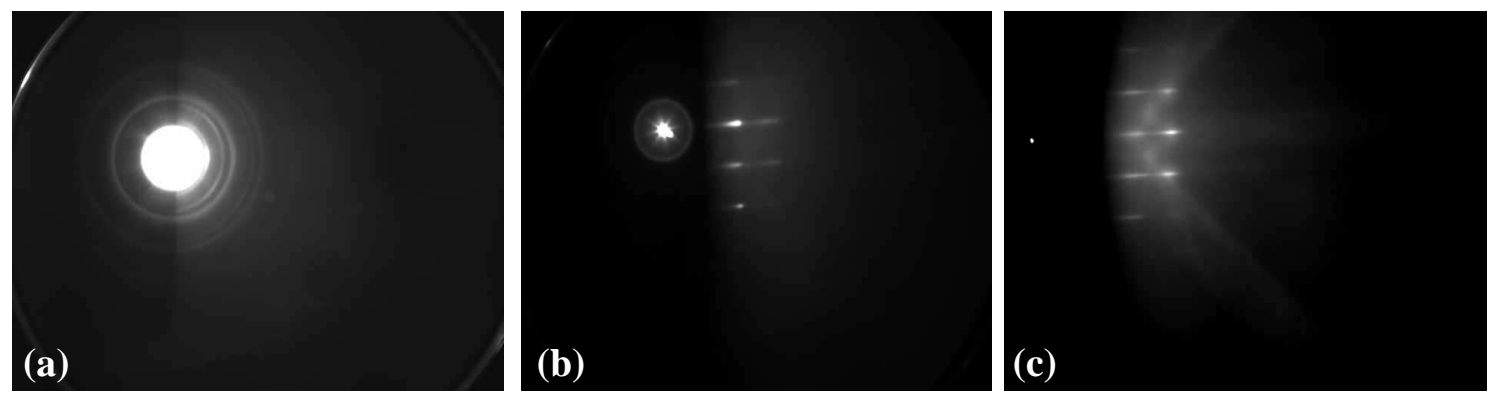

Abbildung 5.5: RHEED-Aufnahmen einer $50 \mathrm{~nm}$ dicken YSZ-Schicht auf einem YSZ(001)-Einkristall für verschiedene Auslagerungstemperaturen: (a) $730^{\circ} \mathrm{C}$, (b) $950^{\circ} \mathrm{C}$, (c) $1100^{\circ} \mathrm{C}$.

Die sehr gute Oberflächenqualität, die so erreicht wird, zeigt sich auch in der Qualität von darauf abgeschiedenen YBCO-Filmen: Auf der bei $1100^{\circ} \mathrm{C}$ ausgelagerten Probe wurde mit gepulster Laserdeposition ein $400 \mathrm{~nm}$ dicker YBCO-Film abgeschieden, der biaxial texturiert ist $\left(2^{\circ}\right.$-FWHM in $\Phi$-Scans) und Stromdichten von $2 \cdot 10^{11} \mathrm{~A} / \mathrm{m}^{2}(8 \mathrm{~K})$ aufweist (Abb. 6.1 in Abschnitt 6.1 zeigt eine magnetooptische Aufnahme).

\subsection{YSZ-Schichten auf IBAD-YSZ Substraten}

Neben den einkristallinen Substraten wurden auch IBAD-YSZ Proben mit MOD-YSZ beschichtet. Die Einzelschichtdicke betrug auch hier ca. $50 \mathrm{~nm}$.

Da bei den IBAD-YSZ-Substraten die rms-Rauhigkeit bei ca. $10 \mathrm{~nm}$ liegt und somit der Topographiekontrast im RHEED überwiegt, wurde die Analyse der Oberflächentextur mit einer aufgesputterten, epitaktisch aufgewachsenen $200 \mathrm{~nm}$ dicken CGO-Schicht durchgeführt (Abschnitt 4.5.2). Die Textur der CGO-Indikatorschicht wurde mit Röntgentexturanalyse ( $\Phi$-Scans) untersucht. 
Als optimaler Temperaturbereich für die Herstellung erwies sich eine Temperatur von 1000$1100^{\circ} \mathrm{C}$ mit Haltezeiten von zwei Stunden. Die Rampe wurde zu ein, bzw. $5 \mathrm{~K} / \mathrm{min}$ gewählt. Auf den mittels MOD hergestellten YSZ-Schichten wurden durch gepulste Laserdeposition YBCO-Filme abgeschieden. Abbildung 6.3 zeigt eine magnetooptische Aufnahme einer $400 \mathrm{~nm}$ dicken PLD-YBCO-Schicht bei $8 \mathrm{~K}$ und einem äußeren Feld von $79.2 \mathrm{mT}$. Es werden Stromdichten von $1.2 \cdot 10^{11} \mathrm{~A} / \mathrm{m}^{2}$ erzielt.

Bei Auslagerungstemperaturen unterhalb $950^{\circ} \mathrm{C}$ beobachtet man keine Textur der direkt auf die MOD-YSZ Puffer deponierten YBCO-Filme. Entfernt man hingegen die obersten $10 \mathrm{~nm}$ der MOD-YSZ-Schicht durch Ionenstrahlsputtern, so kann auf einer solchen Schicht biaxial texturiertes YBCO deponiert werden. Abbildung 5.6 zeigt eine magnetooptische Aufnahme der Flußdichteverteilung einer YBCO-Schicht auf einer bei $780^{\circ} \mathrm{C}$ hergestellten MOD-YSZ-Probe mit aufgesputterter CGO-Zwischenschicht. In der magnetooptischen
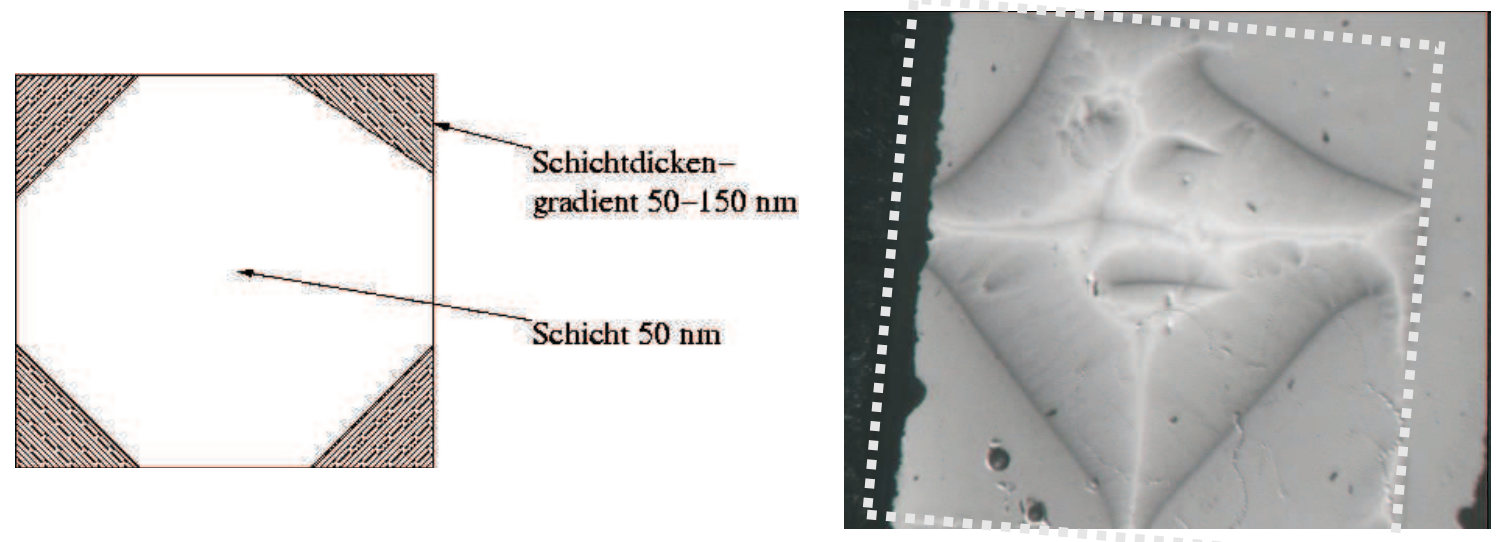

Abbildung 5.6: Magnetooptische Aufnahme eines 400 nm dicken YBCO-Filmes auf CGO (gesputtert) / MOD-YSZ (bei $780^{\circ} \mathrm{C}$ hergestellt) / IBAD-YSZ / PSZ, und Schemaskizze zu den Dickenverhältnissen nach der MOD Deposition; der eingerahmte Bereich in der MO-Messung entspricht dem Substrat.

Aufnahme sieht man einen im Zentrum der Probe epitaktisch angewachsenen YBCO-Film. Im Bereich der Probenecken ist kein MO-Kontrast zu erkennen; dort lag offensichtlich keine texturierte Probenoberfläche vor auf der das YBCO epitaktisch aufwachsen konnte. Ebenfalls in Abbildung 5.6 sieht man eine Skizze der Dickenverteilung der Schicht. An den Probenecken ist die Schicht deutlich dicker (100-150 nm). Die Bereiche grösserer Probendicke entsprechen somit den Gegenden ohne epitaktisch angewachsenes YBCO. Daraus läßt sich eine Skizze der räumlichen Verteilung der auskristallisierten Schicht entwickeln (siehe Abb. 5.7). Die Oberseite der wie ausgelagerten MOD-YSZ Probe ist polykristallin und in einer Tiefe von ca. $10 \mathrm{~nm}$ beginnt im Probenzentrum die epitaktisch am Substrat angewachsene Schicht. An den Probenecken ist die Schicht deutlich dicker, was dazu führt, daß durch das Ionenätzen die epitaktische Schicht nicht erreicht wird. Dadurch kann hier kein 


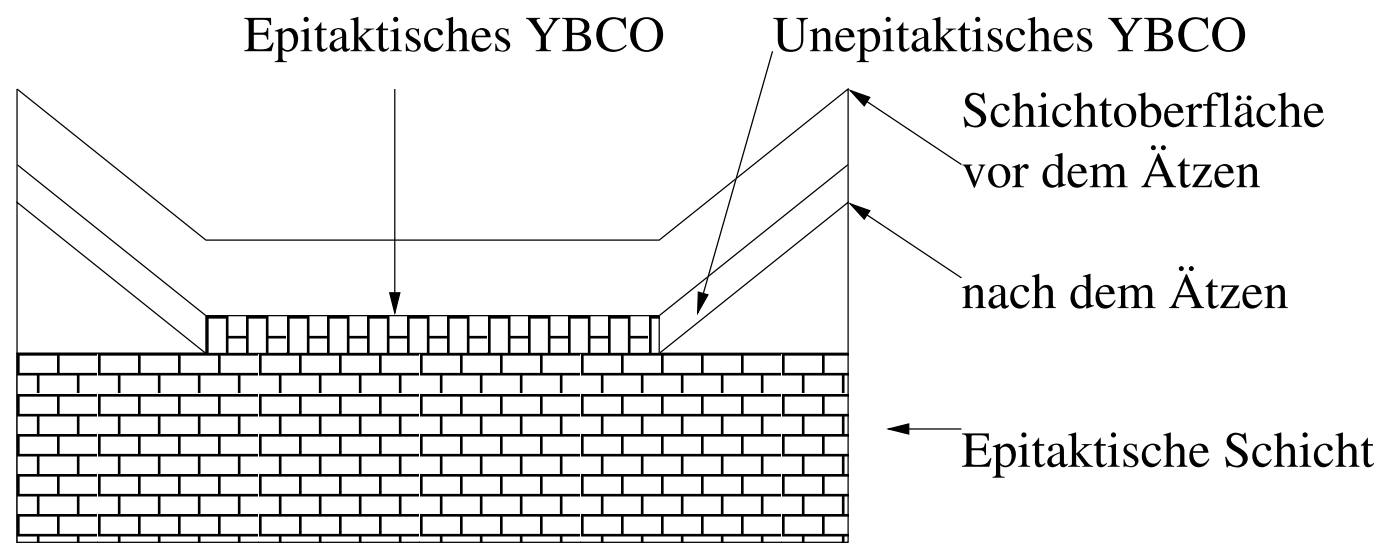

Abbildung 5.7: Probenoberfläche des MOD-Puffers vor und nach dem Ionenätzen und markierter Bereich des epitaktisch aufwachsenden YBCOs.

texturiertes YBCO aufwachsen. Da die bei Endtemperaturen von $1100^{\circ} \mathrm{C}$ ausgelagerten Proben über die gesamte Schichtdicke epitaktisch gewachsen sind, wird der Rekristallisationsprozess offenbar bei Fortsetzen der Temperaturrampe zu höheren Temperaturen zu höheren Schichtdicken hin fortgesetzt. Die Dicke der epitaktischen Schicht ist somit bei gleicher Rampengeschwindigkeit eine Funktion der Auslagerungstemperatur.

\section{$5.4 \quad$ YSZ-Multischichtpakete}

Als Diffusionsbarriere auf metallischen Bändern sind Puffer mit einer Schichtdicke von $50 \mathrm{~nm}$ nicht ausreichend. Da eine sich bis zur Oberfläche fortsetzende epitaktische Schicht bei dickeren Precursorschichten nicht erreicht werden konnte (siehe auch Wachstumsmodell im Diskussionsteil), wurde das homoepitaktische Aufdicken durch Mehrfachbeschichtung untersucht. Darüberhinaus ist die Frage der Texturentwicklung mit wachsender Schichtdicke von Interesse. Dazu wurden jeweils vier Substrate mit identischer Textur in $50 \mathrm{~nm}$ Schritten mit MOD-YSZ aufgedickt. Nach jedem Aufdickungsschritt und anschließender Auslagerung bei $1100^{\circ} \mathrm{C}$ für 2 Stunden (es wurden Aufheizraten von 1 bzw. $5 \mathrm{~K} / \mathrm{min}$ verwendet) wurde ein Substrat entnommen und der Prozeß mit den verbliebenen Proben wiederholt. Zusammen mit einem nicht chemisch beschichteten Referenzsubstrat gleicher Halbwertsbreite des IBAD-YSZ wurden diese Proben mit ca. $200 \mathrm{~nm}$ gesputterten CGO beschichtet 1. Abbildung 5.8 zeigt die Entwicklung der Textur der epitaktischen CGOSchicht mit wachsender Schichtdicke und somit Beschichtungsanzahl. Die Schichten zeigen mit zunehmender Dicke eine Tendenz zu einer leichten Verschlechtung der in-plane-Textur. Somit läßt sich feststellen, daß die MOD-YSZ-Schicht die Oberflächentextur übernimmt und nicht den Texturgradienten in der IBAD-YSZ-Schicht fortsetzt.

\footnotetext{
${ }^{1}$ Ein Ionenätzen der Proben fand vor dem Sputtern nicht statt.
} 


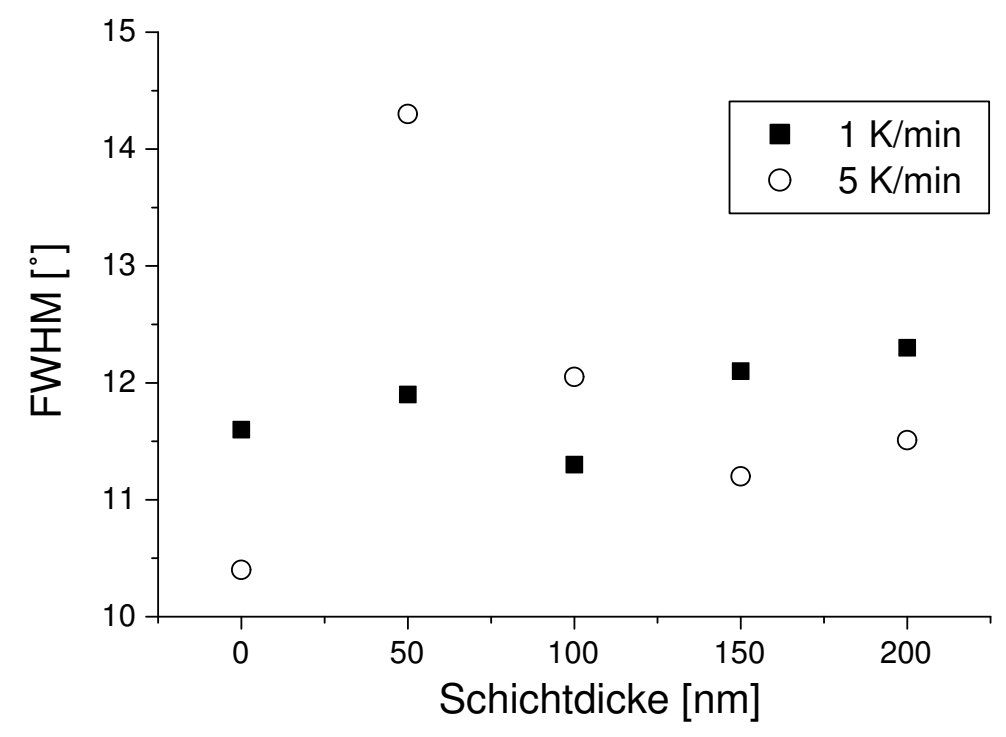

Abbildung 5.8: Änderung der in-plane Textur einer unter epitaktischen Bedingungen aufgesputterten CGO-Schicht auf MOD-YSZ Schichten auf IBAD-YSZ nach mehreren Aufdickprozessen. 


\section{Kapitel 6}

\section{Einfluß von Oberflächenstörungen des MOD-Puffers auf die Stromtragfähigkeit des Supraleiters}

Gegenstand dieses Kapitels ist die Stromtragfähigkeit der mittels gepulster Laserdeposition auf die YSZ- und CGO-MOD-Pufferschichten aufgebrachten YBCO-Schichten. Die Eignung des MOD-Puffers als Templat für die YBCO-Deposition wird über die $\mathrm{j}_{c}$-Verteilung sichtbar gemacht, die YBCO-Deposition wird dabei in allen Fällen als identisch angenommen. Hierbei werden besonders Defektstrukturen in der MOD-Pufferschicht betrachtet, die sich aus dem MOD-Herstellungsprozeß ergeben. Alle hier als Template verwendeten MODPufferschichten wurden mit Acetylacetonaten in einem Essigsäure/iso-Propanol-Gemisch hergestellt.

\subsection{YBCO-Film auf MOD-YSZ/YSZ-(001)-Einkristall}

Die MOD-YSZ-Pufferschicht wurde auf einem YSZ-(001)-Einkristall deponiert, mit $5 \mathrm{~K} / \mathrm{min}$ auf $1100^{\circ} \mathrm{C}$ in $\mathrm{Ar} / \mathrm{H}_{2}(5 \%)$ aufgeheizt und dort für eine Stunde auf Temperatur gehalten. Abbildung 6.1 zeigt eine magnetooptische Aufnahme eines $400 \mathrm{~nm}$ dicken, mit gepulster Laserdeposition hergestellten YBCO-Films ${ }^{1}$ bei $8 \mathrm{~K}$ in einem äußeren Feld von 118.8 mT. Die gesamte Probe zeigt einen magnetooptischen Kontrast, was zeigt, daß das epitaktische Wachstum der YSZ-Pufferschicht vollständig erfolgt ist. Wären polykristalline Bereiche, etwa an den Kanten des Substrates, an der Oberfläche des Puffers verblieben, so würde dort aufgrund der um 2-3 Größenordnungen verschlechterten Stromtragfähigkeit des polykristallinen YBCO kein MO-Kontrast sichtbar sein.

\footnotetext{
${ }^{1}$ Die Halbwertsbreite in YBCO- $\Phi$-Scans beträgt $2^{\circ}$, die in der Literatur bekannte zweifache Epitaxiebeziehung [140] wird nicht beobachtet.
} 
Kapitel 6. Einfluß von Oberflächenstörungen des MOD-Puffers auf die Stromtragfähigkeit des Supraleiters

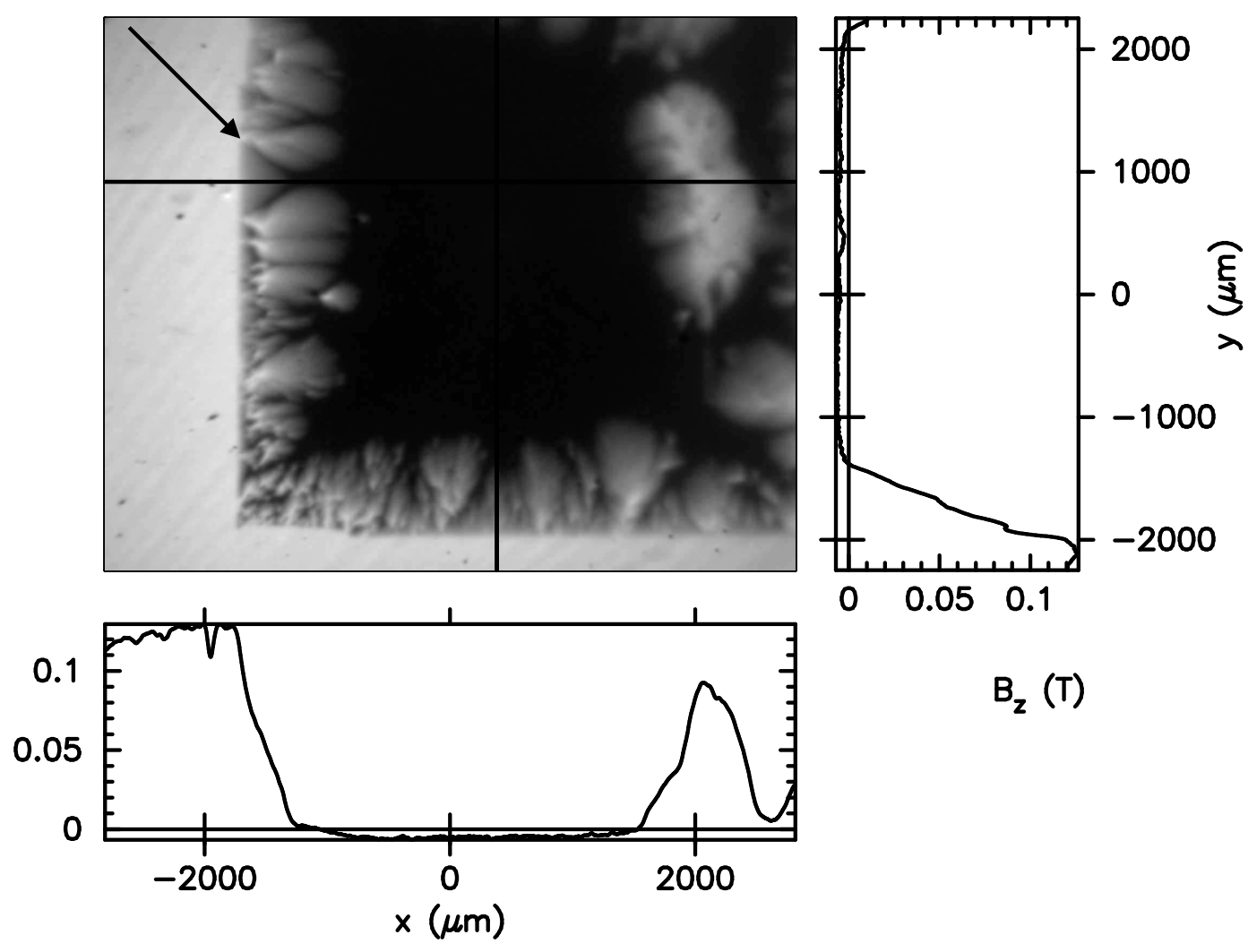

Abbildung 6.1: Magnetooptische Aufnahme eines $400 \mathrm{~nm}$ dicken YBCO-Filmes auf einer MOD-YSZ-Schicht auf einem YSZ-Einkristall bei $8 \mathrm{~K}$ und $118.8 \mathrm{mT}$.

Besonders am Probenrand werden Defekte beobachtet, die sich in der Flußdichteverteilung als parabolische Strukturen äußern (Pfeil in Abb. 6.1). Aus dem Verlauf der Parabeln läßt sich die Ausdehnung $\mathrm{R}$ der als normalleitend angenommenen Defekte berechnen, die zur Entstehung derselben geführt haben [141]:

$$
x=\frac{1}{R} y^{2}-R
$$

Für die gekennzeichnete Struktur ergibt sich eine Defektgröße von ca. $115 \mu \mathrm{m}$. Außerdem gibt es noch eine Reihe kleinerer Defekte mit Ausdehnungen von 50-100 $\mu \mathrm{m}$, die besonders an den Probenrändern auftreten. Diese Konzentration ist darauf zurückzuführen, daß es nach dem Auftropfen des Precursors auf das Substrat ein deutliches Höhengefälle von der Probenmitte in Richtung der Kanten gibt (Abb. 6.2). Verunreinigungen im Precursor (z.B. Prezipitate Abschn. 5.1) sammeln sich daher an den Rändern der Probe an und ergeben nach der Auslagerung gestörte Bereiche in der MOD-YSZ-Schicht, die zu den Defekten im Supraleiter führen 2

\footnotetext{
${ }^{2}$ Die Prezipitate stellen Bereiche mit einer stark erhöhten Schichtdicke im $\mu \mathrm{m}$-Bereich dar; das epi-
} 
Kapitel 6. Einfluß von Oberflächenstörungen des MOD-Puffers auf die Stromtragfähigkeit des Supraleiters

51

(a)

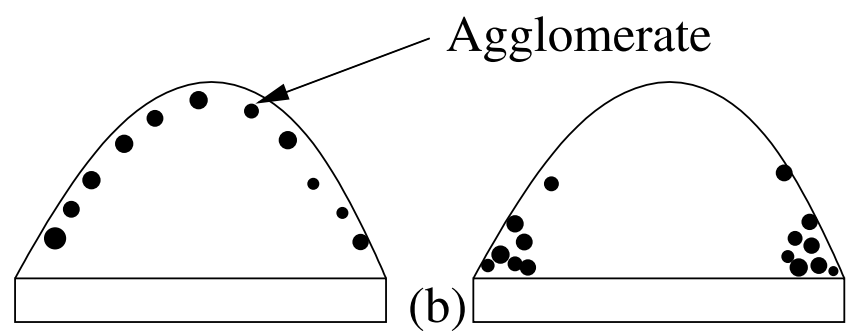

(c)

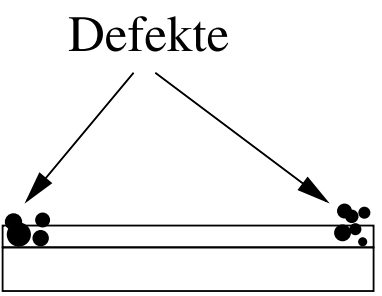

Abbildung 6.2: Entstehung von Defektstrukturen am Probenrand: (a) Verunreinigungen (z.B. Staub) sammeln sich an der Flüssigkeitsoberfläche an; (b) die Verunreinigungen konzentrieren sich an den Probenkanten: (c) nach der Auslagerung liegen an den Probenkante des MOD-YSZ strukturell gestörte Bereiche vor.

Abgesehen von den oben erwähnten Verunreinigungen sind die hergestellten MOD-YSZSchichten sehr glatt mit rms-Rauhigkeiten kleiner als $2.4 \mathrm{~nm}$ (Abb. 5.4). Die niedrige Rauhigkeit in den nicht durch Defekte gestörten Bereichen erlaubt kritische Stromdichten von $2 \cdot 10^{11} \mathrm{~A} / \mathrm{m}^{2}(8 \mathrm{~K})$, was mit Stromdichten auf physikalisch abgeschiedenen YSZ-Schichten vergleichbar ist. Die so erreichten kritischen Stromdichten gehören zu den höchsten in der Literatur auf MOD/Sol-Gel-Pufferschichten angegebenen.

\subsection{YBCO-Film auf MOD-YSZ/IBAD-YSZ}

Abb. 6.3 zeigt eine magnetooptische Aufnahme einer $400 \mathrm{~nm}$ dicken PLD-YBCO-Schicht auf einem MOD-YSZ ${ }^{3} /$ IBAD-YSZ-(12.8 $8^{\circ}$-in-plane-FWHM)-Schichtpaket auf PSZ $\left.\right|^{4}$ bei $8 \mathrm{~K}$ und einem äußeren Feld von $79.2 \mathrm{mT}$. Der magnetooptische Kontrast füllt nicht das gesamte quadratische Substrat aus. An den vier Ecken verbleiben dreiecksförmige Bereiche verschiedener Ausdehnung ohne supraleitenden Kontrast. Offenbar liegt an den Probenecken keine epitaxiefähige Unterlage für das Wachstum des YBCO vor. Aufgrund der größeren Dicke des MOD-YSZ-Puffers an den Probenecken (Abschnitt 3.1.1) erreicht das Schichtwachstum lokal nicht die Oberfläche der Probe. Dort liegt dann untexturiert aufwachsendes YBCO vor, das im MO-Kontrast bei einer Schichtdicke von $400 \mathrm{~nm}$ nicht mehr aufzulösen ist.

Der in der Probenmitte horizontal verlaufende helle Strich ist vermutlich ein Kratzer, der bei der Beschichtung mit MOD-YSZ durch die Probenhandhabung entstand. Die kritische Stromdichte erreicht in dieser Probe Werte von $1.2 \cdot 10^{11} \mathrm{~A} / \mathrm{m}^{2}(8 \mathrm{~K})$. Die im Vergleich zu

taktische Schichtwachstum erreicht daher nicht die Oberfläche der Prezipitate und das YBCO wächst hier polykristallin auf. Dadurch wird die lokale Stromtragfähigkeit reduziert, was zu einem verstärkten Flußeindringen führt.

${ }^{3}$ Die Schicht wurde mit $5 \mathrm{~K} / \mathrm{min}$ auf $1000^{\circ} \mathrm{C}$ in $\mathrm{Ar} / \mathrm{H}_{2}(5 \%)$ geheizt und die Temperatur 2 Stunden gehalten.

${ }^{4}$ Partially Stabilized Zirconia: Zirkondioxid mit 2-6 mol\% $\mathrm{Y}_{2} \mathrm{O}_{3}$ 
Kapitel 6. Einfluß von Oberflächenstörungen des MOD-Puffers auf die Stromtragfähigkeit des Supraleiters
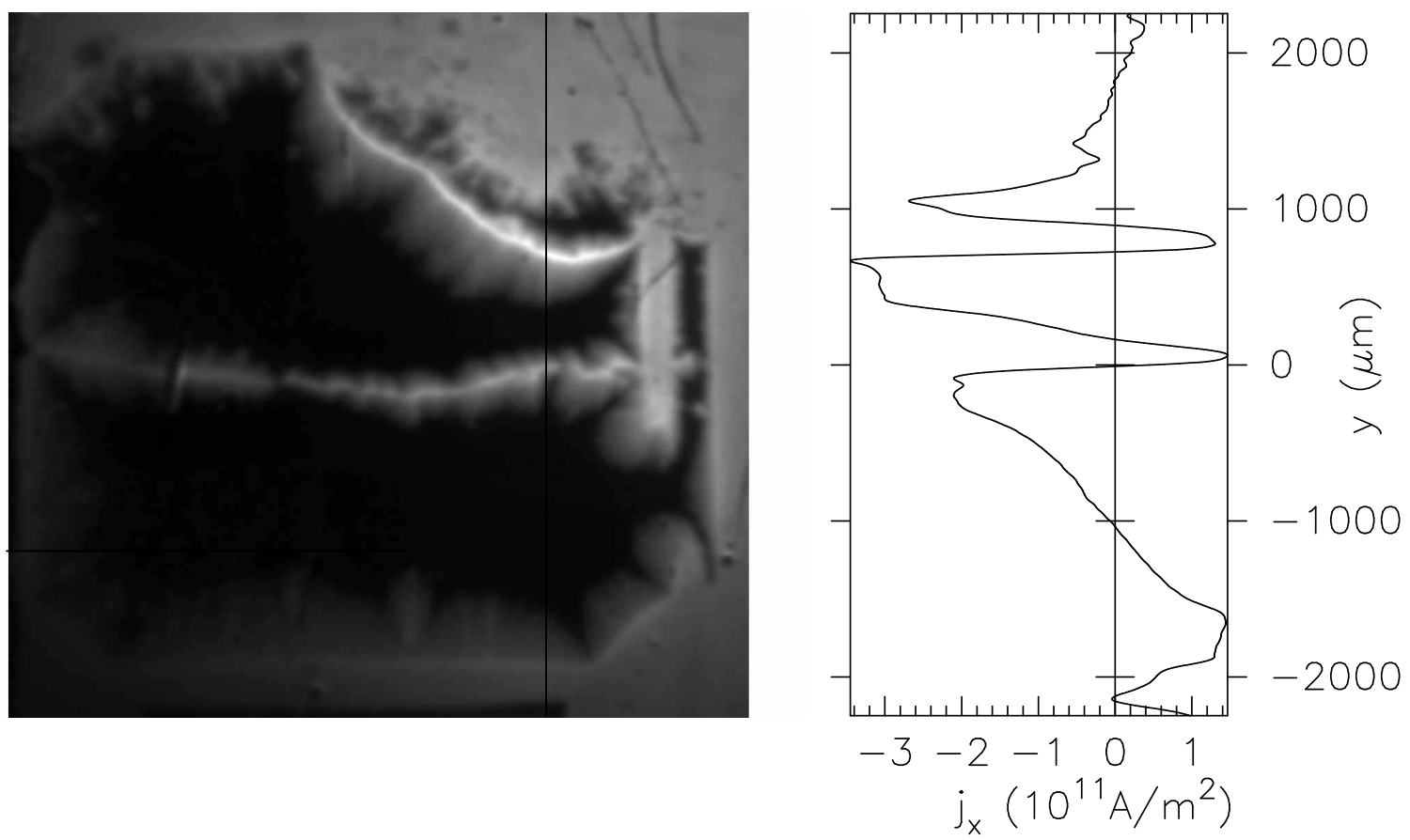

Abbildung 6.3: Magnetooptische Aufnahme einer $400 \mathrm{~nm}$ dicken YBCO-Schicht auf einem MOD-YSZ-Film auf einem 12.8 -IBAD-YSZ-Film auf PSZ bei $8 \mathrm{~K}$ und 79.2 mT äußerem Feld.

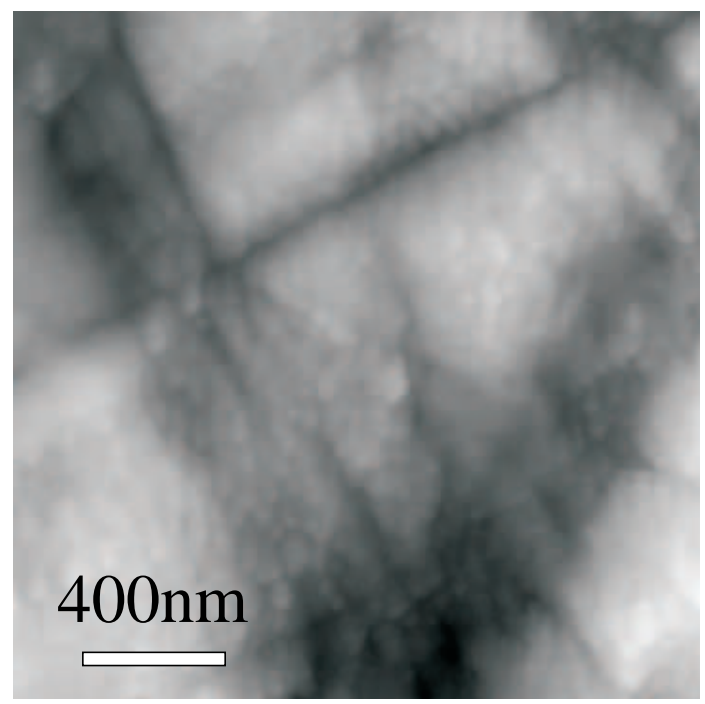

Abbildung 6.4: Rasterkraftmikroskopie an einer MOD-YSZ-Schicht auf IBAD-YSZ (12.8 in-plane FWHM) auf einem PSZ-Substrat. Die rms-Rauhigkeit der Schicht ist mit $9.1 \mathrm{~nm}$ der des Substrates vergleichbar. 
Kapitel 6. Einfluß von Oberflächenstörungen des MOD-Puffers auf die Stromtragfähigkeit

des Supraleiters

der MOD-YSZ-Schicht niedrigere kritische Stromdichte erklärt sich neben dem Texturunterschied auch aus der größeren Rauhigkeit (Abb. 6.4). In der rasterkraftmikroskopischen Aufnahme werden neben der körnigen Schichtstruktur (Korngrößen 20-30 nm) auch Riefen mit Ausdehnungen von einigen $10 \mathrm{~nm}$ sichtbar, die weitere Defekte in den Film einbringen und den kritischen Strom herabsetzen können.

\subsection{YBCO-Film auf MOD-CGO/YSZ-(001)-Einkristall}

Ein mit gepulster Laserdeposition auf einem MOD-CGO-Puffer ${ }^{5}$ abgeschiedener YBCOFilm (Halbwertsbreite in YBCO- $\Phi$-Scans $1.5^{\circ}$ ) zeigt die in Abb. 6.5 gegebene magnetische Flußdichteverteilung. An den Probenrändern des quadratischen Substrates werden wieder Bereiche ohne supraleitenden Kontrast beobachtet. Außer den Probenecken sind hier auch teilweise die Probenkanten betroffen, an denen nach der Beschichtung mit MOD-CGO ebenfalls ein Bereich einer erhöhten Schichtdicke (ca. 100nm) vorliegt (Abb.3.3b). Im Probeninneren liegt abgesehen von einem größeren Defekt in der unteren rechten Probenecke ein homogenes Flußeindringen vor. Das leicht filamentartige Flußeindringen läßt sich auf die Oberflächenstruktur des MOD-CGO-Puffers zurückführen, die in Abb. 6.6 dargestellt ist: Einzelne Defekte mit Höhen von $20 \mathrm{~nm}$ im Abstand von einigen $100 \mathrm{~nm}$ bewirken eine rms-Rauhigkeit von $8.5 \mathrm{~nm}$. Vermutlich kommt es an den großen Rauhigkeiten zu Spannungen oder Schichtdickenschwankungen des YBCO, die sich auf die lokale Stromtragfähigkeit des YBCO-Films auswirken und ein inhomogenes Flußeindringen bewirken.

\footnotetext{
${ }^{5}$ YSZ-(001)-Einkristall als Substrat, $3 \mathrm{~K} / \mathrm{min}$ auf $790^{\circ} \mathrm{C}$, 4 Stunden Haltezeit in $\mathrm{Ar} / \mathrm{H}_{2}$; nach dem Abkühlen mit $5 \mathrm{~K} / \mathrm{min}$ auf $1300^{\circ} \mathrm{C}$ an Luft für 2 Stunden ausgelagert.
} 
Kapitel 6. Einfluß von Oberflächenstörungen des MOD-Puffers auf die Stromtragfähigkeit des Supraleiters

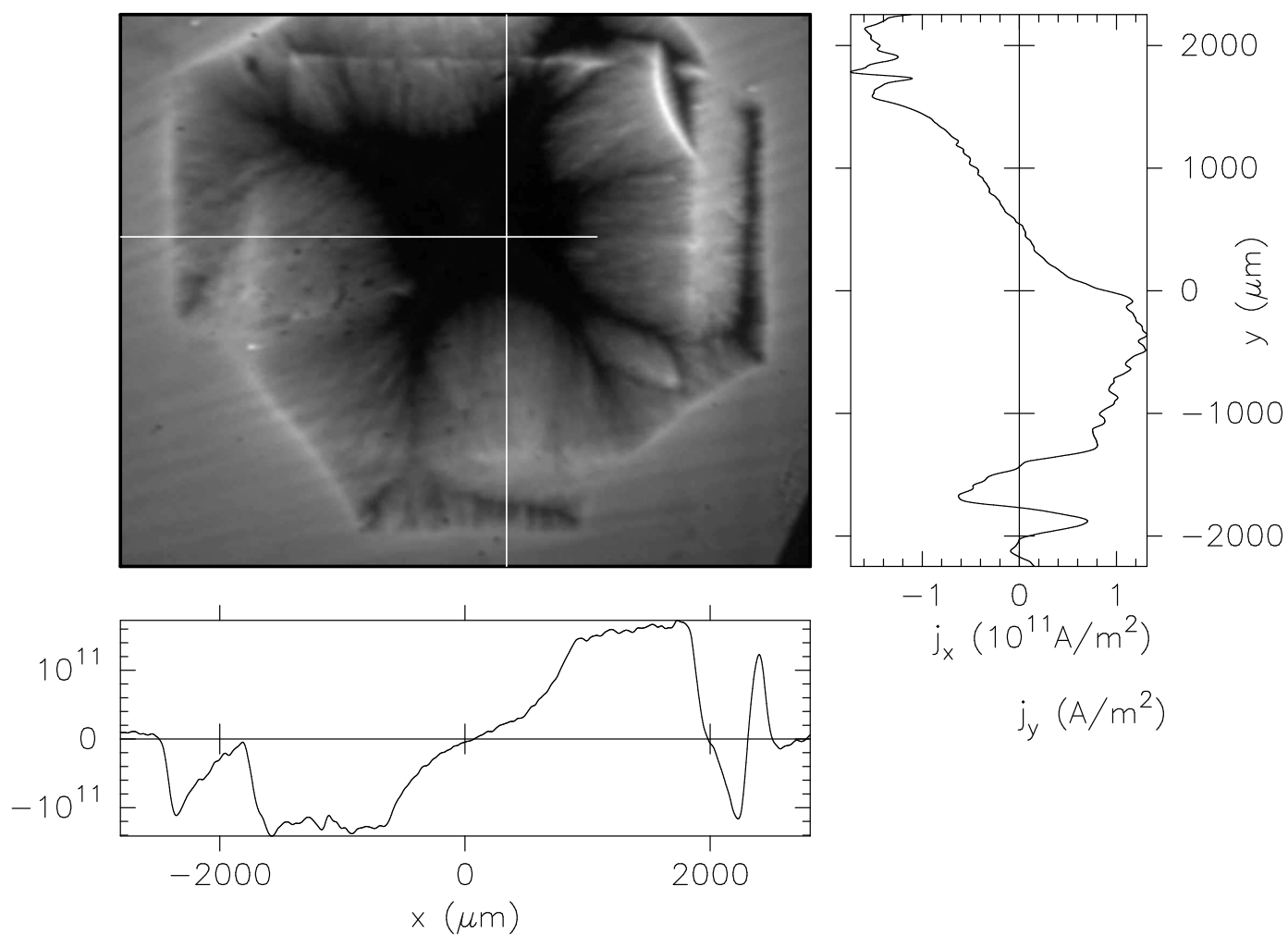

Abbildung 6.5: PLD-YBCO (400 nm)/MOD-CGO (50 nm)/YSZ-(001)-Einkristall: Magnetooptische Aufnahme bei $8 \mathrm{~K}$ und 52.8 $\mathrm{mT}$ angelegtem äußeren Feld; die kritische Stromdichte beträgt $1.1 \cdot 10^{11} \mathrm{~A} / \mathrm{m}^{2}$.

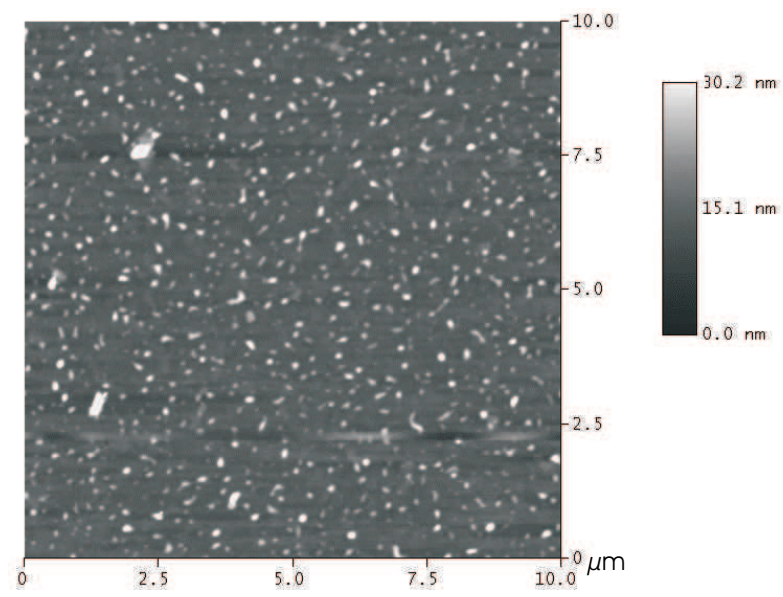

Abbildung 6.6: Rasterkraftmikroskopische Aufnahme an einer MOD-CGO-Schicht auf einem YSZ-(001)-Einkristall. Die punktförmigen Bereiche mit großen Rauhigkeiten lassen sich auf Staub aus der Ofenatmosphäre zurückführen. 


\section{Kapitel 7}

\section{Wachstumsmechanismen}

Die im experimentellen Teil vorgestellten Untersuchungen zeigen, dass der Auslagerungsprozess und die Art und Beschaffenheit der verwendeten Substrate die Ausbildung einer einkristallinen Schicht aus dem aufgebrachten Precursormaterial 1 beeinflussen können:

In Kapitel 4 wurde die Abhängigkeit des Texturierungsgrades von MOD-CGO und MOD$\mathrm{CeO}_{2}$ von Substratrauhigkeit, -textur und der Atmosphäre untersucht. YSZ-Einkristalle wurden dabei als Modellsystem für einzelne Körner des polykristallinen IBAD-YSZ eingesetzt.

Auf durch Ionenbeschuss aufgerauhten YSZ-Einkristallen (0.25-1.5 nm rms-Rauhigkeit) zeigen MOD-CGO-Schichten erhöhte optimale Auslagerungstemperaturen für (100)-Wachstum (für $1.5 \mathrm{~nm}$ rms-Rauhigkeit $870-900^{\circ} \mathrm{C}$ im Vergleich zu $790^{\circ} \mathrm{C}$ bei glatten Oberflächen) (Absch. 4.5.1).

Der Einfluß der Textur, der anhand der Wachstumsbedingungen auf IBAD-YSZ-Substraten untersucht wurde war hingegen gering: Die optimalen Auslagerungstemperaturen lagen weitgehend unabhängig von der Halbwertsbreite des IBAD-YSZ bei $870^{\circ} \mathrm{C}-900^{\circ} \mathrm{C}$ (Absch. 4.5.2). Sowohl auf den einkristallinen Substraten als auch auf IBAD-YSZ wurde eine Interdiffusion zwischen Schicht und Substrat beobachtet.

Bei den wie oben hergestellten Proben verhinderte eine nichttexturierte Oberfläche das epitaktische Anwachsen eines YBCO-Filmes. Diese gestörte Oberfläche konnte durch eine weitere Auslagerung bei höheren Temperaturen im Fall der einkristallinen Substrate beseitigt werden (Absch. 4.4.3).

Die Wachstumstemperaturen für das homoepitaktische System MOD-YSZ auf YSZ-Substraten lagen mit $980-1100^{\circ} \mathrm{C}$ deutlich niedriger als die für eine epitaxiefähige CGO-Oberfläche (Absch. 5.2). Hier war es aufgrund der niedrigeren Auslagerungstemperaturen von 1000$1100^{\circ} \mathrm{C}$ auch möglich, epitaxiefähige Template auf IBAD-YSZ-Substraten herzustellen, die das Wachstum von biaxial texturierten YBCO-Filmen mit Stromdichten von $1.2 \cdot 10^{11} \mathrm{~A} / \mathrm{cm}^{2}$

\footnotetext{
${ }^{1}$ Die Dicke der Schicht reduziert sich während des Auslagerungsprozesses auf 1/3 der Anfangsdicke, was 50-55 nm entspricht.
} 
ermöglichten (Absch. 5.3). Darüberhinaus zeigen diese Messungen, dass das Schichtwachstum nur bis zu einer bestimmten Schichtdicke, die mit der Auslagerungstemperatur wächst, vollständig erfolgt. Überschreitet die Probendicke lokal diesen Wert, so wird kein epitaktisches Ankeimen des YBCO beobachtet. Wird die Schicht dahingegen in Einzelschritten sukzessive aufgedickt, und nach jedem Schritt einer Auslagerungsbehandlung unterzogen, so erreicht das epitaktische Wachstum der MOD-YSZ-Schicht die Oberfläche der Probe auch nach mehreren Einzelschritten (Absch. 5.4).

Diese Ergebnisse lassen sich im Rahmen des Zweistufenprozesses (Abschn. 2.1.1) verstehen: Das Schichtwachstum wird dabei nach der Bildung eines polykristallinen Gefüges durch die Pyrolyse als Konkurrenzprozess zwischen epitaktischem Wachstum und Kornvergrößerung in der polykristallinen Deckschicht verstanden [13]. Die Kinetik der beiden Wachstumsprozesse wird dabei von der Beschaffenheit des Substrates und den gewählten Auslagerungsparametern bestimmt. Die Betrachtung dieser Einflüsse ist Gegenstand dieses Kapitels.

\subsection{Frühstadien des Wachstums nach der Pyrolyse}

Das Ausgangsmaterial für das Wachstum der einkristallinen Schicht ist das Precursormaterial, das nach der Pyrolyse vorliegt. Die durchgeführten Synchrotronmesungen (Abschnitt 4.5.4) zeigen beim Durchfahren einer linearen Temperaturrampe die Bildung von polykristallinem $\mathrm{CeO}_{2}$ (im folgenden: Precursorgefüge) bei ca. $500^{\circ} \mathrm{C}$. Typische Korngrössen liegen bei mit MOD hergestellten Schichten in diesem Stadium der Auslagerung im Nanometerbereich [13], evtl. mit amorphen Bereichen [142]. Das Ausgangsgefüge ist somit, abgesehen von Spuren von Karbonaten, vollständig oxidiert aber nanokristallin und defektreich.

\subsection{Wachstum auf einkristallinen, glatten Substraten}

\subsubsection{Treibende Kräfte der Kristallisation}

Nach der Pyrolyse führt eine weitere Temperaturerhöhung zu einer Rekristallisation des Gefüges. Die treibende Kraft für das epitaktische Wachstum einer MOD-Schicht auf glatten Substratoberflächen ist die Korngrenzenergiedichte im Precursorgefüge [13]. Unter Vernachlässigung der Porosität des Precursorgefüges ergibt sich die Energiedichte $\mathrm{E}_{\text {Prec }}$ desselbigen aus dem Zusammenhang $\mathrm{E}_{\text {Prec }}=\frac{3 \gamma}{d} \mathrm{~L}^{2}$ wobei d den Korndurchmesser und $\gamma$ die

\footnotetext{
${ }^{2}$ Bei einer Kantenlänge d, der als würfelförmig angenommenen Körner, befinden sich $1 / \mathrm{d}^{3}$ Körner im Einheitsvolumen. Jedes Korn trägt $3 \cdot \mathrm{d}^{2}$ zur Gesamtkorngrenzfläche bei; das Produkt aus der Anzahl der Körner, dem Beitrag eines Kornes zur Gesamtkorngrenzfläche und der mittleren Korngrenzenergie $\gamma$ ergibt so $\mathrm{E}_{\text {Prec }}=\frac{3 \gamma}{d}$. Weitere Energiebeiträge, wie z.B. die Energie von Versetzungen, Reaktionsenthalpien von noch nicht vollständig oxidierten Ce-Atomen sowie Oberflächenbeiträge werden vernachlässigt.
} 
Energie pro Korngrenzfläche bezeichnen. Für eine Korngröße von $10 \mathrm{~nm}$ ergibt sich für YSZ unter Verwendung einer mittleren Korngrenzenergie von $0.8 \mathrm{~J} / \mathrm{m}^{2}$ [143] eine mittlere Korngrenzenergiedichte von $240 \mathrm{MJ} / \mathrm{m}^{3}$.

Aus diesem Gefüge bildet sich mit steigender Auslagerungstemperatur eine epitaktische Keimschicht, deren Volumenanteil bei Temperaturerhöhung wächst (siehe Abschn. 4.5.4). Die epitaktische Natur dieser Keimschicht wurde durch die Messung der in-plane-Textur dieser Schicht bestätigt (Abb. 4.19). Dies schließt eine Wachstumsselektion aufgrund unterschiedlicher Oberflächenenergien von (001)- und (111)-Körnern aus. Darüberhinaus läßt sich daraus ableiten, dass das Schichtwachstum an der Grenzfläche zum Substrat beginnt.

Das Wachstum dieser Schicht stagniert und verstärktes untexturiertes (111)-Wachstum im Volumen wird beobachtet, wenn die Auslagerungstemperatur nicht mehr weiter erhöht wird (Abb. 4.18). Nach erfolgter Keimschichtbildung haben die maximale Auslagerungstemperatur, die Temperaturrampe bis zum Erreichen der maximalen Auslagerungstemperatur und die Haltezeit einen starken Einfluß auf das Schichtwachstum. Der Mechanismus des Schichtwachstums und der Einfluß dieser Parameter wird im folgenden diskutiert.

Während der Auslagerung konkurrieren zwei Prozesse: das epitaktische Schichtwachstum und ein unorientiertes Kornwachstum in der verbleibenden polykristallinen Deckschicht 88, 37] (Abb. 7.1 verdeutlicht den Zusammenhang). Mit steigender Temperatur

(a)
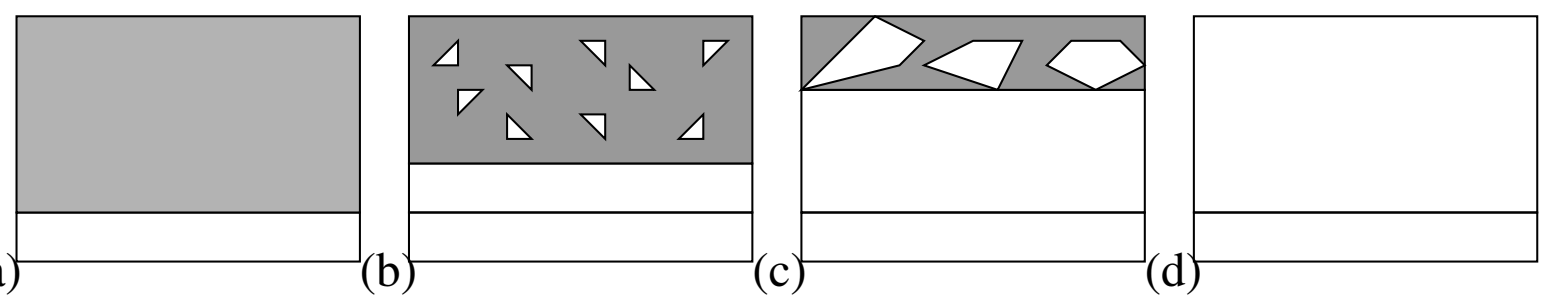

Abbildung 7.1: Entwicklung der Mikrostruktur während eines Auslagerungsprozesses: (a) nanokristallines Gefüge nach der Pyrolyse, (b) Keimschichtbildung, (c) Wachstum der Keimschicht und Kornvergrößerung im Precursorgefüge, (d) vollständig texturierte Schicht.

wächst die Keimschicht an und es findet darüberhinaus ein Kornwachstum in der polykristallinen Deckschicht statt 3. Das Kornwachstum in der polykristallinen Deckschicht erfolgt in alle Raumrichtungen, wohingegen die epitaktische Schicht auf eine Wachstumsrichtung festgelegt ist. Bei gleicher treibender Kraft für das Kornwachstum sollte aufgrund der Geometrie also die Kornvergrößerung bezogen auf das rekristallisierte Volumen in der Deckschicht schneller erfolgen als in der epitaktischen Schicht. Allerdings ist die Energiedifferenz zwischen epitaktischer Schicht und Precursorgefüge größer als die Differenz

\footnotetext{
${ }^{3}$ Diese Kornvergrößerung kann beobachtet werden, wenn MOD-YSZ-Schichten für mehrere Stunden unterhalb von $900^{\circ} \mathrm{C}$ ausgelagert werden. Bei dieser Temperatur erreicht das epitaktische Wachstum nicht die Oberfläche der Probe. Eine darauffolgende Auslagerung mit den optimalen Parametern führt dann ebenfalls nicht zu einem epitaktischen Schichtwachstum bis zur Schichtoberfläche.
} 
zwischen einem einzelnen Polykristall und der umgebenen Matrix. Energetisch ist also das epitaktische Schichtwachstum bevorzugt. Durch die Kornvergröberung wird die Korngrenzenergie in der polykristallinen Deckschicht herabgesetzt und dadurch das epitaktische Schichtwachstum kinetisch gehemmt. Ein weiteres Fortschreiten der Epi-Front kann daher erst bei höheren Temperaturen erfolgen, bis der Endzustand der bis zur Oberfläche texturierten Schicht erreicht ist (Abb. 7.1(d)). Aus diesem Zusammenhang wird deutlich, dass die Kontrolle der Kinetik von zentraler Bedeutung ist. Wählt man die Temperaturrampe bis zum Erreichen der Auslagerungstemperatur zu hoch (grösser als $3 \mathrm{~K} / \mathrm{min}$ ), so findet bevorzugt das untexturierte Wachstum in der Deckschicht statt (Abb. 4.8) ${ }^{4}$, was wiederum zu einer Erniedrigung der Korngrenzenergie führt. Das Wachstum der epitaktischen Schicht wird dadurch gebremst. Wird die Temperaturrampe kleiner als $3 \mathrm{~K} / \mathrm{min}$ eingestellt, so bestimmt die Energiedifferenz epitaktische Schicht/Matrix bzw. Polykristall/Matrix das Schichtwachstum.

\subsubsection{Einfluß der Gitterfehlpassung}

Die Korngrenzenergie als die treibende Kraft des epitaktischen Schichtwachstums wird für Systeme mit Gitterfehlpassung durch weitere Energiebeiträge ergänzt. Die Gitterfehlpassung zwischen Substrat und Schicht führt zu einem weiteren Energiebeitrag und kann durch zwei Mechanismen abgebaut werden: Zum einen ist es möglich, daß die Schicht die Gitterkonstante des Substrates übernimmt und verspannt aufwächst. Zum anderen können Versetzungen eingebracht werden, die die Spannung abbauen. In der Regel wächst bis zu einer kritischen Dicke eine verspannte Schicht auf dem Substrat auf. Ab dieser Dicke wird der Einbau von Versetzungen energetisch günstiger.

Für eine verspannt aufwachsende Schicht ist die Spannungsenergie $\mathrm{E}_{m}$ gegeben durch [144

$$
E_{m}=\epsilon_{m}^{2} B h
$$

mit $\epsilon_{m}=\frac{a_{s}-a_{f}}{a_{f}}$ der Gitterfehlpassung ( $a_{s}$ : Gitterkonstante des Substrates, a a $_{f}$ Volumengitterkonstante des Filmes), h der Filmdicke und B einer Konstante gegeben durch:

$$
B=\frac{1}{2}\left(C_{11}+2 C_{12}\right)\left[3-\frac{C_{11}+2 C_{12}}{C_{11}+2\left(2 C_{44}-C_{11}+C_{12}\right)\left(l^{2} m^{2}+m^{2} n^{2}+n^{2} l^{2}\right)}\right]
$$

Dabei sind l, m, n die Richtungskosinus, die die Substratnormale mit der kubischen Einheitszelle verknüpfen und $\mathrm{C}_{i j}$ die elastischen Konstanten des Schichtmaterials. Ist die Ebene zwischen Schicht und Substrat vom Typ $\{100\}$, so vereinfacht sich diese Gleichung $\mathrm{zu}$

$$
B=\frac{\left(C_{11}+2 C_{12}\right)\left(C_{11}-C_{12}\right)}{C_{11}}
$$

\footnotetext{
${ }^{4}$ Hier bestimmt also der oben beschriebene Geometrieeffekt.
} 
Setzt man die elastischen Konstanten des $\mathrm{CeO}_{2}$ [5 ein, so erhält man Energiedichten der verspannt aufwachsenden Schichten von $1,2 \mathrm{GJ} / \mathrm{m}^{3}$, also ca. fünffach höhere Werte als der Energieinhalt der Korngrenzen im Precursormaterial (siehe Abschnitt 7.2.1) 6. Daraus ergibt sich:

- Eine verspannte CGO-Schicht kann für einen stufenartigen Übergang zwischen Substrat und Schicht nicht aus dem polykristallinen Gefüge wachsen. Durch zusätzliche Mechanismen müssen die fehlpassungsbedingten Verspannungen abgebaut werden. Entweder werden in einem frühen Stadium des Schichtwachstums Versetzungen eingebaut, oder die Gitterkonstanten müssen durch Interdiffusion von Substrat und Schicht kontinuierlich verändert werden.

- Systeme ohne Gitterfehlpassung wie das in Kapitel 5 untersuchte MOD-YSZ auf YSZ(001)-Einkristallen sollten bei niedrigeren Temperaturen epitaktisch bis zur Oberfläche der Schicht wachsen als das heteroepitaktische System MOD-CGO auf YSZ-(001)Einkristallen, da die fehlpassungsinduzierten Zusatzenergie zu einer Verringerung der treibenden Kräfte führt. Dies drückt sich experimentell durch die um $250^{\circ} \mathrm{C}$ niedrigere Temperatur zum Erreichen des vollständigen epitaktischen Wachstums im Falle des homoepitaktischen MOD-YSZ-Systems aus.

Der Einfluss einer Interdiffusion zwischen YSZ-Substrat und CGO-Schicht, die die Verspannungsenergie der epitaktischen Keimschicht herabsetzt, wird im folgenden diskutiert.

\subsubsection{Einfluß der Interdiffusion zwischen Substrat und Schicht}

Müßte die $\mathrm{CeO}_{2}$-Schicht direkt auf dem Substrat aufwachsen, so würde der Energieinhalt der aufzuwachsenden verspannten Schicht den Energieinhalt des polykristallinen Precursorgefüges überschreiten (Abschnitt 7.2.2). Somit würde die treibende Kraft für das epitaktische Schichtwachstum verschwinden und es dürfte kein epitaktisches Ankeimen beobachtet werden. Durch Interdiffusion, die experimentell mit SIMS und RBS beobachtet wurde (Abb. 4.6 bzw. 4.17), wird die Gitterfehlpassung zwischen Substrat und Schicht verringert, wie Abb. 7.2 zeigt. Die Gitterkonstante ändert sich bis zu $70 \mathrm{~mol} \% \mathrm{CeO}_{2}$ linear mit der $\mathrm{CeO}_{2}$-Zugabe. Durch die Ce-Zr-Interdiffusion und dem daraus resultierenden Gradienten in der Zusammensetzung ändert sich also die Fehlpassung zwischen Substrat und epitaktisch aufwachsender Schicht. Dadurch wird die Verspannungsenergie in der epitaktisch am Substrat ankeimenden Schicht verringert, und die Schicht kann epitaktisch wachsen.

Ein weiterer Aspekt ist die Yttrium-Segregation in dem YSZ-Substrat: Yttrium reichtert sich für Auslagerungstemperaturen größer als $1000^{\circ} \mathrm{C}$ an den Oberflächen des YSZ an.

\footnotetext{
${ }^{5}$ Aus Ramanmessungen bei $15 \mathrm{~K}: \mathrm{C}_{11}=403 \mathrm{GPa}, \mathrm{C}_{12}=105 \mathrm{GPa}, \mathrm{C}_{44}=60 \mathrm{GPa}$ 145; Hartee-FockRechnungen ergeben ähnliche Werte 146 .

${ }^{6}$ Aufgrund der geringen Änderung der Gitterkonstante bei Dotierung mit 5 at\% $\mathrm{Gd}_{2} \mathrm{O}_{3}$ [97, sind die Werte für $\mathrm{CeO}_{2}$ und CGO praktisch identisch.
} 


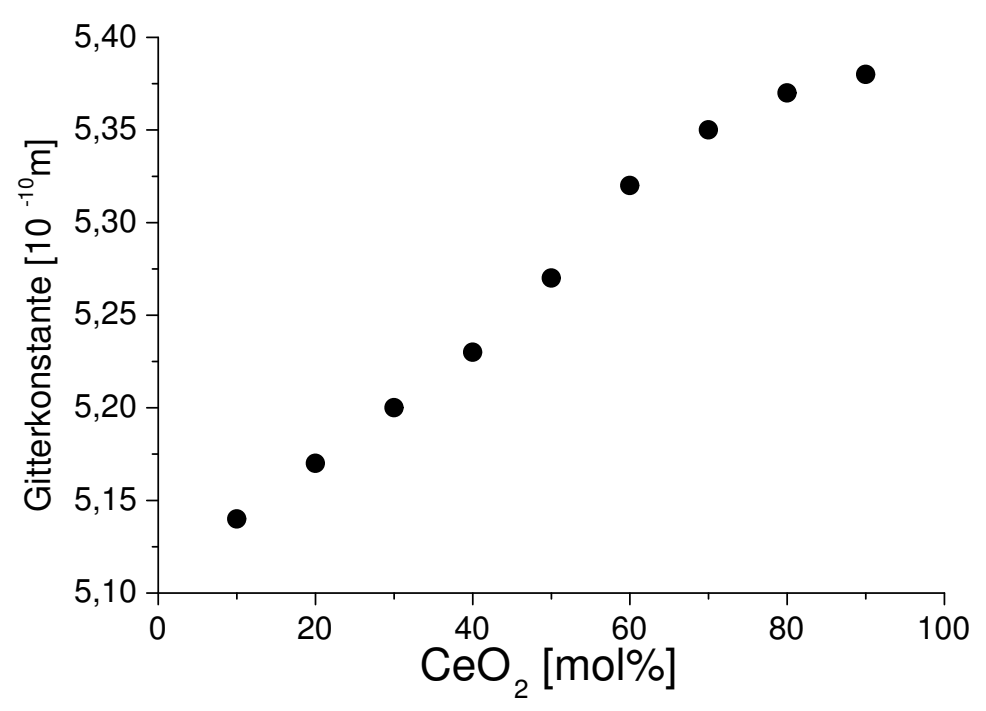

Abbildung 7.2: Änderung der Gitterkonstante im System $\mathrm{CeO}_{2}-\mathrm{ZrO}_{2}$ mit wachsendem $\mathrm{CeO}_{2}$-Gehalt; Datenpunkte entnommen aus [101].

Die so erreichte Oberflächenkonzentration erreicht bei $10 \mathrm{~mol} \% \mathrm{Y}_{2} \mathrm{O}_{3}$-Volumendotierung Werte zwischen 30 und 34\% Y [116, 114]. Dadurch wird die Gitterkonstante des Substrates auf ca. 5,2 Åheraufgesetzt (Abb. 7.3). Damit einher geht eine Verringerung der Verspannungsenergie um ca. 40\%. Außerdem unterdrückt eine $\mathrm{Y}_{2} \mathrm{O}_{3}$-Dotierung von $\mathrm{CeO}_{2}$ das Kornwachstum [147]. Dadurch verzögert sich die Kornvergrößerung in der polykristallinen Deckschicht und die Korngrenzenenergie als treibende Kraft für das Schichtwachstum wird zu höheren Temperaturen stabilisiert.

Zusammenfassend läßt sich also sagen, daß die Interdiffusion zwischen Substrat und Precursormaterial bzw. Y-Segregation im Substrat das epitaktische Wachstum durch Herabsetzen der Verspannungsenergie vereinfacht bzw. ermöglicht.

\subsection{Wachstum auf rauhen und polykristallinen Sub- straten}

In diesem Abschnitt wird ein Modell für das heteroepitaktische Wachstum auf IBADYSZ-Substraten entwickelt. Dazu wird zuerst die Korngrenzenergiedichte im IBAD-YSZ abgeschätzt und dann der Einfluß der Substratrauhigkeit auf die Wachstumskinetik diskutiert. 


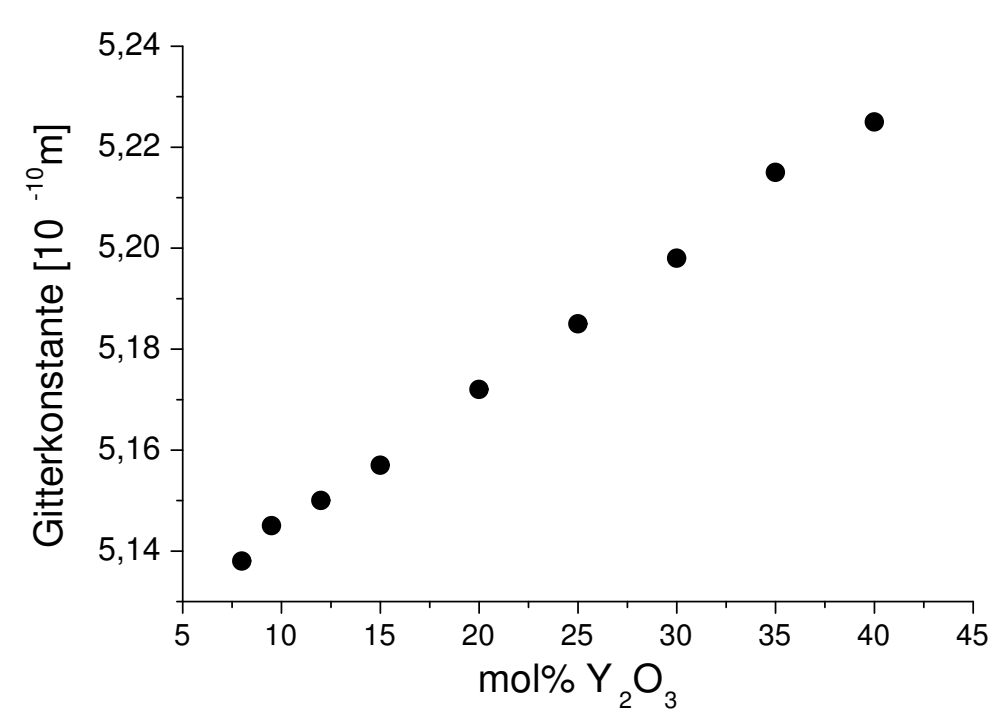

Abbildung 7.3: Änderung der Gitterkonstante im System $\mathrm{Y}_{2} \mathrm{O}_{3}-\mathrm{ZrO}_{2}$ mit wachsendem $\mathrm{Y}_{2} \mathrm{O}_{3}$-Gehalt; Datenpunkte entnommen aus [13].

\subsubsection{Einfluß von Substrattextur und Morphologie}

Experimentell wurde nur ein kleiner Beitrag der Substrattextur zu den Wachstumsbedingungen der MOD-CGO-Schicht festgestellt (Abschnitt 4.5.2). Dies läßt sich verstehen, wenn man die Energiedichte des polykristallinen Precursorgefüges $\mathrm{E}_{\text {Prec }}$ mit der Energiedichte des Substrates $\mathrm{E}_{0}$ vergleicht. Für einkristalline YSZ-Substrate ist das in Abschnitt 7.2.1 vorgeführt worden. Die Berechnung des Korngrenzbeitrages bei den IBADYSZ-Substraten gestaltet sich aufgrund der Textur und der kolumnaren Struktur (Abb 2.3) schwieriger als im Falle eines untexturierten polykristallinen Gefüges.

Hierzu wurde die Mikrostruktur des IBAD-YSZ (Absch. 2.3) als säulenförmig mit einer Säulenbreite von $100 \mathrm{~nm}$ modelliert . Da experimentelle Daten der Korngrenzflächenenergie nur für ein polykristallines Gefüge vorlagen, wurde anhand von Röntgentexturmessungen und einem theoretischen Verlauf der Korngrenzenergie die texturabhängige Korngrenzenergie des IBAD-YSZ berechnet.

Als Maß für die in-plane Verkippung der einzelnen Körner wurden Röntgentexturmessungen ( $\Phi$-Scans für die in-plane-Komponente, Rocking-Kurven für die out-of-plane-Komponente) an einer aufgesputterten CGO-Schicht herangezogen. Diese Schicht übernimmt die Textur der obersten YSZ-Schicht; ihre Textur gibt daher die für das Schichtwachstum relevante Oberflächentextur des IBAD-YSZ wieder. In Abb. 7.4 findet sich neben dem gestrichelt dargestellten theoretischen $\sin (2 \Phi)$-Verlauf der Korngrenzenergie mit dem Verkippungswinkel auch ein Aussschnitt aus einem $\Phi$-Scan, der als Verteilungsfunktion der in-plane 
Verkippung der Körner angenommen werden kann. Ein Maß für die mittlere Korngrenzenergie pro Fläche $\mathrm{KG}_{I B A D}$ ergibt sich durch Multiplikation des theoretischen Verlaufs mit dem $\Phi$-Scan

$$
K G_{I B A D}=\int_{-45}^{45} \sin (2 \Phi) \cdot \operatorname{Phiscan}(\Phi) \cdot d \Phi
$$

unter der Nebenbedingung $\int_{-45}^{45} \operatorname{Phiscan}(\Phi) \cdot \mathrm{d} \Phi=1$. Absolute Werte erhält man, wenn die Berechnung für eine Gerade Poly=const. durchgeführt wird mit $\int_{-45}^{45}$ Poly·d $\Phi=1$

$$
K G_{\text {poly }}=\int_{-45}^{45} \sin (2 \Phi) \cdot \text { Poly } \cdot d \Phi
$$

Da die mittlere Korngrenzflächenenergie für einen YSZ-Polykristall bekannt ist $\left(0.8 \mathrm{~J} / \mathrm{m}^{2}\right.$ [143]), läßt sich die mittlere Korngrenzflächenenergie des IBAD-YSZ aus dem Wert für den YSZ-Polykristall bestimmen. Analog verfährt man mit der out-of-plane-Komponente anhand von Rockingkurven.

Die Korngrenzfläche des IBAD-YSZ pro $\mathrm{m}^{3}$ ergibt sich aus der säulenförmigen Struktur zu $2 \cdot 10^{7} \mathrm{~m}^{2}$. Daraus ergeben sich Korngrenzenergien von $2 \mathrm{MJ} / \mathrm{m}^{3}$ für eine $15^{\circ}$-IBAD-YSZProbe. Abbildung 7.5 zeigt den Verlauf der in den Korngrenzen gespeicherten Energie mit der in-plane-Verkippung. Zusätzlich ist in dieser Auftragung der Energieinhalt der Korngrenzen in einem polykristallinen Gefüge mit einer Korngröße von $10 \mathrm{~nm}$ angegeben. Der Korngrenzenergieinhalt des Polykristalls ist um zwei Größenordnungen höher als der des IBAD-YSZ. Bezogen auf das polykristalline Gefüge sind die Unterschiede in der Korngrenzenergie zwischen IBAD-YSZ und YSZ-Einkristall also gering. Nimmt man die Differenz der Korngrenzenergie zwischen Precursorgefüge und Oberfläche der epitaktischen Schicht als Maß für die Kinetik des Schichtwachstums, so sollten die Wachstumsbedingungen für IBAD-YSZ und YSZ-Einkristall weitestgehend identisch sein.

\subsubsection{Einfluß der Rauhigkeit}

Experimentell wurde eine Erhöhung der optimalen Auslagerungstemperatur mit steigender Rauhigkeit beobachtet (Abschnitt 4.5.1). Als Ursache für dieses Verhalten wird in diesem Abschnitt eine sich an der Grenzfläche zwischen deponierter Schicht und rauher Oberfläche bildende poröse Grenzschicht angenommen.

Die Entstehung der Porosität an der Grenzfläche verdeutlicht Abb 7.6. Nach der Beschichtung des Substrates bedeckt der Precursor die Substratoberfläche. Während der Trocknung und der Pyrolyse sinkt das Schichtvolumen auf ca. 1/3 des Anfangswertes zusammen. Das Verdampfen des Lösungsmittels und der Transport der Precursorreste aus der Schicht sind diffusionsgesteuerte Prozesse. Die treibende Kraft dafür ist ein Konzentrationsgefälle in Richtung Schichtoberfläche. Daher beginnt die Entstehung des Precursorgefüges an der Oberfläche (Abb. 7.6(a)); die Porosität in der Schicht ermöglicht hier den Abtransport der Precursorreste. Im Fall des glatten Substrates schreitet diese Reaktion bis zum Erreichen 


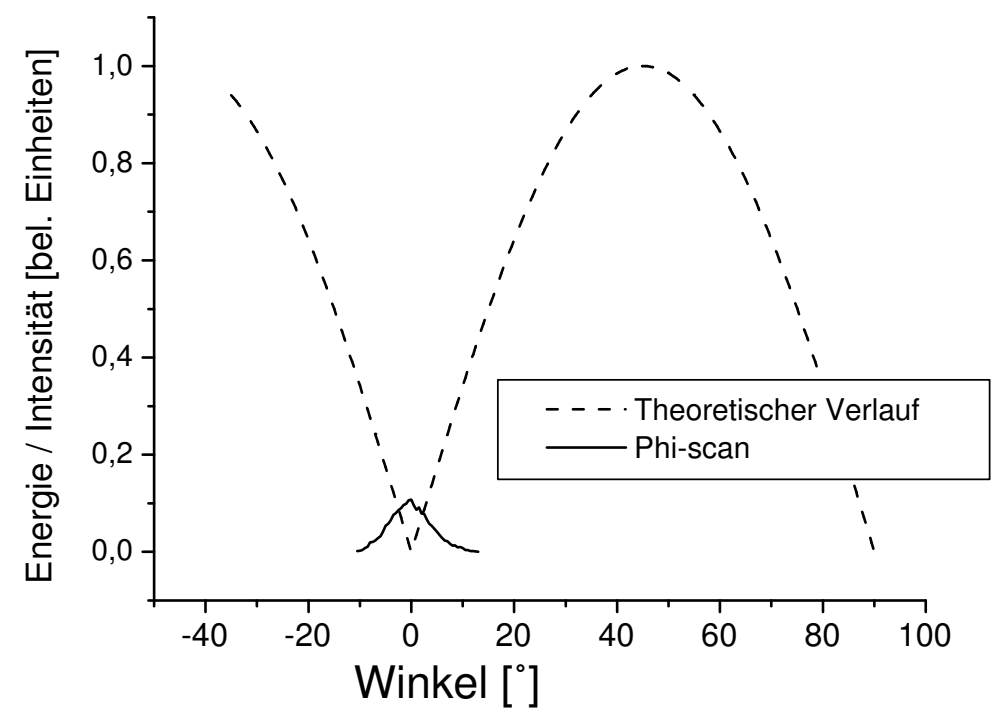

Abbildung 7.4: Theoretischer Verlauf der Korngrenzenergie mit dem Verkippungswinkel (gestrichelt) und Teil eines YSZ- $\Phi$-Scans als Verteilungsfunktion der polykristallinen Körner.

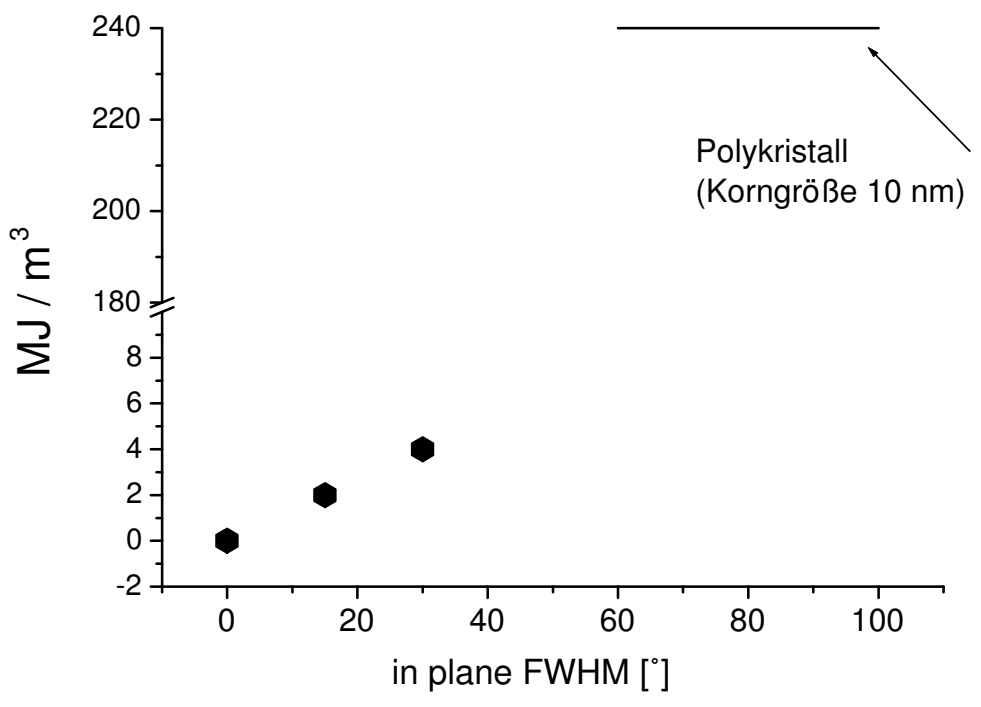

Abbildung 7.5: Energieinhalt eines polykristallinen Gefüges relativ zu der Korngrenzenergie von IBAD-YSZ-Substraten verschiedener Textur. Der YSZ-Einkristall liegt im Ursprung. 
der Substratoberfläche fort. Auf den rauhen Substraten kann die getrocknete Schicht beim Erreichen der Oberfläche nicht mehr nachsacken um den nötigen Volumenabbau der Schicht vorzunehmen (Abb. 7.6(b)). Daraus resultiert an der Substratoberfläche eine zusätzliche Porosität (Abb. 7.6(c)), die das Wachstum auf rauhen Substraten auf verschiedene Arten modifiziert:

(a)

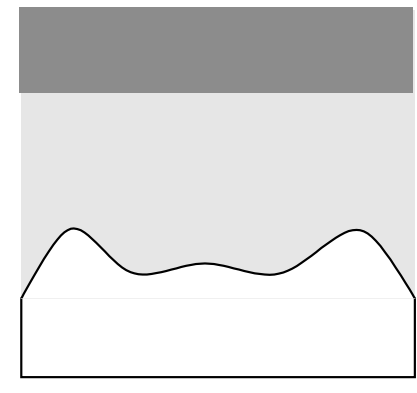

(b)

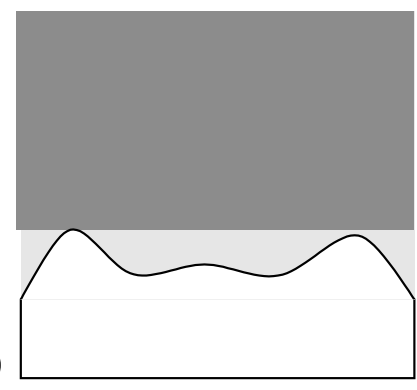

(c)

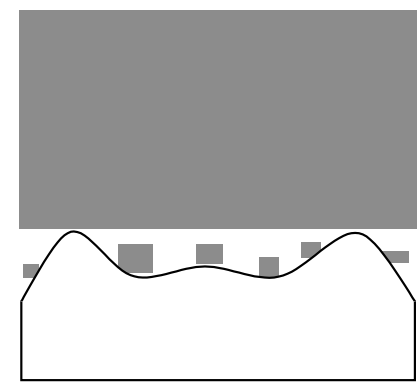

Abbildung 7.6: Entstehung der Rauhigkeit an der Grenzfläche zwischen Substrat und Schicht während der Trocknung und Zersetzung des Precursors.

- Beim epitaktischen Wachstum muß jetzt diese zusätzliche Porosität durch die Schicht hindurch bewegt werden, wozu gegenüber einer glatten Substratoberfläche eine höhere Energie erforderlich ist, weil die Beseitigung dieser Porosität wiederum als ein diffusiver Prozess verstanden werden kann.

- Die Poren dienen als zusätzliche Keimstellen für das Wachstum polykristalliner Körner. Dadurch muß die epitaktische Schicht durch einen Bereich mit größeren Körner wachsen, als dass ohne die Poren der Fall wäre. Auch hierzu ist eine höhere Energie (Temperatur) nötig.

- Die Porosität behindert außerdem die Eindiffusion von Yttrium. Dadurch kommt die kornvergröberungshemmende Wirkung des Yttrium schwächer zum Tragen und die relative Bedeutung der Korngrenzenergie als die treibende Kraft für das Schichtwachstum sinkt (vgl. Absch. 7.2.3). Dies führt auch hier zu einer Erhöhung der benötigten Temperatur für das epitaktische Schichtwachstum.

In Abb. 7.7 ist die Entwicklung der Mikrostruktur für glatte und rauhe Oberflächen für verschiedene Auslagerungstemperaturen skizziert. Auf der glatten Oberfläche liegt nach der Pyrolyse ein polykristallines Precursorgefüge vor (Abb. 7.7b); auf der rauhen Oberfläche gibt es eine zusätzliche Porosität an der Grenzfläche zum Substrat (Abb. 7.7g). Erhöht man die Temperatur, so beginnt für beide Substrate das epitaktische Schichtwachstum. Gleichzeitig findet in dem Precursorgefüge ein Kornwachstum statt ( $7.7 \mathrm{c}, \mathrm{h})$. Die zusätzliche Porosität des rauhen Substrates behindert nun das epitaktische Schichtwachstum, weswegen die bis zu dieser Temperatur gebildete Dicke der Epi-Schicht geringer als auf 
dem glatten Substrat ist. Wird die Temperatur weiter erhöht (Abb. 7.7 d,i), so macht sich auf den rauhen Substraten die Porosität dadurch bemerkbar, daß die Korngröße an der Grenze Epi-Schicht-Precursor höher ist. Dadurch wird die Korngrenzenergie im Precursorgefüge kleiner und die treibende Kraft für das Wachstum der Epi-Schicht nimmt ab. Während also nach einer weiteren Temperaturerhöhung im Falle des glatten Substrates das Schichtwachstum abgeschlossen ist, hat bei dieser Temperatur die Wachstumsfront auf dem rauhen Substrat noch nicht die Oberfläche der Schicht erreicht (Abb. 7.7.j).

a)

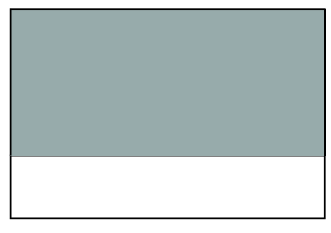

b)

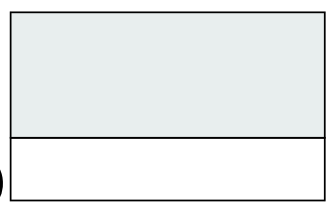

c)

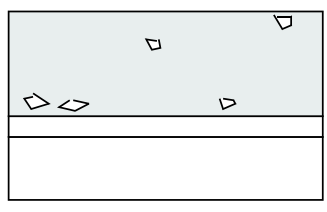

d)

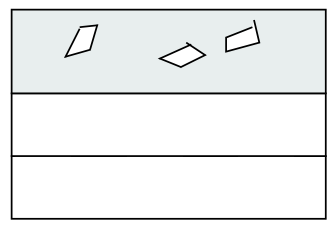

e)

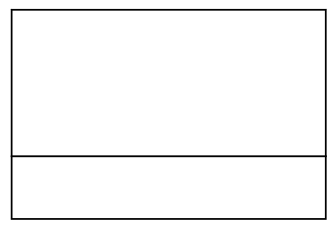

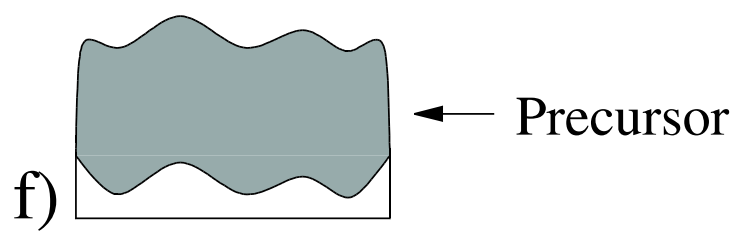
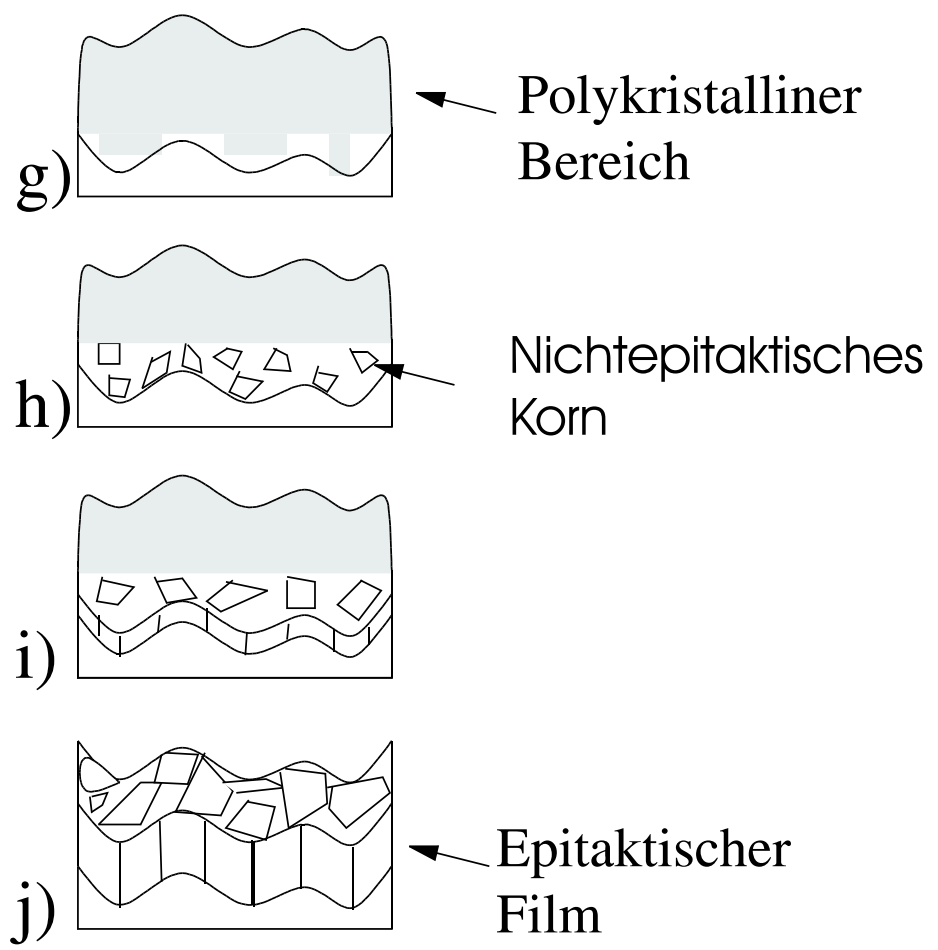

Abbildung 7.7: Wachstum auf rauhen Substraten

Mit diesem Mechanismus lassen sich die unterschiedlichen Wachstumsbedingungen für YSZ-Einkristalle (glatte Oberfläche) und IBAD-YSZ-Substraten (rms-Rauhigkeit $\approx 10 \mathrm{~nm}$ ) verstehen. 


\subsection{Vergleich mit anderen Arbeiten}

Es liegen eine Reihe von Veröffentlichungen vor, in denen von röntgentexturierten Pufferschichten berichtet wird, ohne dass auf diesen Puffern ein epitaktisches Anwachsen möglich ist. Dies lässt sich durch die mangelnde Eignung der Röntgenanalytik zur Charakterisierung der Schichtqualität von mit MOD/Sol-Gel hergestellten Proben erklären: in den vorangehenden Kapiteln wurde gezeigt, daß die Texturentwicklung als Konkurrenzprozeß zwischen epitaktischem Schichtwachstum und Kornvergröberung im polykristallinen Precursorgefüge verstanden werden kann. Es liegen dadurch in weiten Bereichen der Herstellungstemperaturen beide Mikrostrukturen nebeneinander vor. Beide Schichten tragen aufgrund ihrer Mikrostruktur sehr unterschiedlich zur Gesamtintensität in Röntgenmessungen bei. Betrachtet man eine Probe, bei der Messungen in $\Theta / 2 \Theta$-Geometrie ein Verhältnis zwischen (111) und (200)-Intensität von $\frac{(200)}{(200)+(111)}=0.95$ ergeben, so kann man daraus nicht schließen, daß das Anteil der (200)-Körner in der Schicht ca. 95\% beträgt, was folgende Abschätzung zeigen soll: Zur Intensität bei Messungen in $\Theta / 2 \Theta$-Geometrie tragen nur diejenigen Netzebenen bei, die (mit einer gewissen Toleranz) parallel zu Oberfläche liegen. Ist ein Korn also stärker als der Toleranzwinkel relativ zur Oberfläche verkippt, so trägt es nicht zur Röntgenintensität bei. Geht man von einer vollständig polykristallinen Schicht aus, so wird effektiv nur ein Anteil von Toleranzwinkel $/ 90^{\circ}$ durch die Messung erfasst. Mit einem Toleranzwinkel von $3^{\circ}$ tragen in der polykristallinen Schicht also nur rund 1/30 der Körner zur Röntgenintensität bei. Ein gemessener (111)-Anteil von $5 \%$ entspricht also nicht einer Schichtdicke des polykristallinen Bereiches von $\mathrm{a}_{P o l y}=\mathrm{a}_{(111) /(200)+(111)}$, sondern von 30a(111)/(200)+(111). In Röntgenmessungen wird also die Dicke der polykristallinen Deckschicht stark unterschätzt. Aus einem Intensitätsverhältnis in Röntgenmessungen von $\frac{(200)}{(111)+(200)}$ von $99 \%$ ist also noch nicht ein fast vollständiges (100)-Wachstum abzuleiten.

Daraus erklärt sich die Vielzahl von Veröffentlichungen, die die Herstellung von röntgentexturierten Pufferschichten berichten, ohne das auf diesen Puffern ein weiteres epitaktisches Wachstum möglich ist. Die polykristalline Deckschicht verhindert in diesem Fall das epitaktische Ankeimen. Einige Autoren verwenden gesputterte Deckschichten auf den MODFilmen, was zur unbeabsichtigten Beseitigung der polykristallinen Deckschicht führen kann und die hohen so erreichten kritischen Stromdichten erklären könnte. Eine Aufstellung der Ergebnisse der Abscheidung supraleitender Filme auf MOD-Pufferschichten findet sich in untenstehender Tabelle (nicht berücksichtigt sind Veröffentlichungen ohne Angabe der erreichten Stromdichte des auf den MOD-Puffern deponierten YBCO).

Ein gängiges Verfahren zur Abscheidung eines MOD-Puffers auf einem Substrat mit Gitterfehlpassung ist es, vor der eigentlichen MOD-Schicht eine Keimschicht des Schichtmaterials aufzubringen, auf der dann ein homoepitaktisches Wachstum des Pufferschichtmaterials möglich wird. Solche Keimschichten werden mit gepulster Laserdeposition [148, 89 oder auch mit MOD/Sol-Gel [14, 39] aufgebracht. Bei den mit gepulster Laserdeposition hergestellten epitaktischen Keimschichten wird die Fehlpassung zwischen Schicht und Substrat reduziert, da die Verspannung der epitaktischen Keimschicht mit der Keimschichtdicke sinkt. Das verbesserte epitaktische Wachstum bei den MOD-Keimschichten kann im Rah- 
men des obigen Modells verstanden werden (Absch. 7.2.3): durch die Interdiffusion zwischen Schicht und Substrat wird in der Keimschicht die Gitterfehlpassung herabgesetzt, wodurch das epitaktische Anwachsen an den Keimen erleichtert wird.

Häufig in der Literatur untersucht wird das Wachstum von MOD/Sol-Gel-Schichten auf einkristallinen Substraten oder amorphen Unterlagen. Es finden sich wenige Untersuchungen zum Einfluß der Rauhigkeit auf die Wachstumsbedingungen einer epitaktischen MOD-Schicht. Einflüsse der Oberflächenbeschaffenheit auf das Wachstum werden summarisch einer Nukleations- oder Oberflächenbarriere zugeschrieben [148, 88]. Vergleichbar hohe Auslagerungstemperaturen wie in dieser Arbeit werden bei $\mathrm{La}_{2} \mathrm{Zr}_{2} \mathrm{O}_{7}$ auf RABiTSBändern beobachtet, jedoch ohne detailiert auf die Rolle der Oberflächenbeschaffenheit einzugehen [149]. Eine Untersuchung des Wachstums von MOD-Schichten auf IBAD-YSZ fehlte bislang.

\begin{tabular}{|c|c|c|c|c|c|}
\hline Puffer & Substrat & $\begin{array}{l}\mathrm{j}_{c} \\
{\left[\mathrm{MA} / \mathrm{cm}^{2}[77 \mathrm{~K}]\right]}\end{array}$ & $\begin{array}{l}\text { Gesputterte } \\
\text { Zwischenschicht? }\end{array}$ & Kommentar & Quelle \\
\hline $\mathrm{Eu}_{2} \mathrm{O}_{3}$ & $\mathrm{Ni}$ & 1.1 & ja & & [74, 69 \\
\hline $\mathrm{NiGd}_{2} \mathrm{O}_{3}$ & $\mathrm{Ni}$ & 1.2 & ja & & 1149 \\
\hline $\mathrm{La}_{2} \mathrm{Zr}_{2} \mathrm{O}_{7}$ & $\mathrm{Ni}$ & 1.9 & ja & & [149] \\
\hline $\mathrm{Gd}_{2} \mathrm{O}_{3}$ & $\mathrm{Ni}$ & 1.2 & ja & & 72 \\
\hline $\mathrm{La}_{2} \mathrm{Zr}_{2} \mathrm{O}_{7}$ & $\mathrm{Ni}$ & 0.48 & ja & & [76] \\
\hline $\mathrm{Gd}_{2} \mathrm{O}_{3}$ & $\mathrm{Ni}$ & 0.4 & ja & & 73 \\
\hline $\mathrm{La}_{2} \mathrm{Zr}_{2} \mathrm{O}_{7}$ & $\mathrm{Ni}$ & 1.88 & ja & & [77] \\
\hline $\mathrm{CeO}_{2}$ & $\mathrm{Ni}$ & 1.5 & ja & & 150 \\
\hline $\mathrm{NdGaO}_{3}$ & $\mathrm{SrTiO}_{3}(001)$ & 1 & & & 111 \\
\hline $\mathrm{Eu}_{2} \mathrm{O}_{3} / \mathrm{CeO}_{2}$ & $\mathrm{Ni}$ & 0.2 & & Multilayer & 6 \\
\hline YSZ & $\mathrm{Ni}$ & $0.016[4 \mathrm{~K}]$ & & untexturiert & 1113 \\
\hline $\mathrm{Gd}_{2} \mathrm{O}_{3}$ & $\mathrm{Ni}$ & $0.1[4 \mathrm{~K}]$ & & & [151] \\
\hline $\mathrm{LaAlO}_{3}$ & $\mathrm{SrTiO}_{3}(001)$ & 2.2 & & & 36 \\
\hline $\mathrm{BaZrO}_{3}$ & $\mathrm{SrTiO}_{3}(001)$ & 0.005 & & & 152 \\
\hline $\mathrm{SrTiO}_{3}$ & $\mathrm{LaAlO}_{3}(001)$ & 0.1 & & & 153 \\
\hline $\mathrm{BaZrO}_{3}$ & $\mathrm{SrTiO}_{3}(001)$ & 0.01 & & & 154 \\
\hline $\mathrm{SrTiO}_{3}$ & $\mathrm{LaAlO}_{3}(001)$ & 0.1 & & & 154 \\
\hline YSZ & YSZ (001) & $20[8 \mathrm{~K}]$ & & & diese Arbeit \\
\hline YSZ & IBAD-YSZ & $12[8 \mathrm{~K}]$ & & & diese Arbeit \\
\hline CGO & YSZ (001) & $11[8 \mathrm{~K}]$ & & & diese Arbeit \\
\hline $\mathrm{BaZrO}_{3}$ & $\mathrm{MgO}(001)$ & 0.49 & & & {$[155$} \\
\hline CGO & $\mathrm{Ni}$ & 0.1 & & & 156 \\
\hline $\mathrm{SrTiO}_{3}$ & $\mathrm{LaAlO}_{3}(001)$ & 0.8 & & & 157 \\
\hline
\end{tabular}




\section{Kapitel 8}

\section{Zusammenfassung}

Im Rahmen dieser Arbeit sollte die Herstellung epitaxiefähiger Puffer als Template für die HTSL-Abscheidung aus $\mathrm{CeO}_{2}$, Gd-dotierten $\mathrm{CeO}_{2}$ (CGO) und YSZ mittels metallorgnischer Deposition untersucht werden. Als Substratmaterialien wurden YSZ-(001)-Einkristalle als Beispiel für eine ideale Oberfläche und IBAD-YSZ-Schichten als repräsentativ für technische Oberflächen untersucht. Dabei kam der Betrachtung des Einflusses der Auslagerungsbedingungen auf die einzelnen Phasen der Pufferbildung besondere Bedeutung zu. Darüber hinaus wurden die Veränderungen der Wachstumsbedingungen von $\mathrm{CeO}_{2}$ bzw. Gd-dotierten $\mathrm{CeO}_{2}$ (CGO) beim Übergang von glatten einkristallinen Substraten auf die rauheren, polykristallinen und biaxial texturierten IBAD-YSZ-Substrate untersucht. Gegenstand der vorliegenden Arbeit war die Untersuchung der Mechanismen des Wachstumsprozesses und die Optimierung der Schichten hinsichtlich Textur und Oberflächenqualität.

Die Schichten wurden mit Metallorganischer Deposition (MOD) hergestellt. Als geeignete Precursoren wurden stöchiometrische Mischungen von Ce-, Gd-, Y- und Zr-Acetylacetonaten in einem Essigsäure/iso-Propanol-Gemisch bzw. Gd- und Ce-2-Ethylhexanoate in Toluol bestimmt. Das thermische Zersetzungsverhalten wurde mit Thermogravimetrie und Infrarotspektroskopie untersucht: nach dem Verdunsten des Lösungsmittels findet eine stufenweise Zersetzung des Precursormoleküls statt, die bei $500-700^{\circ} \mathrm{C}$ bis auf einige Reste von Cerkarbonat im Falle des $\mathrm{CeO}_{2}$ abgeschlossen ist. Die Precursoren wurden durch Spincoating auf die verschiedenen Substrate wie YSZ-Einkristalle verschiedener Rauhigkeit und IBAD-YSZ-Substrate verschiedener in-plane Textur aufgebracht.

Als erstes wurden $\mathrm{CeO}_{2}$ und CGO-Schichten auf YSZ-Einkristallen untersucht, um das Wachstum auf ungestörten, weitgehend defektfreien Oberflächen zu charakterisieren. Die auf YSZ-Einkristallen abgeschiedenen $\mathrm{CeO}_{2}$ und CGO-Schichten weisen nach Optimierung der Parameter der Temperaturrampe in einer $\mathrm{Ar} / \mathrm{H}_{2}$-Atmosphäre bei $725-850^{\circ} \mathrm{C}$ eine glatte Oberfläche mit rms-Rauhigkeiten von 1-2 nm auf. Die Texturbildung wurde mit Röntgentexturanalyse untersucht. Dazu wurde in $\theta / 2 \theta$-Messungen die Auslagerungstemperatur so lange variiert, bis nur noch der ein (100)-Wachstum des $\mathrm{CeO}_{2}$ anzeigende (200)-Reflex 
in den Diffraktogrammen auftrat. Dies war bei $775-790^{\circ} \mathrm{C}$ erreicht. Die so hergestellten Schichten weisen eine biaxiale Textur auf, mit Halbwertsbreiten in $\Phi$-Scans von $0.8^{\circ}$ und $0.4^{\circ}$ in Rockingkurven.

Allerdings konnte auf diesen Proben kein epitaktischer YBCO-Film abgeschieden werden. RHEED-Messungen zeigten eine gestörte, untexturierte Oberflächenschicht, deren Dicke zu 10-15 nm abgeschätzt wurde indem durch Ionenbeschuss die Oberfläche bis zum Auftreten von Reflexen abgetragen wurde. Durch einen weiteren Auslagerungsschritt an Luft bei $1200-1300^{\circ} \mathrm{C}$ mit einer Rampe von $5 \mathrm{~K} / \mathrm{min}$ gelang es dann, das epitaktische Wachstum der MOD-CGO-Schicht bis an die Oberfläche der Probe fortzusetzen. Auf diesen Schichten wurden epitaktische YBCO-Filme mit Stromdichten von $1.1 \cdot 10^{11} \mathrm{~A} / \mathrm{m}^{2}(8 \mathrm{~K})$ abgeschieden, was die hohe Qualität dieser Puffer demonstriert.

IBAD-YSZ-Schichten sind polykristallin mit Korngrößen im Bereich von $100 \mathrm{~nm}-1 \mu \mathrm{m}$. Sie weisen eine Texturverbreiterung im Vergleich zu den Einkristallen auf. Aufgrund des Ionenbeschusses durch den assistierenden Ionenstrahl während der Schichtherstellung tritt eine Rauhigkeit von ca. $10 \mathrm{~nm}$ auf. Der Einfluss der zusätzlichen Substratdefekte und -charakteristika auf das Wachstum wurde untersucht:

- Mit steigender Rauhigkeit verschieben sich die optimalen Wachstumstemperaturen, die mit Röntgenmessungen in $\theta / 2 \theta$-Geometrie bestimmt wurden, zu höheren Werten $\left(870-900^{\circ} \mathrm{C}\right.$ für eine rms-Rauhigkeit von $\left.1.5 \mathrm{~nm}\right)$. Dieses Verhalten wird durch das Einbringen von zusätzlicher Porosität an der Grenzfläche Substrat-Schicht auf den rauhen Substraten im Vergleich zu den glatten Einkristallen erklärt. Diese Porosität behindert das epitaktische Schichtwachstum und dient darüberhinaus als Keimbildungszentrum für polykristallines Kornwachstum in der Deckschicht. Die Epi-Front benötigt dadurch zur Ausdehnung in das polykristalline Gefüge zusätzliche Energie, also höhere Temperaturen.

- Zur Untersuchung des Einflusses der Substrattextur auf die Auslagerungsparameter wurden MOD-CGO-Schichten auf IBAD-YSZ-Substrate mit verschiedenen Halbwertsbreiten deponiert. Die optimalen Auslagerungsparameter lagen weitestgehend unabhängig von der Substrattextur bei $900^{\circ} \mathrm{C}$. Offenbar ist hier die Rauhigkeit des Substrates und nicht die Textur desselbigen bestimmend für die optimale Wachstumstemperatur.

Das Wachstum und die Texturbildung der $\mathrm{MOD}-\mathrm{CeO}_{2}$-Schichten wurde auch in-situ mit Synchrotronstrahlung untersucht. Diese Experimente zeigen die Bildung von polykristallinem $\mathrm{CeO}_{2}$ nach dem Zerfall des Precursors bei $500^{\circ} \mathrm{C}$. Bei weiterem Erhöhen der Auslagerungstemperatur wächst der Anteil der (100)-orientierten Körner auf Kosten der (111)Körner an.

Als homoepitaktisches System wurde das Wachstum von MOD-YSZ-Schichten auf YSZ(001)-Einkristallen und IBAD-YSZ-Substraten untersucht. Die optimalen Auslagerungstemperaturen liegen hier im Bereich $950-1100^{\circ} \mathrm{C}$. Auf den sehr glatten Schichten konnten YBCO-Filme mit Stromdichten von bis zu $2 \cdot 10^{11} \mathrm{~A} / \mathrm{m}^{2}(8 \mathrm{~K})$ abgeschieden werden. 
Aus diesen Experimenten wurde folgendes Wachstumsmodell abgeleitet: Nach der Zersetzung des Precursors liegt ein polykristallines Gefüge vor. Bei weiterer Auslagerung findet sowohl ein epitaktisches Ankeimen an der Substratoberfläche als auch eine Kornvergrößerung im polykristallinen Precursorgefüge statt. Als treibende Energie für die Rekristallisation des Precursorgefüges wird die durch die große Dichte an Korngrenzen erhöhte Energiedichte des Precursorgefüges angenommen. Die zusätzliche Energiedichte, die durch das Aufwachsen der epitaktischen Keimschicht und die Rekristallisation in der Deckschicht abgebaut wird wurde zu $240 \mathrm{MJ} / \mathrm{m}^{3}$ für eine Korngröße von $10 \mathrm{~nm}$ abgeschätzt.

Die unterschiedliche Kinetik dieser Prozesse bestimmt das Schichtwachstum und somit die erforderlichen Herstellungsparameter. Bei nicht perfekten Substratoberflächen beeinflussen zusätzlich auch die Substratparameter das Wachstumsverhalten:

- Auf rauhen Substraten tritt an der Grenzfläche Substrat-Schicht im Vergleich zum glatten Einkristall verstärkt Porosität auf. Diese behindert das Wachstum der epitaktischen Schicht und dient als Keimbildungszentrum für das polykristalline Kornwachstum im Precursorgefüge. Die treibende Kraft für das epitaktische Wachstum wird dadurch verringert. Die Epi-Front benötigt dadurch zur Ausdehnung in das polykristalline Gefüge zusätzliche Energie, also höhere Temperaturen.

- Die Texturverbreiterung des Substrates führt nicht zu einer maßgeblichen Beeinflussung des Wachstums. Dies kann im Rahmen des hier verwendeten Modells verstanden werden, wenn man den Einfluss der Korngrenzenergie auf die Energiedichte des IBAD-YSZ abschätzt: dies wird durch eine Abschätzung des Energieinhaltes der Korngrenzen im IBAD-YSZ im Vergleich zu der des polykristallinen Gefüges bestätigt. Die mittlere Korngrenzenergiedichte liegt im IBAD-YSZ bei ca. $2 \mathrm{MJ} / \mathrm{m}^{3}$ ( $15^{\circ}$ Halbwertsbreite in $\Phi$-Scans), was im wesentlichen durch die kolumnare Struktur des IBAD-YSZ bedingt ist. Die Korngrenzenergiedichte im IBAD-YSZ liegt somit um zwei Größenordnungen niedriger als die Korngrenzenenergiedichte eines polykristallinen YSZ-Gefüges mit einer für MOD typischen Korngröße von $10 \mathrm{~nm}$. Der Unterschied der Korngrenzenergie, und damit der treibenden Kraft und der Kinetik, zwischen IBAD-YSZ und YSZ-Einkristallen ist somit relativ zum polykristallinen Gefüge vernächlässigbar klein.

- Epitaktisches Schichtwachstum bei Systemen mit einer Gitterfehlpassung zwischen Schicht und Substrat erfolgt im Anfangsstadium i.d.R. über die Bildung einer verspannten Schicht. Übersteigt die Verspannungsenergiedichte dieser Keimschicht die Korngrenzenergiedichte im polykristallinen Precursormaterial, so geht die treibende Kraft für das Wachstum verloren. Hier kann das Schichtwachstum aufgehalten werden, bis die Interdiffusion zwischen Schicht- und Substratmaterial die effektive Gitterfehlpassung an der Wachstumsfront herabsetzt und so ein weiteres epitaktisches Wachsen ermöglicht.

- Enthält das Precursorgefüge eine intermediäre Phase (wie Spuren des Cerkarbonates im Falle des CGO), so muß für das Wachstum der gewünschten Struktur erst 
diese Phase zersetzt werden. Dieser Zersetzungsprozess kann durch oxidierende bzw. reduzierende Gase modifiziert werden.

Durch die Untersuchung des Einflusses von Substrattextur, -rauhigkeit sowie der Atmosphäre auf die Wachstumsbedingungen von metallorganisch hergestellten $\mathrm{CeO}_{2}, \mathrm{CGO}$ und YSZ-Schichten gelang es, hochepitaktische Schichten dieser Materialien herzustellen, die als texturvermittelnde Puffer für den Hochtemperatursupraleiter YBCO geeignet sind. Diese Eignung zeigt sich in der hohen kritischen Stromdichte von bis zu $2 \cdot 10^{11} \mathrm{~A} / \mathrm{m}^{2}(8 \mathrm{~K})$, die in supraleitenden Filmen auf diesen Pufferschichten erreicht wurden und die bisher höchsten erreichten Stromdichten auf MOD-Puffern darstellen.

Für technische Anwendungen auf metallischen Substraten sind die in dieser Arbeit vorgestellten Verfahren aufgrund der hohen Auslagerungstemperaturen jedoch nur beschränkt geeignet. Im Falle des IBAD-YSZ auf Stahlbändern bewirken die Spannungen, die während der Herstellung eingebaut werden, bei Temperaturen größer als $1000^{\circ} \mathrm{C}$ eine Verformung des Substrates und ein Abplatzen der IBAD-YSZ-Schicht. 


\section{Literaturverzeichnis}

[1] Kammerlingh-Onnes, H. Leiden Comm. 120 b. 1911

[2] Bednorz, J. G. ; Müller, K. A.: Possible High $T_{c}$ Superconductivity in the Ba-La-Cu-O System. In: Z. Phys. B-Condensed Matter 64 (1986), S. 189-193

[3] Wu, M. K. ; Ashburn, J. R. ; Torng, C. J. ; Hor, P. H. ; Meng, R. L. ; GaO, L. ; Hunng, Z. J. ; Wang, Y. Q. ; Chu, C. W.: Superconductivity at $93 \mathrm{~K}$ in a Mixed-Phase Y-Ba-Cu-O Compound System at Ambient Pressure. In: Phys. Rev. Lett. 58 (1987), S. 908-910

[4] Hilgenkamp, H. ; Mannhart, J.: Grain boundaries in high- $\mathrm{T}_{c}$ superconductors. In: Rev. Mod. Phys. 74 (2002), S. 485-549

[5] Goyal, A. ; Norton, D. P. ; Budai, J. D. ; Paranthaman, M. ; Specht, E. D. ; Kroeger, D. M. ; Christen, D. K. ; He, Q. ; Saffian, B. ; List, F. A. ; Lee, D. F. ; Martin, P. M. ; Klabunde, C. E. ; Hartfield, E. ; Sikka, V. K.: High critical current density superconducting tapes by epitaxial deposition of $\mathrm{YBa}_{2} \mathrm{Cu}_{3} \mathrm{O}_{x}$ thick films on biaxially textured metals. In: Appl. Phys. Lett. 69 (1996), S. 1795-1797

[6] Iijima, Y. ; Tanabe, N. ; Kohno, O. ; Ikeno, Y.: In-plane aligned $\mathrm{YBa}_{2} \mathrm{Cu}_{3} \mathrm{O}_{7-x}$ thin films deposited on polycrystalline metallic substrates. In: Appl. Phys. Lett. 60 (1992), S. 769-771

[7] DzIck, J.: Mechanismen der ionenstrahlunterstützten Texturbildung in Yttriumstabilisierten Zirkondioxid-Filmen, Universität Göttingen, Diss., 2000

[8] Thiele, Ch. Vergleich der ionenstrahl-unterstützten Filmdeposition von Yttriumstabilisiertem Zirkondioxid und Gadolinium-Zirkonat, Diplomarbeit. 2003

[9] Thiele, K. ; Sievers, S. ; Jooss, C. ; Hoffmann, J. ; Freyhardt, H. C.: Room-temperature preparation of biaxially textured indium tin oxide thin films with ion-beam-assisted deposition. In: J. Mat. Res. 18 (2003), S. 442-447

[10] Issajev, A. Zentrum für Funktionswerkstoffe gGmbH Göttingen, Persönliche Mitteilung. 2003 
[11] Paranthaman, M. ; Shoup, S. S. ; Beach, D. B. ; Morrell, J. S. ; Goyal, A. ; Specht, E. D. ; Mathis, J. E. ; Verebelyi, D. T. ; Christen, D. K.: Growth of textured buffer layers and superconductors on rolled-Ni substrates using sol-gel alkoxide precursors. In: 9th Cimtec-World-Forum on New Materials, 1999, S. 185192

[12] Paranthaman, M. ; Lee, D. F. ; Goyal, A. ; Specht, E. D. ; Martin, P. M. ; Cui, X. ; Mathis, J. E. ; Feenstra, R. ; Christen, D. K. ; Kroeger, D. M.: Growth of biaxially textured $\mathrm{RE}_{2} \mathrm{O}_{3}$ buffer layers on rolled-Ni substrates using reactive evaporation for HTS-coated conductors. In: Supercond. Sci. Technol. 12 (1999), S. $319-325$

[13] Miller, K. T. ; Chan, C-J. ; Cain, M. G. ; Lange, F. F.: Epitaxial zirconia thin films from aqueous precursors. In: J. Mater. Res. 8 (1993), S. 169-177

[14] Miller, K. T. ; Lange, F. F.: Highly oriented thin films of cubic zirconia on sapphire through grain growth seeding. In: J. Mater. Res. 6 (1991), S. 2387-2392

[15] Mantese, J. V. ; Micheli, A. L. ; Hamdi, A. H. ; Vest, R. W.: Metalorganic Deposition (MOD): A Nonvacuum, Spin-on, Liquid-Based, Thin Film Method. In: MRS Bull. XIV 48 (1989), S. 48-53

[16] Caulton, K. G. ; Hubert-Pfalzgraf, L. G.: Synthesis, Structural Principles, and Reactivity of Heterometallic Alkoxides. In: Chem. Rev. 90 (1990), S. 969-995

[17] Hubert-Pfalzgraf, L. G. ; Poncelet, O. ; Sirio, C. ; Daran, J. C.: Tailoring Metal Alkoxides Using Functional Alcohols: Some Examples in Yttrium, Copper, and Main-Group Chemistry (Bismuth, Barium). In: Chemical Processing of Advanced Materials (1992), S. 277-284

[18] Ribot, F. ; Sanchez, C. ; Livage, J.: Tailoring of Cerium(IV) Oxide Precursors Through Modification of Cerium(IV) Isopropoxides with beta-Diketonates. In: Chemical Processing of Advanced Materials, John Wiley and Sons Inc. (1992), S. $267-275$

[19] Hubert-Pfalzgraf, L. G.: Heterometallic Alkoxides and Oxoalkoxides as Intermediates in Chemical Routes to Mixed Metal Oxides. In: Polyhedron. 13 (1994), S. $1181-1195$

[20] Bradley, D. C. ; Mehrotra, R. C. ; Gaur, D. P.: Metal Alkoxides. Academic Press, 1978

[21] Scriven, L. E.: Physics and Applications of Dip Coating and Spin Coating. In: MRS Symp. Proc. 121 (1988), S. 717-729

[22] Brinker, C. J. ; Hurd, A. J. ; Ward, K. J.: Fundamentals of Sol-Gel Thin-Film Formations. In: Ultrastructure Processing of Advanced Ceramics, 1988, S. 223-240 
[23] Brinker, C. J. ; Scherer, G. W.: Sol-Gel Science. Academic Press, 1990

[24] Matijevic, E.: Production of Monodispersed Colloidal Particles. In: Ann. Rev. Mater. Sci. 15 (1985), S. 483-516

[25] Mantese, J. V. ; Catalan, A. B. ; Hamdi, A. H. ; Micheli, A. L.: Use of ion beams to decompose metalorganics into patterned thin-film superconductors. In: Appl. Phys. Lett. 52 (1988), S. 1741

[26] Mantese, J. V. ; Catalan, A. B. ; Hamdi, A. H. ; Micheli, A. L. ; StuderRABELER, K.: Use of electron beam lithography to selectively decompose metalorganics into patterned thin-film superconductors. In: Appl. Phys. Lett. 53 (1988), S. 526

[27] Mantese, J. V. ; Catalan, A. B. ; Mance, A. M. ; Hamdi, A. H. ; Micheli, A. L. ; Sell, J. A. ; Meyer, M. S.: Selective laser pyrolysis of metalorganics as a method of forming patterned thin-film superconductors. In: Appl. Phys. Lett. 53 (1988), S. 1335

[28] Wakagi, M. ; Chahara, K. ; Onisawa, K. ; Kawakubo, Y. ; Kichikawa, T. ; Satoh, T. ; Minemura, T.: Rapid heat treatment for spin coated ITO films by electron plasma annealing method. In: Thin Solid Films 411 (2002), S. 46-49

[29] Liu, W.-C. ; Wu, D. ; Li, A.-D. ; Ling, H.-Q. ; Tang, Y.-F. ; Ming, N.-B.: Annealing and doping effects on structure and optical properties of sol-gel derived $\mathrm{ZrO}_{2}$ thin films. In: Appl. Surf. Science 191 (2002), S. 181-187

[30] He, Q. ; Christen, D. K. ; Klabunde, C. E. ; Thaczyk, J. E. ; Lay, K. W. ; Paranthaman, M. ; Thompson, J. R. ; Goyal, A. ; Pedraza, A. J. ; Kroeger, D. M.: High-current superconducting $\mathrm{TlBa}_{2} \mathrm{Ca}_{2} \mathrm{Cu}_{3} \mathrm{O}_{y}$ thick films on polycrystalline Ag by spin coating. In: Appl. Phys. Lett. 67 (1995), S. 294-296

[31] Fabes, B. D. ; Doyle, W. F. ; Silverman, L. S. ; Zelinski, B. J. J. ; Uhlmann, D. R.: Stronger Glass via Sol-Gel Coatings. In: 2nd Int. Conf. on Ultra-Structure Processing of Ceramics, Glasses and Composites, 1986, S. 217-223

[32] Turner, C. W. ; Franklin, K. J.: Multinuclear $\left({ }^{1} \mathrm{H},{ }^{29} \mathrm{Si},{ }^{17} \mathrm{O}\right)$ NMR Study of the Hydrolysis and Condensation of Tetraethylorthosilicate (TEOS). In: 2nd Int. Conf. on Ultra-Structure Processing of Ceramics, Glasses and Composites, 1986, S. 81-86

[33] Aegerter, M. A.: Sol-Gel Chromogenic Materials and Devices. In: Structure and Bonding 85 (1996), S. 149-194

[34] Joshi, P. C. ; Krupanidhi, S. B.: Strontium titanate thin films by rapid thermal processing. In: Appl. Phys. Lett. 61 (1992), S. 1525-1527 
[35] Talin, A. A. ; Smith, S. M. ; Voight, S. ; Finder, J. ; Eisenbeiser, K. ; Penunuri, D. ; Yu, Z. ; Fejes, P. ; Eschrich, T. ; Curless, J. ; Convey, D. ; Hooper, A.: Epitaxial PbZr ${ }_{.52} \mathrm{Ti}_{.48} \mathrm{O}_{3}$ films on $\mathrm{SrTiO}_{3} /(001) \mathrm{Si}$ substrates deposited by sol-gel method. In: Appl. Phys. Lett. 81 (2002), S. 1062-1064

[36] Rupich, M. W. ; Palm, W. ; Zhang, W. ; Siegal, E. ; Annavarapu, S. ; FritZemeier, L. ; Teplitsky, M. D. ; Thieme, C. ; Paranthaman, M.: Growth and Characterization of Oxide Buffer Layers for YBCO Coated Conductors. In: IEEE Transactions on Applied Superconductivity 9 (1999), S. 1527-1530

[37] Schwartz, R. W. ; Clem, P. G. ; Voigt, J. A. ; Byhoff, E. R. ; Stry, M. V. ; Headley, T. J. ; Missert, N. A.: Control of Microstructure and Orientation in Solution-Deposited $\mathrm{BaTiO}_{3}$ and $\mathrm{SrTiO}_{3}$ Thin Films. In: J. Am. Ceram. Soc. 82 (1999), S. 2359-2367

[38] Ueno, K. ; Sakamoto, W. ; Yogo, T. ; Hirano, S.: Processing of Novel Strontium Titanate-Based Thin-Film Varistors by Chemical Solution Deposition. In: J. Am. Ceram. Soc. 86 (2003), S. 99-104

[39] Dawley, J. T. ; Ong, R. J. ; Clem, P. G.: Chemical solution deposition of (100)oriented $\mathrm{SrTiO}_{3}$ buffer layers on Ni substrates. In: J. Mat. Res. 17 (2002), S. $1678-1685$

[40] Yamagiwa, K. ; Matsumoto, M. ; Hirabayashi, I.: Solid-phase epitaxial growth of oxide buffer materials for $\mathrm{RBa}_{2} \mathrm{Cu}_{3} \mathrm{O}_{7-y}$ ( $\mathrm{R}$ : rare earth and $\mathrm{Y}$ ) superconductor. In: J. Mater. Res. 15 (2000), S. 2547-2557

[41] Tsai, K. Y. Chen L. L. Lee D. S.: Barium and strontium titanate films from hydroxide-alkoxide precursors. In: J. Mater. Sci. Lett. 10 (1991), S. 1000-1002

[42] Hasenkox, U. ; Hoffmann, S. ; Waser, R.: Influence of Precursor Chemistry on the Formation of $\mathrm{MTiO}_{3}(\mathrm{M}=\mathrm{Ba}, \mathrm{Sr})$ Ceramic Thin Films. In: J. Sol-Gel Sci. Techn. 12 (1998), S. 67-79

[43] Sathyamurthy, S. ; Salama, K.: Chemical solution deposition of highly oriented strontium titanate buffer layers for coated conductors. In: Supercond. Sci. Technol. 13 (2000), S. L1-L3

[44] Kamalasanan, M. N. ; Chandra, S. ; Joshy, P. C. ; Mansingh, A.: Structural and optical properties of sol-gel-processed $\mathrm{BaTiO}_{3}$ ferroelectric thin films. In: Appl. Phys. Lett. 59 (1991), S. 3547-3549

[45] Frey, M. H. ; PAyne, D. A.: Nanocrystalline barium titanate: Evidence for the absence of ferroelectricity in sol-gel derived thin-layer capacitors. In: Appl. Phys. Lett. 63 (1993), S. 2753-2755 
[46] Tuchiya, T. ; Kawano, T. ; Sei, T. ; Hatano, J.: Preparation of Ferroelectric $\mathrm{BaTiO}_{3}$ Films by Sol-Gel Process and Dielectric Properties. In: J. Ceram. Soc. Jpn. 98 (1990), S. 743-748

[47] Bendersky, L. A. ; Lu, C. J. ; Scott, J. H. ; Chang, K. ; Takeuchi, I.: Microstructure and microstructural evolution in $\mathrm{BaTiO}_{3}$ films fabricated using the precursor method. In: J. Mat. Res. 10 (2002), S. 2499-2506

[48] Celik, E. ; Schwartz, J. ; Avci, E. ; Schneider-Muntau, H. J. ; HasciceK, Y. S.: $\mathrm{CeO}_{2}$ Buffer Layers for YBCO: Growth and Processing via Sol-Gel Technique. In: IEEE Transactions on applied superconductivity 9 (1999), S. 2264-2267

[49] Manabe, T. ; Yamaguchi, I. ; Tsuchiya, T. ; Kondo, W. ; Mizuta, S. ; KumaGAI, T.: Preparation of Epitaxial $\mathrm{YBa}_{2} \mathrm{Cu}_{3} \mathrm{O}_{7-y} / \mathrm{CeO}_{2}$ Multilayer Films on Yttriastabilized Zirconia (100) by All-Coating-Pyrolysis Process. In: Jpn. J. Appl. Phys. 40 (2001), S. 4866-4869

[50] ÖzER, N.: Optical properties and electrochromic characterization of sol-gel deposited ceria films. In: Solar Energy Materials 85 Solar Cells 68 (2001), S. 391-400

[51] Stangar, U. L. ; Orel, B. ; Grabec, I. ; Ogorevc, B. ; Kalcher, K.: Optical and electrochemical properties of $\mathrm{CeO}_{2}$ and $\mathrm{CeO}_{2}-\mathrm{TiO}_{2}$ coatings. In: Solar Energy Materials $\&$ Solar Cells 31 (1993), S. 171-185

[52] Hascicek, Y. S. ; Mutlu, I. H. ; Celik, E. ; Okuyucu, H. ; Akin, Y. ; ElKawni, M. I. ; Aslanoglu, Z. ; Sigmund, W.: Non-Vacuum coated conductor development at NHFML. In: The 2001 international workshop on superconductivity co-sponsored by ISTEC and MRS, 2001, S. 122

[53] Hiei, H. ; Yamagiwa, K. ; Takahashi, Y. ; Kim, S. B. ; Yamada, Y. ; Shibata, J. ; Hirayama, T. ; Ikuta, H. ; Hirabayashi, I. ; Mizutani, U.: YBCO thin films on multilayers prepared by all-chemical solution deposition processing. In: Physica C 357-360 (2001), S. 942-945

[54] Kosacki, I. ; Suzuki, T. ; Petrovsky, V. ; Anderson, H. U.: Electrical Conductivity of Nanocrystalline Ceria and Zirconia Thin Films. In: Solid State Ionics 136-137 (2000), S. 1225-1233

[55] Kosacki, I. ; Petrovsky, V. ; Anderson, H. U. ; Colomban, P.: Raman Spectroscopy of Nanocrystalline Ceria and Zirconia Thin Films. In: J. Am. Ceram. Soc. 85 (2002), S. 2646-2650

[56] Caruso, R. ; Diaz-Parralejo, A. ; Miranda, P. ; Guiberteau, F.: Controlled preparation and characterization of multilayer sol-gel zirconia dip-coatings. In: $J$. Mater. Res. 16 (2001), S. 2391-2398 
[57] Chu, P.-Y. ; Buchanan, R. C.: Characteristics of oxide thin films from carboxylate precursors. In: J. Mater. Res. 6 (1991), S. 1736-1743

[58] Shane, M. ; Mecartney, M. L.: Sol-gel synthesis of zirconia barrier coatings. In: J. Mater. Sci. 25 (1990), S. 1537-1544

[59] Peshev, P. ; Slavova, V.: Preparation of Yttria-Stabilized Zirconia Thin Films by a Sol-Gel Procedure Using Alkoxide Precursors. In: Mater. Res. Bulletin 27 (1992), S. $1269-1275$

[60] Languahr, P. A. ; Lange, F. F. ; Wagner, T. ; Rühle, M.: Lattice Mismatch Accomodation in Perovskite Films on Perovskite Substrates. In: Acta Materialia 46 (1998), S. 773-785

[61] Shoup, S. S. ; Paranthaman, M. ; Beach, D. B. ; Specht, E. D. ; Williams, R. K.: Sol-gel synthesis of $\mathrm{LaAlO}_{3}$; Epitaxial growth of $\mathrm{LaAlO}_{3}$ thin films on $\mathrm{SrTiO}_{3}$ (100). In: J. Mater. Res. 12 (1997), S. 1017-1021

[62] Gust, M. C. ; Momoda, L. A. ; Evans, N. D. ; Mecartney, M. L.: Crystallization of Sol-Gel-Derived Barium Strontium Titanate Thin Films. In: J. Am. Ceram. Soc. 84 (2001), S. 1087-1092

[63] Cheng, J.-G. ; Tang, J. ; Meng, X.-J. ; Guo, S.-L. ; Chu, J.-H. ; Wang, M. ; Wang, H. ; WAng, Z.: Fabrication and Characterization of Pyroelectric $\mathrm{Ba}_{0.8} \mathrm{Sr}_{0.2} \mathrm{TiO}_{3}$ Thin Films by a Sol-Gel Process. In: J. Am. Ceram. Soc. 84 (2001), S. $1421-1424$

[64] Yang, C.-Y. ; Ichinose, A. ; Babcock, S. E. ; Morrell, J. S. ; Mathis, J. E. ; Verebelyi, D. T. ; Paranthaman, M. ; Beach, D. B. ; Christen, D. K.: Microstructure of a high $\mathrm{J}_{c}$, laser-ablated $\mathrm{YBa}_{2} \mathrm{Cu}_{3} \mathrm{O}_{7-\delta}$ /sol-gel deposited $\mathrm{NdGaO}_{3}$ buffer layer/(001) $\mathrm{SrTiO}_{3}$ multi-layer structure. In: Physica $C 331$ (2000), S. 73-78

[65] Aytug, T. ; Paranthaman, M. ; Kang, B. W. ; Sathyamurthy, S. ; Goyal, A. ; Christen, D. K.: $\mathrm{La}_{0.7} \mathrm{Sr}_{0.3} \mathrm{MnO}_{3}$ : A single, conductive-oxide buffer layer for the development of $\mathrm{YBa}_{2} \mathrm{Cu}_{3} \mathrm{O}_{7-d}$ coated conductors. In: Appl. Phys. Lett. 79 (2001), S. 2205-2207

[66] Modak, A. R. ; Krishnan, K. M.: Epitaxy and Magnetotransport Properties of $\mathrm{La}_{0.8} \mathrm{Sr}_{0.2} \mathrm{MnO}_{3}$ Films Synthesized by both Pulsed Laser Deposition and Novel Chemical Routes. In: MRS Symp. Proc. 401 (1996), S. 443-448

[67] Tsunashima, A. ; Asai, T. ; Kodaira, K. ; Matsushita, T.: Preparation of TinDoped Indium Oxide Thin Films by Thermal Decomposition of Metal Octanoates. In: Chem. Lett. (1978), S. 855-856

[68] Arfsten, N. J.: Sol-Gel Derived Transparent IR-Reflecting ITO Semiconductor Coatings and Future Applications. In: J. Non-Cryst. Solids 63 (1984), S. 243-249 
[69] Paranthaman, M. ; Chirayil, T. G. ; Sathyamurthy, S. ; Beach, D. B. ; Goyal, A. ; List, F. A. ; Lee, D. F. ; Cui, X. ; Lu, S. W. ; Kang, B. ; Specht, E. D. ; Martin, P. M. ; Kroeger, D. M. ; Feenstra, R. ; Cantoni, C. ; ChriSTEn, D. K.: Fabrication of Long Lengths of YBCO Coated Conductors using a Continuous Reel-to-Reel Dip-Coating Unit. In: IEEE Trans. Appl. Supercond. 11 (2001), S. 3146-3149

[70] Okuyucu, H. ; Celik, E. ; Ramazanoglu, M. K. ; Akin, Y. ; Mutlu, I. H. ; Sigmund, W. ; Crow, J. E. ; Hascicek, Y. S.: Textured Buffer Layers for YBCO Coated Conductors by Continuous Sol-Gel Processing. In: IEEE Trans. Appl. Supercond. 11 (2001), S. 2889-2892

[71] Celik, E. ; Okuyucu, H.; Mutlu, I. H. ; Tomsic, M. ; Schwartz, J. ; Hascicek, Y.S.: Textured $\mathrm{La}_{2} \mathrm{Zr}_{2} \mathrm{O}_{7}, \mathrm{Gd}_{2} \mathrm{O}_{3}$, and $\mathrm{Er}_{2} \mathrm{O}_{3}$ Buffer Layers for Long-Length YBCO Coated Conductors by Non-Vacuum Process. In: IEEE Trans. Appl. Supercond. 11 (2001), S. 3162-3165

[72] Aytug, T. ; Paranthaman, M. P. ; Kang, B. W. ; Beach, D. B. ; Sathyamurthy, S. ; Specht, E. D. ; Lee, D. F. ; Feenstra, R. ; Goyal, A. ; Kroeger, D. M. ; Leonard, K. J. ; Martin, P. M. ; Christen, D. K.: Reel-to-Reel Continuous Chemical Solution Deposition of Epitaxial $\mathrm{Gd}_{2} \mathrm{O}_{3}$ Buffer Layers on Biaxially Textured Metal Tapes for the Fabrication of $\mathrm{YBa}_{2} \mathrm{Cu}_{3} \mathrm{O}_{7}$. In: J. Am. Ceram. Soc. 86 (2003), S. 257-265

[73] Morrell, J. S. ; Xue, Z. B. ; Specht, E. D. ; Goyal, A. ; Martin, P. M. ; Lee, D. F. ; Feenstra, R. ; Verebelyi, D. T. ; Christen, D. K. ; Chirayil, T. G. ; Paranthaman, M. ; Vallet, C. E. ; Beach, D. B.: Epitaxial growth of gadolinium oxide on roll-textured nickel using a solution growth technique. In: $J$. Mater. Res. 15 (2000), S. 621-628

[74] Paranthaman, M. ; Chirayil, T. G. ; List, F. A. ; Cui, X. ; Goyal, A. ; Lee, D. F. ; Specht, E. D. ; Martin, P. M. ; Williams, R. K. ; Kroeger, D. M. ; Morrell, J. S. ; Beach, D. B. ; Feenstra, R. ; Christen, D. K.: Fabrication of Long Lengths of Epitaxial Buffer Layers on Biaxially Textured Nickel Substrates Using a Continuous Reel-to-Reel Dip-Coating Unit. In: J. Am. Ceram. Soc. 84 (2001), S. 273-278

[75] Beach, D. B. ; Vallet, C. E. ; Paranthaman, M. ; Specht, E. D. ; Morrell, J. S. ; XuE, Z. B.: Sol-Gel Synthesis of Rare Earth Aluminate Films as Buffer Layers for High $\mathrm{T}_{c}$ Superconducting Films. In: MRS Symp. Proc. 495 (1988), S. 263-270

[76] Chirayil, T. G. ; Paranthaman, M. ; Beach, D. B. ; Lee, D. F. ; Goyal, A. ; Williams, R. K. ; Cui, X. ; Kroeger, D. M. ; Feenstra, R. ; Verebelyi, D. T. ; Christen, D. K.: Epitaxial growth of $\mathrm{La}_{2} \mathrm{Zr}_{2} \mathrm{O}_{7}$ thin films on rolled Ni-substrates 
by sol-gel process for high $\mathrm{T}_{c}$ superconducting tapes. In: Physica $C 336$ (2000), S. 63-69

[77] Sathyamurthy, S. ; Kang, B. W. ; Paranthaman, M. ; Aytug, T. ; Feenstra, R. ; Goyal, A. ; Kroeger, D. M.: Solution Deposition Approaches to conductor fabrication on biaxially textured Ni-W Alloy Substrates. In: The 2001 International Workshop on Superconductivity Co-Sponsored by ISTEC and MRS, 2001, S. 119-121

[78] Li, A.-D. ; Ge, C.-Z. ; Wu, D. ; Lü, P. ; Zuo, Y.-Q. ; YAng, S.-Z. ; Ming, N.-B.: Conductive metallic $\mathrm{LaNiO}_{3}$ films from metallo-organic precursors. In: Thin Solid Films 298 (1997), S. 165-169

[79] Cho, M.-H. ; Ko, D.-H. ; Choi, Y. K. ; Lyo, I. W. ; JeOng, K. ; Whang, C. N.: Epitaxial $\mathrm{Y}_{2} \mathrm{O}_{3}$ film growth on an oxidized Si surface. In: Thin Solid Films 402 (2002), S. 38-42

[80] Yamaguchi, I. ; Manabe, T. ; Sohma, M. ; Tsuchiya, T. ; Yamaguchi, Y. ; Suzuki, S. ; Kumagai, T. ; Mizuta, S.: Preparation of $\mathrm{YBa}_{2} \mathrm{Cu}_{3} \mathrm{O}_{7-x} / \mathrm{EuAlO}_{3}$ multilayer films on alpha- $\mathrm{Al}_{2} \mathrm{O}_{3}$ substrates by all-coating-pyrolysis process. In: $P h y$ sica C 382 (2002), S. 269-275

[81] Mendez-Vivar, J. ; Mendoza-Bandala, A.: Spectroscopic study on the early stages of the polymerization of hybrid TEOS-RSi (OR')3 sols. In: J. Non-Cryst. Solids 261 (2000), S. 127-136

[82] Artaki, I. ; Bradley, M. ; Zerda, T. W. ; Jonas, J. ; Orcel, G. ; Hench, L.L: NMR, Raman Study of the Effect of Formamide on the Sol-Gel Process. In: HenCH (Hrsg.) ; UlRICH (Hrsg.): 2nd Int. Conf. on Ultra-Structure Processing of Ceramics, Glasses and Composites, Wiley-Interscience, New York, 1986, S. 73-80

[83] Assink, R. A. ; KAY, B. D.: Study of Sol-Gel Chemical Reaction Kinetics by NMR. In: Ann. Rev. Mater. Sci. 21 (1991), S. 491-513

[84] Leaustic, A. ; Babonneau, F. ; Livage, J.: Structural Investigation of the Hydrolysis-Condensation Process of Titanium Alkoxides $\mathrm{Ti}(\mathrm{OR})_{4}(\mathrm{OR}=\mathrm{OPri}, \mathrm{OEt})$ Modified by Acetylacetone. 2. From the Modified Precursor to the Colloids. In: Chem. Mater. 1 (1989), S. 248-252

[85] Cachet, H. ; Gamard, A. ; Campet, G. ; Jousseaume, B. ; Toupance, T.: Tin oxide thin films prepared from a new alkoxyfluorotin complex including a covalent Sn-F bond. In: Thin Solid Films 388 (2001), S. 41-49

[86] ChI, F. K.: Carbon-Containing Monolithic Glasses via the Sol-Gel Process. In: Ceram. Eng. \& Sci. Proc. 4 (1983), S. 704-717 
[87] Kamiya, K. ; Yoko, T. ; Sano, T. ; Tanaka, K.: Distribution of Carbon Particles in Carbon $/ \mathrm{SiO}_{2}$ Glass Composites made from $\mathrm{CH}_{3} \mathrm{Si}\left(\mathrm{OC}_{2} \mathrm{H}_{5}\right)_{3}$ by the Sol-Gel Method. In: J. Non-Cryst. Solids 119 (1990), S. 14-20

[88] Braunstein, G. ; Paz-Pujalt, G. R. ; Mason, M. G. ; Blanton, T. ; Barnes, C. L. ; Margevich, D.: The processes of formation and epitaxial alignment of $\mathrm{SrTiO}_{3}$ thin films prepared by metallo-organic decomposition. In: JAP 73 (1993), S. $961-970$

[89] Ishikawa, K. ; Sakura, K. ; Fu, D. S. ; Yamada, S. ; Suzuki, H. ; Hayashi, T.: Effect of PbTiO3 Seeding Layer on the Growth of Sol-Gel-Derived $\mathrm{Pb}\left(\mathrm{Zr}_{0.53} \mathrm{Ti}_{0.47}\right) \mathrm{O}_{3}$ Thin Film. In: Jpn. J. Appl. Phys. 37 (1998), S. 5128-5131

[90] Fuierer, P. ; Li, B.: Nonepitaxial Orientation in Sol-Gel Bismuth Titanate Films. In: J. Am. Ceram. Soc. 85 (2002), S. 299-304

[91] Miyake, S. ; Yamamoto, K. ; Fujihara, S. ; Kimura, T.: (100)-Orientation of Pseudocubic Perovskite-Type $\mathrm{LaNiO}_{3}$ Thin Films on Glass Substrates via the Sol-Gel Process. In: J. Am. Ceram. Soc. 85 (2002), S. 992-994

[92] McIntyre, P. C. ; Cima, M. J.: Heteroepitaxial growth of chemically derived ex situ $\mathrm{Ba}_{2} \mathrm{YCu}_{3} \mathrm{O}_{7-x}$ thin films. In: J. Mater. Res. 9 (1994), S. 2219-2230

[93] Chen, C. ; JR., D. F. R. ; Spurgeon, W. A.: Synthesis and Microstructure of Highly Oriented Lead Titanate Thin Films Prepared by a Sol-Gel Method. In: $J$. Am. Ceram. Soc. 72 (1989), S. 1495-1498

[94] Fu, X. ; LI, J. ; Song, Z. ; Lin, C.: Growth of highly (100)-oriented Zr-rich PZT thin films on $\mathrm{Pt} / \mathrm{Ti} / \mathrm{SiO}_{2} / \mathrm{Si}$ substrates by a simple sol-gel process. In: Journal of Crystal Growth 220 (2000), S. 82-87

[95] Kushida, K. ; Udayakumar, K. R. ; Krupanidhi, S. B. ; Cross, L. E.: Origin of Orientation in Sol-Gel-Derived Lead Titanate Films. In: J. Am. Ceram. Soc. 76 (1993), S. 1345-1348

[96] Nashimoto, K. ; Cima, M. J.: Epitaxial $\mathrm{LiNbO}_{3}$ thin films prepared by a sol-gel process. In: Mater. Lett. 10 (1991), S. 348-354

[97] Kudo, T. ; Obayashi, H.: Oxygen Ion Conduction of the Fluorite-Type $\mathrm{Ce}_{1-x} \operatorname{Ln}_{x} \mathrm{O}_{2-x / 2}(\mathrm{Ln}=$ Lanthanoid Element). In: J. Electrochem. Soc. 122 (1975), S. $142-147$

[98] Horita, T. ; Sakai, N. ; Yokokawa, H. ; Dokiya, M. ; Kawada, T. ; Herle, J. V. ; SASAKI, K.: Ceria-Zirconia Composite Electrolyte for Solid Oxide Fuel Cells. In: J. Electroceram. 1:2 (1997), S. 155-164 
[99] Ghodsi, F. E. ; Tepehan, F. Z. ; Tepehan, G. G.: Optical and electrochromic properties of sol-gel made $\mathrm{CeO}_{2}-\mathrm{TiO}_{2}$ thin films. In: Electrochim. Acta 44 (1999), S. $3127-3136$

[100] Dislich, H. ; Hussmann, E.: Amorphous and Crystalline Dip Coatings Obtained from Organometallic Solutions: Procedures, Chemical Processes and Products. In: Thin Solid Films 77 (1981), S. 129-139

[101] Nakatani, T. ; Okamoto, H. ; Ota, R.: Preparation of $\mathrm{CeO}_{2}-\mathrm{ZrO}_{2}$ Mixed Oxide Powders by the Coprecipitation Method for the Purification Catalysts of Automotive Emission. In: J. Sol-Gel Sci. Technol. 26 (2003), S. 859-863

[102] Sorensen, O. T.: Thermodynamic Studies of the Phase Relationships of Nonstochiometric Cerium Oxides at Higher Temperatures. In: J. Solid State Chem. 18 (1976), S. 217-233

[103] Wu, X. D. ; Dye, R. C. ; Muenchausen, R. E. ; Foltyn, S. R. ; Maleyand, M. ; Rollett, A. D. ; Garcia, A. R. ; Nogar, N. S.: Epitaxial $\mathrm{CeO}_{2}$ films as buffer layers for high-temperature superconducting thin films. In: Appl. Phys. Lett. 58 (1991), S. 2165-2167

[104] Shi, D. Q. ; Ionescu, M. ; Silver, T. M. ; Dou, S. X.: Relationship between epitaxial deposition and growth modes of $\mathrm{CeO}_{2}$ films. In: Physica $C 384$ (2003), S. $475-481$

[105] Maul, M. ; Schulte, B.: Epitaxial $\mathrm{CeO}_{2}$ buffer layers for $\mathrm{YBa}_{2} \mathrm{Cu}_{3} \mathrm{O}_{7-\delta}$ films on sapphire. In: J. Appl. Phys. 74 (1993), S. 2942-2944

[106] Cole, B. F. ; Liang, G.-C. ; Newman, N. ; Char, K. ; Zaharchuk, G. ; MarTENS, J. S.: Large-area $\mathrm{YBa}_{2} \mathrm{Cu}_{3} \mathrm{O}_{7-d}$ thin films on sapphire for microwave applications. In: Appl. Phys. Lett. 61 (1992), S. 1727-1729

[107] Liang, S. ; Chern, C. S. ; Shi, Z. Q. ; Lu, P. ; Kear, B. H.: Control of $\mathrm{CeO}_{2}$ growth by metalorganic chemical vapor deposition with a special source evaporator. In: J. Crystal Growth 151 (1995), S. 359-364

[108] Unuma, H. ; Kanehama, T. ; Yamamoto, K. ; Watanabe, K. ; Ogata, T. ; Sugawara, M.: Preparation of thin films of $\mathrm{MnO}_{2}$ and $\mathrm{CeO}_{2}$ by a modified chemical bath (oxidative-soak-coating) method. In: J. Mat. Sci. 38 (2003), S. 255-259

[109] Mogensen, M. ; Sammes, N. M. ; Tompsett, G. A.: Physical, Chemical and Electrochemical Properties of Pure and Doped Ceria. In: Solid State Ionics 129 (2000), S. 63-94

[110] Celik, E. ; Avci, E. ; Mutlu, H. I. ; HasciceK, Y. S.: Non-Vacuum, Sol-Gel Buffer Layers for YBCO Surface Coated Conductors. In: Adv. Cryog. Eng. 46 (2000), S. 895-900 
[111] Hannink, R. H. J. ; Kelly, P. M. ; Muddle, B. B.: Transformation Toughening in Zirconia-Containing Ceramics. In: J. Am. Ceram. Soc. 83 (2000), S. 461-487

[112] Tsoga, A. ; Gupta, A. ; Naoumidis, A. ; Skarmoutsos, D. ; Nikolopoulos, P.: Performance of a Double-Layer CGO/YSZ Electrolyte for Solid Oxide Fuel Cells. In: Ionics 4 (1998), S. 234-240

[113] Aslanoglu, Z. ; Akin, Y. ; El-Kawni, M. I. ; andY. S. Hascicek, W. S.: Influence of the low oxygen partial pressures on thick YBCO coated conductor by sol-gel process. In: Physica C 384 (2003), S. 501-506

[114] Hughes, A. E.: Segregation in Single-Crystal Fully Stabilized Yttria-Zirconia. In: J. Am. Ceram. Soc. 78 (1995), S. 369-378

[115] Dickey, E. C. ; Fan, X. ; Pennycook, S. J.: Structure and Chemistry of YttriaStabilized Cubic-Zirconia Symmetric Tilt Grain Boundaries. In: J. Am. Ceram. Soc. 84 (2001), S. 1361-1368

[116] De Ridder, M. ; van Welzenis, R. G. ; van Der, A. W. D. ; Brongersma, H. H. ; WulfF, S. ; Chu, W.-F. ; Weppner, W.: Subsurface segregation of yttria in yttria stabilized zirconia. In: JAP 92 (2002), S. 3056-3064

[117] Hughes, A. E. ; Badwal, S. P. S.: Impurity and Yttrium Segregation in YttriaTetragonal Zirconia. In: Solid State Ionics 46 (1991), S. 265-274

[118] Varsano, F. ; Decker, F. ; Masetti, E. ; Cardellini, F. ; Licciuli, A.: Optical and electrochemical properties of cerium-zirconium mixed oxide thin films deposited by sol-gel and r.f. sputtering. In: Electrochim. Acta 44 (1999), S. 3149-3156

[119] Coyle, T. W. ; Coblenz, W. S. ; Bender, B. A.: Transformation Toughening in Large-Grain-Size $\mathrm{CeO}_{2}$-Doped $\mathrm{ZrO}_{2}$ Polycrystals. In: J. Am. Ceram. Soc. 71 (1988), S. C88-C92

[120] Minet, A. N. Khodan J.-P. Contour D. Michel O. Durand R. Lyonnet M.: ZrO $2^{-}$ $\mathrm{CeO}_{2}$ and $\mathrm{CeO}_{2}-\mathrm{La}_{2} \mathrm{O}_{3}$ film growth on oxide substrates and their applications in oxide heterostructures. In: J. Cryst. Growth 209 (2000), S. 828-841

[121] Duh, J. G. ; LeE, M. Y.: Fabrication and sinterabiliy in $\mathrm{Y}_{2} \mathrm{O}_{3}-\mathrm{CeO}_{2}-\mathrm{ZrO}_{2}$. In: $J$. Mater. Sci. 24 (1989), S. 4467-4474

[122] Urabe, K. ; Ogata, K. ; Ikawa, H. ; Udagawa, S.: Phase Transformation and Lattice Constants of Zirconia Solid Solutions in the System $\mathrm{Y}_{2} \mathrm{O}_{3}-\mathrm{CeO}_{2}-\mathrm{ZrO}_{2}$. In: Mater. Sci. Forum 34-36 (1988), S. 147-152

[123] Tsoga, A. ; Naoumidis, A. ; Gupta, A. ; Stöver, D.: Microstructure and Interdiffusion Phenomena in YSZ-CGO Composite Electrolyte. In: Materials Science Forum 308-311 (1999), S. 794-799 
[124] Lange, F. F.: Transformation toughening Part 5 Effect of temperature and alloy on fracture toughness. In: J. Mater. Sci. 17 (1982), S. 255-263

[125] Tani, E. ; Yoshimura, M. ; Somiya, S.: Revised Phase Diagram of the System $\mathrm{ZrO}_{2}-\mathrm{CeO}_{2}$ Below $1400^{\circ} \mathrm{C}$. In: J. Am. Ceram. Soc. 66 (1983), S. 506-510

[126] Usoskin, A. ; Dzick, J. ; Knoke, J. ; Garcia-Moreno, F. ; Sturm, K. ; FreyHARDT, H. C.: Critical currents in long-length YBCO-coated conductors. In: Supercond. Sci. Technol. 14 (2001), S. 676-679

[127] Wiesmann, J.: Wachstum von biaxial texturierten YSZ-Dünnfilmen mittels ionenstrahlunterstützter Deposition, Universität Göttingen, Diss., 1998

[128] Kautschor, L.-O.: Mikrostruktur und Wachstum bei der ionenstrahlunterstützten Deposition von Yttrium-stabilisierten Zirkonoxid-Filmen, Universität Göttingen, Diss., 2002

[129] Born, V. ; Hoffmann, J. ; Sievers, S. ; Thiele, Ch. ; Guth, K. ; Freyhardt, H. C. ; Jooss, Ch.: Current suppression in thin $\mathrm{YBa}_{2} \mathrm{Cu}_{3} \mathrm{O}_{7}$ films on IBAD buffer layers of Yttrium stabilised $\mathrm{ZrO}_{2}$. In: Zur Veröffentlichung vorgesehen in Superconductor Science and Technology

[130] Lagally, M. G. ; Savage, D. E. ; Tringides, M. C.: Diffraction from Disordered Surfaces: An Overview. In: Reflection High Energy Diffraction and Reflection Electron Imaging of Surfaces, 1985 (NATO ASI Series Series B: Physics Vol. 188), S. $139-173$

[131] BoRN, V. Institut für Materialphysik der Universität Göttingen. 2003

[132] Jooss, Ch. ; Warthmann, R. ; Forkl, A. ; Kronmüller, H.: High-resolution magneto-optical imaging of critical currents in $\mathrm{YBa}_{2} \mathrm{Cu}_{3} \mathrm{O}_{7-\delta}$ thin films. In: Physica C 299 (1998), S. 215-230

[133] Uhrmacher, M. ; Pampus, K. ; Bergmeister, F. J. ; Purschke, D. ; Lieb, K. P.: Energy Calibration of the $500 \mathrm{keV}$ Heavy Ion Implanter IONAS. In: Nucl. Instr. Meth. Phys. Res. B9 (1985), S. 234-242

[134] Doolittle, L. R.: A Semiautomatic Algorithm for Rutherford Backscattering Analysis. In: Nucl. Instr. Meth. Phys. Res. B 15 (1986), S. 227-231

[135] Lobinger, P.: In Vorbereitung, Universität Göttingen, Diss., 2004

[136] Gmelin Handbook RE Main Vol. C 12 b p. 23

[137] Sandiumenge, F. Institut de Ciencia de Materials de Barcelona, Persönliche Mitteilung. 2003 
[138] Xiao, W. ; Guo, Q. ; Wang, E. G.: Transformation of $\mathrm{CeO}_{2}(111)$ to $\mathrm{Ce}_{2} \mathrm{O}_{3}(0001)$ films. In: Chemical Physics Letters 368 (2003), S. 527-531

[139] Natter, H. ; LÖffler, M.-S. ; Krill, C. E. ; Hempelmann, R.: Crystallite growth of nanocrystalline transition metals studied by high temperature synchrotron X-ray diffraction. In: Scr. Mater. 44 (2001), S. 2321-2325

[140] Skofronick, G. L. ; Carim, A. H. ; Foltyn, S. R. ; Muenchhausen, R. E.: Interfacial reaction products and film orientation in $\mathrm{YBa}_{2} \mathrm{Cu}_{3} \mathrm{O}_{7-x}$ on zirconia substrates with and without $\mathrm{CeO}_{2}$ buffer layers. In: J. Mater. Res. 8 (1993), S. 2785-2798

[141] Jooss, Ch. ; Albrecht, J. ; Kuhn, H. ; Kronmüller, H. ; Leonhardt, S.: Magneto-optical studies of current distributions in high $\mathrm{T}_{c}$ superconductors. In: Rep. Prog. Phys. 65 (2002), S. 651-788

[142] Partlow, D. P. ; Greggi, J.: Properties and microstructure of thin $\mathrm{LiNbO}_{3}$ films prepared by a sol-gel process. In: J. Mat. Res. 2 (1987), S. 595-605

[143] Chaim, R. ; Heuer, A. H. ; Brandon, D. G.: Phase Equilibration in $\mathrm{ZrO}_{2}-\mathrm{Y}_{2} \mathrm{O}_{3}$ Alloys by Liquid-Film Migration. In: J. Am. Ceram. Soc. 69 (1986), S. 243-248

[144] Matthews, J. W.: Coherent Interfaces and Misfit Dislocations. In: Epitaxial Growth Part B. Academic Press, 1975, S. 559-609

[145] Nakajima, A. ; Yoshinara, A. ; Ishigame, M.: Defect-induced Raman spectra in doped $\mathrm{CeO}_{2}$. In: Phys. Rev. B 50 (1994), S. 13297-13307

[146] Gennard, S. ; Cora, F. ; Richard, A. ; Catlow, A.: Comparison of the Bulk and Surface Properties of Ceria and Zirconia by ab Initio Investigations. In: J. Phys. Chem. B 103:46 (1999), S. 10158-10170

[147] Markmann, J. ; Tschöpe, A. ; Birringer, R.: Low temperature processing of dense nanocrystalline yttrium-doped cerium oxide ceramics. In: Acta Materialia 50 (2002), S. 1433-1440

[148] Li, A.-D. ; Mak, C. L. ; Wong, K. H. ; Wu, D. ; Ming, N.: Novel route for the epitaxial growth of $(\mathrm{SrBa}) \mathrm{Nb}_{2} \mathrm{O}_{6}$ thick films by the sol-gel method using a selftemplate layer. In: J. Mater. Res. 16 (2001), S. 3179-3183

[149] Paranthaman, M. ; Aytug, T. ; Sathyamurthy, S. ; Beach, D. B. ; Goyal, A. ; Lee, D. F. ; Kang, B. W. ; Heatherly, L. ; Specht, E. D. ; Leonard, K. J. ; Christen, D. K. ; Kroeger, D. M.: Bulk solution techniques to fabricate high $\mathrm{J}_{c}$ YBCO coated conductors. In: Physica C 378-381 (2002), S. 1009-1012

[150] Bhuiyan, M. S. ; Paranthaman, M. ; Sathyamurthy, S. ; Aytug, T. ; Kang, S. ; Lee, D. F. ; Goyal, A. ; Payzant, E. A. ; Salama, K.: MOD approach for the growth of epitaxial $\mathrm{CeO}_{2}$ buffer layers on biaxially textured Ni-W substrates for YBCO coated conductors. In: Supercond. Sci. Technol. 16 (2003), S. 1305-1309 
[151] El-Kawni, M. I. ; Okuyucu, H. ; Aslanoglu, Z. ; Akin, Y. ; Hascicek, Y. S.: Growth and Characterization of YbBCO Films on Textured $\mathrm{Gd}_{2} \mathrm{O}_{3}$ Buffer-Layered Ni Tapes: All Sol-Gel Process. In: J. Supercond: Incorporating Novel Magnetism 16 (2003), S. 533-536

[152] Sathyamurthy, S. ; Salama, K.: Processing of Y123 Coated Conductors using Metal Organic Deposition. In: IEEE Trans. Appl. Supercond. 9 (1999), S. 1971-1974

[153] Sathyamurthy, S. ; Salama, K.: Fabrication of Y123 Coated conductors using Metal Organic Decomposition process. In: Physica C 341-348 (2000), S. 2479-2480

[154] Sathyamurthy, S. ; Salama, K.: Application of metal-organic decomposition techniques for the deposition of buffer layers and Y123 for coated-conductor fabrication. In: Physica C 329 (2000), S. 58-68

[155] Takechi, A. ; Matsumoto, K. ; Osamura, K.: $\mathrm{YBa}_{2} \mathrm{Cu}_{3} \mathrm{O}_{7-x}$ films on oxides buffer layer with perovskite structure prepared by metal-organic deposition method. In: Physica C 392-396 (2003), S. 895-899

[156] Takahashi, Y. ; Aoki, Y. ; Hasegawa, T. ; Watanabe, T. ; Maeda, T. ; Honjo, T. ; ShioharA, Y.: In-plane textured oxide buffer layer for the TFA-MOD method on $<100>\{001\}$ Ni tapes using MOD process. In: Physica $C$ 392-396 (2003), S. $887-894$

[157] Sathyamurthy, S. ; Salama, K.: Application of solution deposition to fabricate Y-Ba-Cu-O coated conductor. In: IEEE Trans. Appl. Supercond. 11 (2001), S. 2935-2938 


\section{Danksagung}

Mein Dank gilt allen, die zum Gelingen dieser Arbeit beigetragen haben, insbesondere

Herrn Prof. Dr. H. C. Freyhardt für die Ermöglichung und stete Förderung dieser Arbeit, Frau Dr. S. Sievers für vielfältige Unterstützung und Anregungen und eine kritische Durchsicht des Manuskriptes,

Herrn Prof. X. Obradors, Frau Dr. T. Puig, Herrn Dr. F. Sandiumenge, Herrn A. Cavallaro und Herrn O. Castaño vom Institut de Ciencìa de Materials de Barcelona für anregende Diskussionen und eine Reihe von AFM-Untersuchungen,

Herrn Dipl. Chem. P. Lobinger für eine ausgesprochen interessante Zusammenarbeit bei der Untersuchung der chemischen Eigenschaften des Precursoren,

Herrn M. Malchow für ständige Hilfsbereitschaft bei technischen Problemen,

Herrn PD. Dr. Ch. Jooss für eine kritische Durchsicht des Manuskriptes, Herrn Dipl. Phys. K. Guth für die Herstellung der YBCO-Filme,

Frau Dr. C. Borchers für die TEM-Aufnahmen,

Herrn Dipl. Ing. D. Plischke für die EDX-Untersuchungen und eine Reihe von REMAufnahmen,

Herrn Dipl. Phys. J. Garleff vom IV. Physikalischen Institut der Universität Göttingen für einige AFM- Untersuchungen,

den Herren Dipl. Phys. S. Eyhusen und Dipl. Phys. H. Kröger vom II. Physikalischen Institut der Universität Göttingen für die Bestrahlung am ADONIS und die RBS Messungen,

den Damen D. Kumpart, S. Petrich, A. Wraage und H. Rusev vom Analytischen Labor des Institutes für Anorganische Chemie der Universität Göttingen für die thermogravimetrischen Untersuchungen, sowie Herrn M. Hesse für die infrarotspektroskischen Messungen, Herrn Dr. Wilbrandt für die SIMS-Messungen,

Herrn Dr. F. Berberich vom ESRF in Grenoble für die Überlassung der Synchrotrondaten, den Herren Dr. M. Noltemeyer und H. G. Schmidt vom Institut für Anorganische Chemie für die Durchführung der Röntgeneinkristallstrukturanalyse, 
allen Mitarbeiterinnen und Mitarbeitern des Institutes für Materialphysik und des Zentrums für Funktionswerkstoffe für die angenehme Arbeitsatmosphäre, und den Beteiligten am europäischen Forschungsvorhaben SOLSULET für anregende Diskussionen. 


\section{Lebenslauf}

Persönliche Daten:

Name:

Nationalität:

Geburtsort:

Geburtstag:

Eltern:

\section{Schulausbildung}

1982-1986

1986-1992

1992-1995

26.6.1995

\section{Wehrdienst}

Juli 1995 - April 1996

$\underline{\text { Hochschulausbildung }}$

April 1996

Oktober 1996

17.7.1998

11.5.2001

Juni 2001
Harald Jarzina

Deutsch

Kassel

10.01.1976

Dieter Jarzina und Lydia Jarzina, geb. Heun
Grundschule in Calden

Gesamtschule in Grebenstein

Gymnasiale Oberstufenschule in Hofgeismar Abitur

Grundwehrdienst in Sondershausen

Beginn des Studiums der Japanologie und Philosophie an der Georg August Universität Göttingen

Beginn des Physikstudiums

Vordiplom in Physik

Diplom in Physik, Diplomarbeit mit dem Thema:

Stromverteilungen von supraleitenden

Filmen in weichmagnetischen Umgebungen

Beginn der Dissertation in der Arbeitsgruppe von

Herrn Prof. Dr. H. C. Freyhardt am Institut für

Materialphysik der Universität Göttingen 